Portland State University

PDXScholar

Summer 8-7-2013

\title{
The Role of Wood Microsites at Timberline-Alpine Meadow Borders for Conifer Regeneration
}

Adelaide Chapman Johnson

Portland State University

Follow this and additional works at: https://pdxscholar.library.pdx.edu/open_access_etds

Part of the Other Environmental Sciences Commons, and the Other Forestry and Forest Sciences Commons

Let us know how access to this document benefits you.

\section{Recommended Citation}

Johnson, Adelaide Chapman, "The Role of Wood Microsites at Timberline-Alpine Meadow Borders for Conifer Regeneration" (2013). Dissertations and Theses. Paper 1056.

https://doi.org/10.15760/etd.1056

This Dissertation is brought to you for free and open access. It has been accepted for inclusion in Dissertations and Theses by an authorized administrator of PDXScholar. Please contact us if we can make this document more accessible: pdxscholar@pdx.edu. 
The Role of Wood Microsites at Timberline-Alpine Meadow Borders for Conifer Regeneration

by

Adelaide Chapman Johnson

A dissertation submitted in partial fulfillment of the requirements for the degree of

Doctor of Philosophy

in

Environmental Sciences and Resources

Dissertation Committee:

Alan Yeakley, Chair

Sarah Eppley

Andrew Fountain

Joe Maser

Yangdong Pan

Portland State University

2013 
(C) 2013 Adelaide Chapman Johnson 


\begin{abstract}
This research aimed to determine whether wood microsites ("nurse logs"), which are regeneration sites in Pacific Northwest (PNW) subalpine forests, supported regeneration at timberline-alpine meadow borders. Upward advance of forests and conifer invasion into alpine meadows, which may be occurring in conjunction with climate warming, have gained worldwide attention. Successful alpine meadow seedling regeneration depends on suitable substrate availability, or microsites, for seedling establishment. To better understand factors associated with wood microsite occurrence, mechanisms of wood input were determined and four specific hypotheses were posed to assess: (1) seedling density and seedling survival; (2) growing season length, summer mean growing temperature, and growing degree hours (GDH); (3) active measures of seedling growth; and (4) global wood microsite climate associations.

Of four studies, three were conducted in the Cascade Mountains of Washington state along a west - east precipitation gradient and one study, assessed various microsites globally. For Cascades-related research, wood and adjacent soil substrate temperature, moisture, and associated seedling density, survival, stomatal conductance, water potential, and leaf nitrogen were compared by percent transmitted radiation at 4 to 14 study sites. Analysis of variance (ANOVA), t-tests, regressions, and classification and regression trees (CARTs) were used to assess significance of comparisons.

Wood microsites, common at 13 of 14 random Cascade sites, had greater seedling densities, greater seedling survival, greater volumetric moisture content (VWC), greater temperature, and greater number of GDH, as compared to adjacent soils. Greater seedling
\end{abstract}


densities were positively associated with VWC (> 12\%), conditions most commonly associated with wood substrate presence. For sites having $>25 \%$ percent transmitted radiation, positive relationships existed between stomatal conductance and VWC. Globally, high-elevation forests with wood microsites had mean annual precipitation from $86 \mathrm{~cm}$ to $320 \mathrm{~cm}$ and mean annual temperatures from $1.5^{\circ} \mathrm{C}$ to $4.7^{\circ} \mathrm{C}$.

In general, wood microsites facilitated alpine meadow regeneration better than adjacent soils. Management implications included enhanced understanding of factors associated with upward forest advance and wood use for restoration. Globally, wood microsites importance is likely underrepresented. Wood microsites role with warming climate will depend on precipitation pattern, timing, magnitude, and frequency. 


\section{Dedication}

This dissertation is dedicated to the memory of my Dad who died only weeks after learning of my decision to start my Ph.D. process. His energy and interest in the natural world fostered an abiding curiosity in me; a passion in the world I am lucky to see continued daily in my son, Aubrey. 


\section{Acknowledgements}

First of all, I thank my advisor, Alan Yeakley. Alan's sound advice and positive support extended throughout the dissertation process from conception to completion. Considering challenges inherent to Juneau - Portland long-distance communication, this support is especially appreciated. Each of my committee members, Yangdong Pan, Joe Maser, Sarah Eppley, and Andrew Fountain provided provocative questions and assistance with research design. Todd Rosenstiel aided by suggesting field and data analysis techniques and by providing field equipment. Jerry Franklin provided important initial research design suggestions.

I am indebted to Regina Rochefort, Science Advisor, of the North Cascades National Park Complex who facilitated field operations. She was instrumental in finding extremely qualified hard working field volunteers, providing back country permits, and providing practical advice.

I stand on the shoulders of Wilhelmina Bradley, Elizabeth MacWhinney, Stephanie Engelbrecht, Kate Freund, Mignone Biven, and Lucas Nardella who provided stellar enthusiastic field assistance in often arduous work conditions. USDA Forest Service, PNW Research Station support was provided by John Chase, for GIS analysis and to Rick Edwards and Dave D'Amore, supporting work leave for Ph.D. pursuit.

Finally, I thank my family Mike Hekkers and Aubrey Hekkers for their interest and support throughout my dissertation journey. This work, accomplished while off-duty from my regular hydrologist position, involved a great deal of compassion, patience, and humor. I am fortunate my family is imbibed with these characteristics. 


\section{Table of Contents}

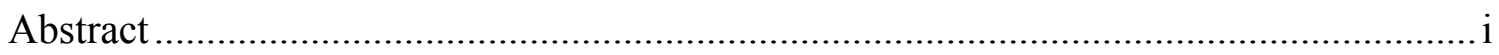

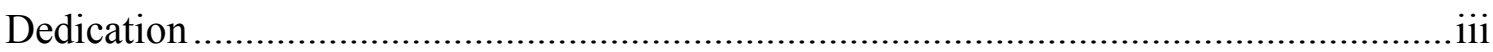

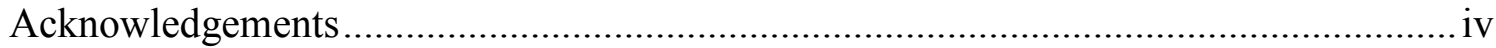

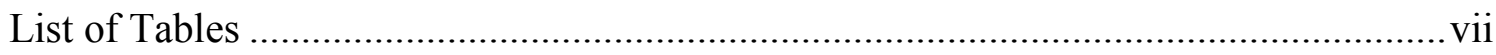

List of Figures ...........................................................................................................

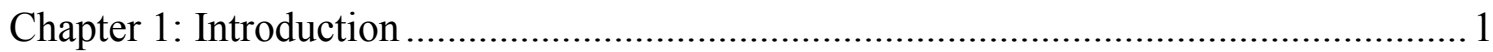

Chapter 2: Wood Microsites at Timberline-Alpine Meadow Borders: Role for Conifer Seedling Regeneration and Implications for Alpine Meadow Conifer Invasion ............. 11

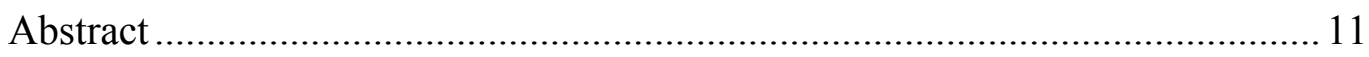

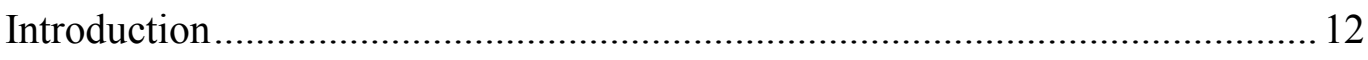

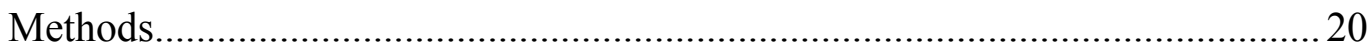

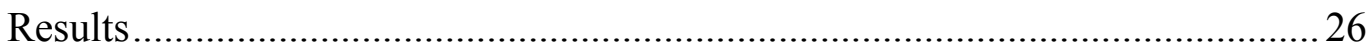

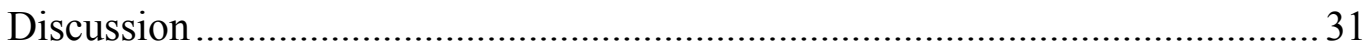

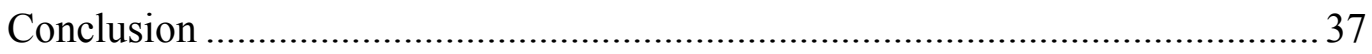

Chapter 3: Percent Transmitted Radiation and Associated Temperature and Moisture Associations for Wood and Soil Substrates Supporting Conifer Regeneration at Timberline-Alpine Meadow Borders ...................................................................... 51

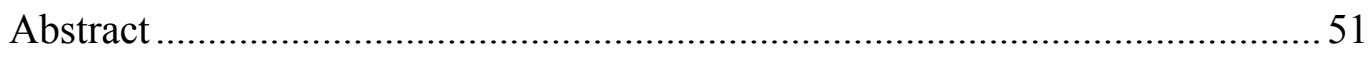

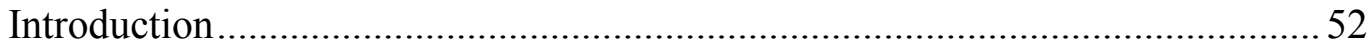

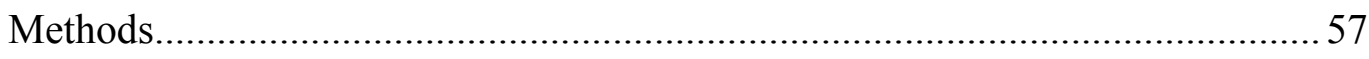

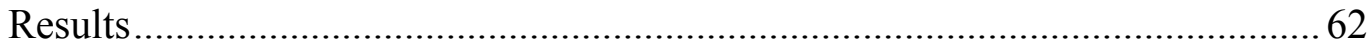

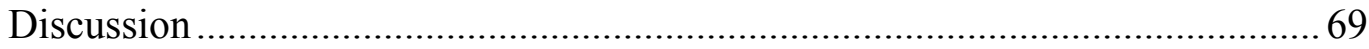

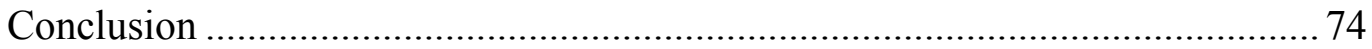

Chapter 4: Timberline Microsites and Seedling Plant Water Relations ......................... 92

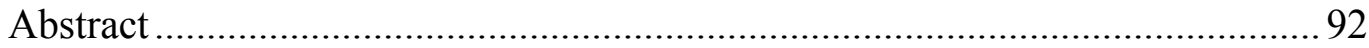

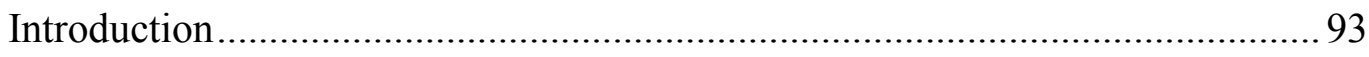




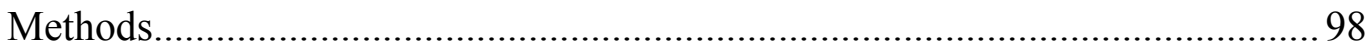

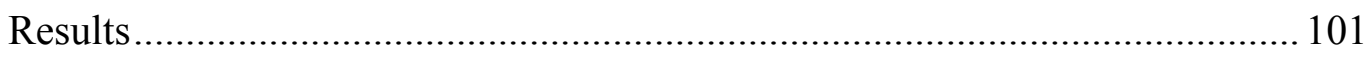

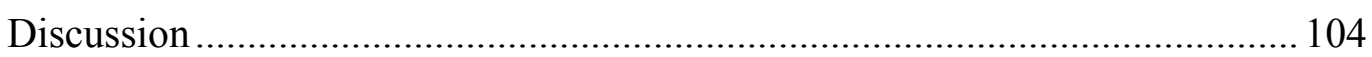

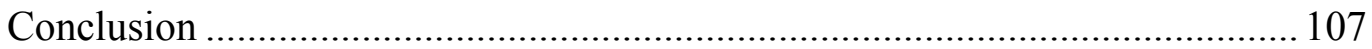

Chapter 5: Evaluation of Microsites in the Alpine Treeline Ecotone: A Global

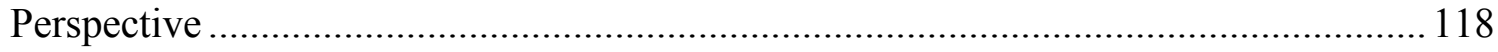

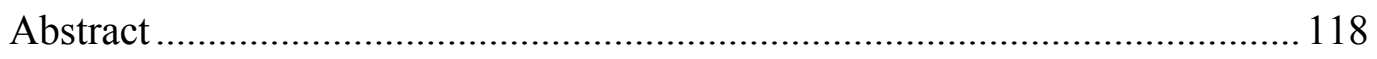

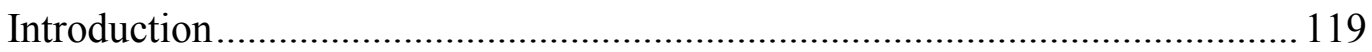

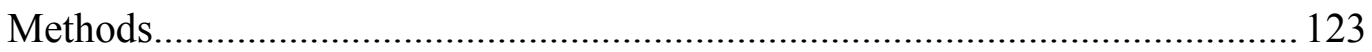

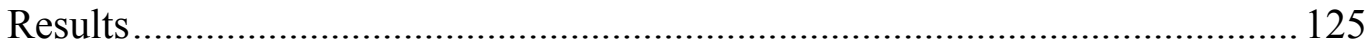

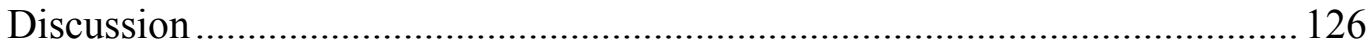

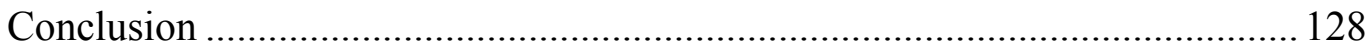

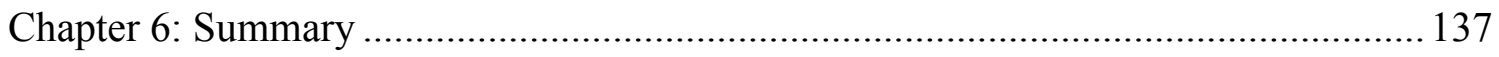

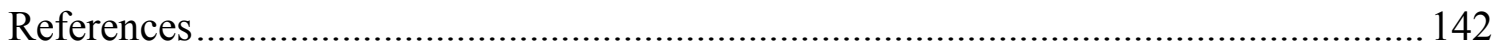

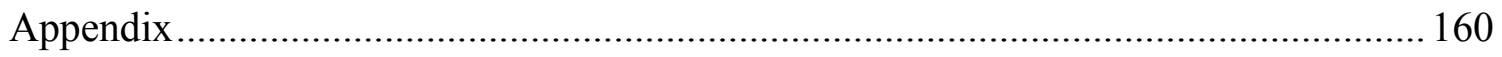




\section{List of Tables}

Table 1. Factors attributed to wood microsites in subalpine and low-elevation forests... 9

Table 2. Characteristics of 14 study sites and mean climatic variables 39

Table 3. Number of natural (and transplanted) seedlings at study sites 40

Table 4. Estimates of conifer alpine invasion rate on wood microsites using equation,

$$
\text { (3), } \mathrm{TI}=\frac{\mathrm{d}_{\text {seed }}}{\mathrm{W}_{\text {mature }}+\mathrm{W}_{\text {decay }}}
$$

Table 5. Characteristics of six study sites and mean climatic variables...................... 76

Table 6. Location of i-Buttons in association with canopy closure and percent transmitted radiation at each site ................................................................. 77

Table 7. Characteristics of four study sites and mean climatic variables.................... 108

Table 8. Typical characteristics of alpine treeline ecotone (ATE) microsite

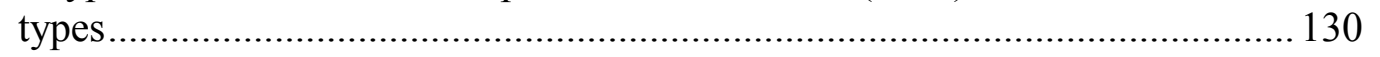

Table 9. Locations of wood microsites in alpine treeline ecotones of the world ......... 131

Table 10. Depression (D), elevation (E), shade (S), and topographic (T) microsite

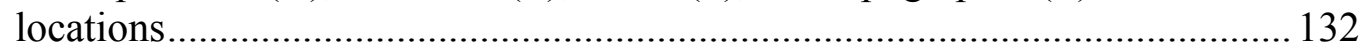




\section{List of Figures}

Figure 1. Location of timberline within the alpine treeline ecotone (ATE).

10

Figure 2. A conceptual model describing wood input, wood decay, seeding regeneration, and seedling growth and invasion of trees in alpine meadows

Figure 3. Study site locations in Washington State, USA. Western sites are the seven sites located west of site 14 and eastern sites are all sites east of site 7

Figure 4. A typical study site having a forest patch, adjacent alpine meadow, downed wood, and seedlings.

Figure 5. Stratified sampling used to seedling density on soil

Figure 6. Barplots of seedling number and height on wood microsites. Means for 14 sites with $95 \%$ confidence intervals for: a) seedling number on wood substrates by shade category and $b$ ) seedling height by shade category. (for both a and $b: n=4$, 7, and 3 for short-, medium-, and long- shadow categories, respectively). Short-, medium-, and long-shadow length categories were based upon direction of site aspect with respect to tree patch (see Methods for further description). No significant differences were found for seedling number or seedling height by shade.

Figure 7. Barplots of wood and soil moisture content. Means and 95\% confidence intervals for a) wood and soil substrates ( $\mathrm{n}=14$ per bar), b) substrate type and eastside or westside location ( $\mathrm{n}=7$ per bar, see Fig. 1 for description), $\mathrm{c}$ ) substrate and shadow category ( $\mathrm{n}=$ range of 3 to 7 per bar), and $\mathrm{d}$ ) substrate and aspect (four directions, $\mathrm{n}=$ range of 2 to 6 per bar). Wood microsites are indicated by shaded bars and soil is indicated by open bars. Tukey results are indicated by letters above barplots. If one of the letters is the same, no statistical difference is indicated. If letters are different, significant differences exist ( $p<$ $0.05)$

Figure 8. Barplots of wood and soil temperature. Means and 95\% confidence intervals for: a) wood and soil substrates $(n=14$ per bar $), b)$ substrate type and eastside or westside location ( $\mathrm{n}=7$ per bar, see Fig. 1 for description), c) substrate and shadow category ( $\mathrm{n}=$ range of 3 to 7 per bar), and $\mathrm{d}$ ) substrate and aspect (four directions, $\mathrm{n}=$ range of 2 to 6 per bar). Wood microsites are indicated by shaded bars and soil is indicated by open bars. Tukey results are indicated by letters above barplots. If one of the letters is the same, no statistical difference is indicated. If letters are different, significant differences exist $(p<$ $0.05)$ 
Figure 9. Barplots of wood and soil substrate nitrogen content. Means and $95 \%$ confidence intervals for: a) wood and soil substrates $(n=14$ per bar), and $b)$ substrate and shadow category ( $\mathrm{n}=3$ to 7 per bar). Wood microsites are indicated by shaded bars and soil is indicated by open bars. No significant differences were found for nitrogen content in wood and soil substrates.....

Figure 10. Boxplots and barplots of density, survival, and carbon content of seedlings on wood and soil. Boxplots for: a) seedling density ( $\mathrm{n}=6$ per box $)$, and $\mathrm{b}$ ) natural seedling survival $(\mathrm{n}=6$ per box $), \mathrm{c})$ transplanted seedling survival $(\mathrm{n}=6$ per box). Note: Data were non-parametric and significant differences were found for density and survival. In the boxplot, the central line in the box indicates the median, the box includes $50 \%$ of the data, the top of the box indicates $75^{\text {th }}$ percentile (upper quartile) of the data, the bottom of the box indicates the $25^{\text {th }}$ percentile, and the vertical lines extend to the upper and lower deciles $\left(90^{\text {th }}\right.$ and $10^{\text {th }}$ percentiles). Barplots for $\left.d\right)$ total percent carbon $(n=6$ per bar). Significant differences are indicated by letters above boxplots and barplots $(\mathrm{p}<0.05) \ldots \ldots . . .50$

Figure 11. A typical timberline location in the alpine treeline ecotone with stresses indicated

Figure 12. Location of the six study sites in Washington State 79

Figure 13. Wood substrates, soil plots, and overstory canopy categories. Overstory categories were related to incoming radiation categories (see Table 6)

Figure 14. Site aspect and location of i-buttons in wood and adjacent soil with respect to each patch of large standing timberline trees at the six sites

Figure 15. Barplots of spring thaw and fall freeze date for wood and soil substrates. Means for six sites (each having three radiation categories) and 95\% confidence intervals indicated for: a) spring thaw by substrate and location $(n=18$ per bar), b) thaw date for combined substrates by location $(n=36$ per bar, mean thaw of June 27 and July 4, respectively for west side and east side, $p=0.02$ ), c) freeze date by substrate and east side or west side location ( $\mathrm{n}=18$ per bar, $p=0.02)$, and $\mathrm{d})$ freeze date for combined substrates by location $(n=36$ per bar, mean freeze of November 10 and October 23, respectively for west side and east side, $p=0.009)$

Figure 16. Boxplots and barplots of wood and soil substrate mean annual temperature for six sites. Boxplots of: a) wood and soil $(n=35019$ per bar, $p<0.001)$ with central line in box indicating the median, box includes $50 \%$ of data, top of box indicates $75^{\text {th }}$ percentile (upper quartile) of data, bottom of box indicates $25^{\text {th }}$ percentile, and vertical lines extending to upper and lower deciles $\left(90^{\text {th }}\right.$ and $10^{\text {th }}$ percentiles). 
For barplots, means for sites (each having three radiation categories) and 95\% confidence intervals indicated for: $\mathrm{b}$ ) wood and soil by radiation category $(\mathrm{n}=$ $11673, p<0.001$ for low radiation), and c) wood and soil by shade and location (n $=3891$ per bar; $p<0.001$ and $p=0.002$ for low and medium on west locations and $p<0.001$ and $p<0.001$ for low and high radiation east side sites). Note: for comparisons were made between wood and soil substrates having similar radiation categories only. For these pairs, significant differences are indicated by different letters.

Figure 17. Boxplots of summer wood and soil temperature. Means for six sites (each having three radiation categories) and $95 \%$ confidence intervals for a) wood and soil $(\mathrm{n}=4848$ per bar, $p=0.0013), \mathrm{b})$ for wood and soil by radiation category $(\mathrm{n}=1616$ per bar; $p<0.001$, wood is warmer than soil for high radiation sites only), and c) wood and soil by percent transmitted radiation category and summer month $(\mathrm{n}=566$ per bar for July, $\mathrm{n}=372$ per bar for August, $\mathrm{n}=678$ per bar for September; wood is warmer than soil at high radiation sites during the month of July only, $p<0.001)$. Note: comparisons were made between wood and soil substrates having similar radiation categories only. For these pairs, significant differences are indicated by different letters

Figure 18. Barplots of summer substrate temperature by location. Means for six sites (each having three radiation categories) and 95\% confidence intervals for a) wood and soil ( $\mathrm{n}=2424$ per bar; wood is warmer than soil on east side, $p=$ $0.028)$ and $b)$ wood and soil by radiation category $(\mathrm{n}=808$ per bar; on west side, wood is warmer than wood at high radiation sites, $p=0.04$; on east side wood is cooler than soil at low radiation sites and warmer than soil in high radiation sites, $p<0.001, p<0.001$, respectively). Note: comparisons were made between wood and soil substrates having similar location category or radiation categories only. For these pairs, significant differences are indicated by different letters ... 85

Figure 19. Barplots of wood and soil summer growing degree hours (GDH). Means for six sites (each having three radiation categories) and 95\% confidence intervals by a) substrate type ( $\mathrm{n}=1540$ wood, 1490 soil, $p=0.0002), \mathrm{b})$ radiation category $(\mathrm{n}=$ a range of 470 to 535 per bar, wood has more GDH than soil at medium radiation sites, $p=0.04), \mathrm{c})$ substrate by east and west location $(\mathrm{n}=964$ and 926 west side; 576 and 563 east side for wood and soils, respectively); wood at east sites had more GDH than soil $(p=0.035), \mathrm{d})$ substrate type by time period and west and east location ( $\mathrm{n}=$ a range of 136 to 385 per bar), and e) substrate type by shade category by west or east side ( $\mathrm{n}=$ a range of 136 to 360 per bar); wood with medium radiation has more GDH $(p=0.0002)$. Note: comparisons were made between wood and soil substrates having similar location categories or radiation categories only. For these pairs, significant differences are indicated by different letters 
Figure 20. Barplots of wood and soil volumetric water content (VWC). Means for six sites (each having three radiation categories) and 95\% confidence intervals for a) substrate and radiation category $(n=$ range of 53 to 84 per bar; wood had greater VWC than soil for low and medium radiation, $p=0.0009, p=0.015$, respectively) and $b)$ west side and east side radiation category $(n=$ a range of 18 to 43 per bar; on west site wood VWC is greater for medium and high radiation sites, on east side wood has greater VWC at low radiation sites only $p=$ $0.004, p=0.008, p=0.01$, respectively. Note: comparisons were made between wood and soil substrates having similar radiation categories only. For these pairs, significant differences are indicated by different letters

Figure 21. Density of $<3$ yr old seedlings versus wood and soil substrate temperature. Density versus mean substrate temperature by: a) radiation category (no significant relationships) and b) location (significant decreases in seedling density at east locations for wood substrates with increases in mean substrate temperature, $p=0.047, \mathrm{r}^{2}=0.38$ )

Figure 22. Seedling density versus mean volumetric water content (VWC) on wood and soil substrates. Density is indicated for a) both west and east locations (six sites each having three radiation categories), and b) east locations (three sites with three radiation categories each) alone where a significant increases in seedling density are associated with increases in mean VWC (eastside wood $p=0.03$, $\mathrm{r}^{2}=0.42$; east side soil $p=0.01, \mathrm{r}^{2}=0.51$, for west side $p=0.1$ for wood and 0.07 for soil)

Figure 23. Volumetric water content (VWC) versus mean temperature for wood and soil substrates. Regressions for: a) wood substrates by radiation level, b) soil substrates by radiation level (medium radiation sites, $p=0.04, \mathrm{r}^{2}=0.6$ ), and $\mathrm{c}$ ) wood substrates by east and west side location (wood west, $p=0.046, \mathrm{r}^{2}=0.38$, and $\mathrm{d}$ ) soil substrates by west side and east side location (soil west, $p=0.03, \mathrm{r}^{2}=$ 0.31 ; east, $p=0.002, \mathrm{r}^{2}=0.73$ ). Data represents six sites each having three radiation categories. Unless noted, $p>0.05$

Figure 24. Seedling density as classified by classification and regression trees (CARTs). Labels on these CARTs indicate splitting to the left side. CART a) indicates decreases in seedling density associated with radiation $\geq 19.44$ and further density reductions with with volumetric water content $(\mathrm{VWC})<15.85$ and CART b) indicatest greatest seedling density is classified by VWC (log transformed) $>1.2$ and substrate temperature $>7.012^{\circ} \mathrm{C}$

Figure 25. Location of the four study sites in Washington State

Figure 26. Patch of trees with canopy overstory categories from which measurements of radiation were calculated 
Figure 27. Site aspect and location of seedling clusters where measurements of stomatal conductance, water potential, and volumetric water content were made 111

Figure 28. Barplots of stomatal conductant by radiation category. Means for four sites (each having three radiation categories) and 95\% confidence intervals for stomatal conductance by radiation category for a) entire field season $(\mathrm{n}=$ ranges

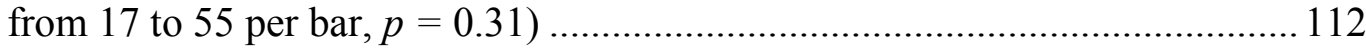

Figure 29. Stomatal conductance and site moisture. a) Stomatal conductance versus volumetric water content (VWC) for wood and soil with radiation category indicated. An increase in VWC for wood in the high radiation category (yellow triangles for wood) is associated with an increase in stomatal conductance ( $p=$ $\left.0.03, r^{2}=0.24\right)$, b) Barplots showing means and $95 \%$ confidence intervals for stomatal conductance by low $(<14 \%)$, medium (14 to $21 \%)$, and high $(>21 \%)$ categories of VWC. Data represent four sites each having three radiation categories

Figure 30. Stomatal conductance versus volumetric water content (VWC) for wood and soil in September when the VWC is lowest. Here, percent transmitted transmitted radiation considered high is $>25 \%$. For high radiation wood and soil sites combined, significant increases in stomatal conductance occur with increase in VWC $\left(p=0.004, \mathrm{r}^{2}=0.44\right)$. Assessed by separately, no significant relationships exist $(\mathrm{p}>0.1)$

Figure 31. Stomatal conductance and leaf temperature for seedlings on wood and soil substrates during the month of August. For four sites, each having three radiation categories stomatal conductance is presented: a) versus leaf temperature (for all sites combined, $p=0.0005, \mathrm{r}^{2}=0.17$ ); and by barplots showing means and $95 \%$ confidence intervals for $b$ ) low, medium, and high levels of radiation for wood and soil substrates combined $(\mathrm{n}=32,22$, and 9 for low, medium, and high radiation categories, respectively; medium transmitted radiation had significantly higher stomatal conductance than sites with high transmitted radiation, $p=$ 0.028 ), and by c) leaf temperature by $14^{\circ} \mathrm{C}$ threshold for seedlings on substrates combined ( $\mathrm{n}=35$ and 28 for $<14^{\circ} \mathrm{C}$ and $>14^{\circ} \mathrm{C}$, respectively; $\left.p<0.001\right)$. Note: Significant differences are indicated by different letters

Figure 32. Classification and regression tree for prediction of stomatal conductance. Major splits (labels indicate split direction to the left) are elevation and moisture (volumetric water content, VWC). Elevation split at $1936 \mathrm{~m}$ represents a split between the most east site (5) in the Cascade Mts with the other sites $(1,2,4)$ having elevations below $1936 \mathrm{~m}$.

Figure 33. Early morning water potential for seedlings growing on wood and soil substrates. Mean values and 95\% confidence intervals for: a) wood and soil substrates $(\mathrm{n}=69$ and 54 per bar for wood and soil, respectively, $p=0.007$, 
wood is less negative), b) wood and soil substrates by radiation category $(\mathrm{n}=$ ranges from 15 to 22 per bar, $p=0.89$ )

Figure 34. Dominant microsites for seedling regeneration at the alpine treeline ecotone around the world

Figure 35. Boxplots of precipitation, mean annual temperature, and elevation per microsite. Microsite types are as follows: $\mathrm{S}=$ shading, $\mathrm{T}=$ topographic, $\mathrm{W}=$ wood microsites, $\mathrm{E}=$ elevations, and $\mathrm{D}=$ depressions (precipitation is significantly different for microsite types, $\mathrm{p}=0.0033$ )

Figure 36. Boxplots of precipitation, mean annual temperature, and elevation per genus group (precipitation was significantly different for species, $p=0.027, \mathrm{n}=2$ to 14 per genus group)

Figure 37. Annual mean temperature versus annual mean precipitation for microsites in the alpine treeline ecotone globally. For a) all five microsites a significant positive relationship between temperature and precipitation existed for shade microsites only $\left(p=0.045, \mathrm{r}^{2}=0.34\right)$ and $\left.\mathrm{b}\right)$ wood microsite presence summarized by mean annual temperature and mean annual precipitation

Figure 38. Summary of dissertation results by chapter. Results of tests, summarized by $>$ or $<$ indicate level for wood microsites as compared to soil substrates, respectively. Within each box, general information is located at the top and information associated with a particular percent transmitted radiation level is described directly under that level 


\section{Chapter 1:}

\section{Introduction}

Alpine meadow conifer invasion within the alpine timberline ecotone (ATE) is associated with climate warming (Franklin et al. 1971, Lowery 1972, Rochefort and Peterson 1996, Grabherr 2003, Holtmeier 2009). Although climate warming facilitates seeding regeneration due to factors including increased substrate temperature, increased snow-free period, and increased mean summer temperature (Franklin et al. 1971, Peterson 1998, Kullman 2006, Hallinger et al. 2010), factors likely to continue limiting regeneration in the ATE include high radiation, frost, drought, animal predation, and infestation by fungal pathogens found in snow and soil (Baig and Tranquillini 1980, Wardle and Coleman 1992, Calloway 1995, Bansal and Germino 2008, Zhong and van der Kamp 1999).

Timberline, marking the upper boundary of subalpine forests with trees of large stature, is adjacent to alpine meadows that are either treeless or contain clusters of stunted krumholtz trees extending upward in elevation to tree limit or treeline (Fig. 1). Thus, timberline-alpine meadow boundaries generally mark a transition from a micro-climate moderated by dense forest to an open alpine meadow environment having more wind, greater radiation, increased frost stress, and more extremes in temperature (Tranquillini 1979, Holtmeier 2009). Forest disturbances including windthrow and snow avalanching, both common at timberline-alpine meadow borders, introduce large woody debris that 
form potential substrates (along with adjacent soil) that mayfacilitate regeneration of seedlings.

ATE microsites, areas of micro relief ranging in size from millimeters to meters, help ameliorate local environmental factors limiting seed establishment by providing germinating seedlings with necessary shade, moisture, and temperature (Harper et al. 1961, Eriksson and Ehrlén, 1992, Korner 1998, Smith et al. 2003, Graae et al. 2011). Given a particular topographic position and climatic setting, a specific microsite type can determine seedling survival. For example, in areas such as the Pacific Northwest (PNW) where snow accumulation is high, seedling growth is facilitated by convex sites, mounded microsites that facilitate both melting of snow and increase in growing season (Lowery 1972, Rochefort and Peterson 1996, Holtmeier 2009). In contrast, concave microsites facilitate growth of seedlings where moisture is limited (Kullman 2006) and shade microsites facilitate growth of seedlings in dry climates where radiative cooling and frost damage is frequent (Germino et al. 2002).

Large trees at the edge of timberline fall into adjacent alpine meadows, decay, and may provide ideal sites for seedling establishment. These wood microsites, commonly called nurse logs, are much better known as key substrates in lower elevation forests (Christy and Mack 1984, Harmon and Franklin 1989, Gray and Spies 1997) and subalpine forests (Veblen 1989, Gratzer 1999, Zielonka and Niklossen 2001, Narukawa et al. 2003, Brang et al. 2003, Motta et al. 2006, Baier et al. 2007), but may provide conspicuous sites of timberline forest regeneration extending from the forest edge into alpine meadows. At lower elevations, wood microsites lessen the destructive influence of 
snow movement known as snow glide, reduce species competition, often have increased mycorrhizal populations, and have fewer pathogens than the adjacent soil (Zhong and van der Kamp 1999, Baier et al. 2007). These factors as well as others likely facilitate seedling regeneration at timberline-alpine meadow borders (Table 1).

Examination of seedling establishment sites for sensitive young seedlings in the ATE, rather than examination of older resilient trees, gives a clearer understanding of current climatic factors affecting potential expansion of timberline (Rochefort et al. 1994; Smith et al. 2009). For example, distorted krummolz trees at treeline (Fig. 1), potentially living over 2000 years, may have endured many changes in climate whereas a newly germinated subalpine fir will survive only if present site conditions meet survival requirements. Although the importance of seedling establishment to the position of alpine-ecotone is recognized (Holtmeier 2009), little is known about factors affecting the survival of ATE seedlings during initial years of growth and establishment, a period of greatest mortality of all life stages until death of mature trees by disease or fire (Germino et al. 2002). Further, studies linking abiotic factors (i.e. temperature, moisture, nutrient availability) to physiologic trends (i.e. stomatal conductance, water potential, foliar nitrogen content) for young seedlings growing on wood microsite above timberline appear to be absent from the literature.

Examination of wood and soil temperature and moisture in conjunction with assessment of seedling density and seedling survival in the ATE would enhance understanding of likely changes in seedling establishment pattern occurring in association with global climate warming. Although global temperature warming will increase overall 
precipitation amount with increased frequency of intense storms, there is also expected to be periods of drought (Solomon, 2007, Wentz et al. 2007). Precipitation in the PNW is expected to decrease in the summer (Mote and Salathé 2010), likely limiting available substrate moisture. Water stored in wood microsites may support growth of seedlings at the same time water in adjacent soils may be limited.

To gain a better understanding of the ecological role of wood microsites for conifer regeneration at timberline-alpine meadow borders, this research focused on comparing wood substrates to adjacent soil substrates above timberline. There were four broad research goals: (1) determine origin, characteristics, and seedling densities of wood microsites supporting conifer seedlings; (2) compare temperature and moisture attributes of wood microsites and adjacent soil substrates for annual and summer growing seasons; (3) compare measures of active seedling growth on the two substrate types; and (4) evaluate typical climatic features associated with regeneration on wood microsites as compared with other microsites in a world-wide context. These goals were met by conducting four studies.

The first research step was to assess wood microsite characteristics, describe wood microsite formation, and evaluate possible advantages for conifer seedlings regenerating on wood microsites (Chapter 2). Initially, origin, decay class, and species of the seedlings on wood microsites were determined and then, two hypotheses were addressed:

$\mathrm{Ho}_{1}$ : No differences in density and survival of seedlings on wood microsites as compared to adjacent soil microsites, and 
$\mathrm{Ho}_{2}$ : No differences in wood and soil substrate moisture, temperature, and nitrogen.

This study, published by the time this dissertation was complete (Johnson and Yeakley 2013), determined typical number of downed trees at the timberline-alpine meadow edges, mechanisms associated with wood input into alpine meadows, approximate age of standing trees at timberline, typical decay class of wood microsites, seedling density on/off wood microsites; and moisture, nitrogen, and temperature differences in wood and adjacent soils.

Given a general pattern of increased substrate temperature, moisture, and seedling density on wood as compared to soil (Chapter 2), the second part of this research (Chapter 3) was aimed at better quantification of substrate temperature as influenced by radiation level at timberline-alpine meadow borders both annually and during the growing season. Three hypotheses were evaluated for wood and adjacent soil substrates having three levels of percent transmitted radiation:

$\mathrm{Ho}_{1}$ : No differences in annual temperature, growing season temperature, and growing degree hours,

$\mathrm{Ho}_{2}$ : No difference in substrate moisture, and

$\mathrm{Ho}_{3}$ : No differences in density of seedlings (Chapter 2) as associated with determined growing season temperature and moisture trends.

Analyses determined that wood microsite temperature was significantly greater on wood microsites only during the growing season, not annually, and that wood microsites in high radiation areas had warmer temperatures and moister substrates than adjacent 
soils. Seedling density was related more to substrate moisture, particularly on easternmost sites, than radiation level or substrate temperature.

Given greater summer temperature, greater number of growing degree hours, and greater moisture on wood microsites as compared to soil (Chapter 3), the third part of this research (Chapter 4) strove to determine whether these potentially positive abiotic attributes could be linked to significant differences in conifer physiologic response for 3to-5 yr old seedlings on the two substrates. There were three specific hypotheses for seedlings growing on wood as compared to seedlings growing on adjacent soil substrates:

$\mathrm{Ho}_{1}$ : No difference in seedling stomatal conductance,

$\mathrm{Ho}_{2}$ : No difference in seedling pre-dawn water potential, and

$\mathrm{Ho}_{3}$ : No difference in leaf chlorophyll a content.

Although no significant differences were found for stomatal conductance and chlorophyll a content for seedlings growing on wood microsites and soil substrates, plant water potential was less negative for seedlings on wood. It was determined that increased volumetric water content at sites with $>25 \%$ transmitted radiation was associated with increased seedling stomatal conductance.

The final step of this research, a literature review, was conducted to determine climates of the world where wood microsites are most important (Chapter 5). To accomplish this goal, five major microsite types were delineated and mean annual temperature, mean annual precipitation, and most common tree associated with the various microsite types was determined. In this review, typical climates associated with wood substrates were summarized. There were two specific hypotheses: 
$\mathrm{Ho}_{1}$ : No difference in the mean annual precipitation or mean annual temperature for five dominant microsites types, and

$\mathrm{Ho}_{2}$ : No relationship between microsite type and dominant tree species.

It was determined that wood microsites facilitated seedling regeneration in areas of the world having mean annual precipitation of $185 \mathrm{~cm}$ and a mean annual temperature of $3.0^{\circ} \mathrm{C}$. Wood microsites were found in a range of high elevation tropical subalpine forests and cold and dry forests. Given microsite preference, it was surmised that a global increase in temperature and precipitation would likely increase the dominance of shade microsites worldwide particularly if temperature surpassed $5^{\circ} \mathrm{C}$.

The overarching central aim of this research was to evaluate how presence of wood microsites, a product of forest disturbance, might ultimately lead to alpine conifer invasion in alpine meadows. Six management-related implications of this research included: (1) a better understanding of forest disturbances occurring at timberlines including treefall, snow avalanching, and fire; processes associated with wood input; (2) an enhanced understanding of relationships among radiation and substrate moisture and temperature, factors controlling timberline advance; (3) better predictions of microsites most favorable to conifer regeneration in the ATE by evaluation of seedling density, seedling survival, and stomatal conductance; (4) better predictions of the rate of conifer invasion rate on wood microsites with better understanding of downed wood decay class supporting seedling regeneration; (5) better understanding of the role of radiation on conifer advance at PNW timberlines through comparisons seedling density and survival at sites having a range of incoming radiation levels; and (6) better understanding of 
abiotic-biotic linkages associated with seedling survival through evaluation of site factors associated with active measures of active seedling growth including stomatal conductance and early morning seedling water potential. 
Table 1. Attributes associated with wood microsites located in subalpine and lowelevation forests.

\begin{tabular}{|c|c|c|c|}
\hline Attribute & $\begin{array}{l}\text { Comparison of Wood } \\
\text { Microsite to Soil } \\
\text { Substrate }\end{array}$ & $\begin{array}{l}\text { Location and/or } \\
\text { Forest Type }\end{array}$ & Reference(s) \\
\hline Seedling density & $\begin{array}{l}\text { On wood there is greater } \\
\text { density, particularly for } \\
\text { sites having more shade. }\end{array}$ & $\begin{array}{l}\text { Pacific Northwest } \\
\text { forests }\end{array}$ & $\begin{array}{l}\text { Christy and Mack } 1984 \\
\text { Gray and Spies } 1997\end{array}$ \\
\hline Seed size & $\begin{array}{l}\text { On wood, small seeds } \\
\text { having small roots can } \\
\text { better penetrate substrate }\end{array}$ & South-central Chile & $\begin{array}{l}\text { Nakashizuka 1989, } \\
\text { Lusk 1995, Lusk and } \\
\text { Kelly } 2003\end{array}$ \\
\hline Competition & $\begin{array}{l}\text { Wood has fewer herbs } \\
\text { and mosses than soil }\end{array}$ & Picea-Tsuga forests & $\begin{array}{l}\text { Harmon and Franklin } \\
1989\end{array}$ \\
\hline Nutrients & $\begin{array}{l}\text { Wood has lower } \mathrm{N} \text { and } \mathrm{P} \\
\text { Wood has higher } \mathrm{N}\end{array}$ & $\begin{array}{l}\text { Rocky Mtn. Forests } \\
\text { Dawodang Mtn., } \\
\text { China }\end{array}$ & $\begin{array}{l}\text { Laiho and Prescott } 1999 \\
\text { Ran et al. } 2010\end{array}$ \\
\hline Mychorrizae & $\begin{array}{l}\text { Wood has more } \\
\text { mychorrizae than soil }\end{array}$ & Rocky Mtn. Forests & Germino 2006 \\
\hline Moisture & $\begin{array}{l}\text { Wood has greater } \\
\text { moisture than soil }\end{array}$ & $\begin{array}{l}\text { Canada, lodgepole } \\
\text { pine (Pinus } \\
\text { contorta) }\end{array}$ & Bulmer et al. 2007 \\
\hline Species diversity & $\begin{array}{l}\text { Wood has greater lichen } \\
\text { and moss diversity than } \\
\text { soil }\end{array}$ & Finland & $\begin{array}{l}\text { Vanha-Majamaa et al. } \\
2007\end{array}$ \\
\hline Frost heave & $\begin{array}{l}\text { Wood has less frost heave } \\
\text { than soil }\end{array}$ & $\begin{array}{l}\text { Southeast Alaska } \\
\text { Picea-Tsuga forests }\end{array}$ & Shaw et al.1987 \\
\hline Temperature & $\begin{array}{l}\text { Wood is cooler than soil } \\
\text { during peaks in summer } \\
\text { temperature }\end{array}$ & Oregon coast range & Klubler et al. 2009 \\
\hline Seed cache sites & $\begin{array}{l}\text { Wood is common site of } \\
\text { caching for nutcrackers } \\
\text { and chipmunks }\end{array}$ & Chilean rain forest & Lusk 1995 \\
\hline Snow glide & $\begin{array}{l}\text { Wood has less snow glide } \\
\text { than soil }\end{array}$ & Bavarian Alps & Baier et al. 2006 \\
\hline $\begin{array}{l}\text { Fungal } \\
\text { pathogens }\end{array}$ & $\begin{array}{l}\text { Wood has fewer fungal } \\
\text { pathogens than soil }\end{array}$ & $\begin{array}{l}\text { Eastern hemlock } \\
\text { (Tsuga canadensis) }\end{array}$ & O'Hanlon-Manners 2004 \\
\hline
\end{tabular}




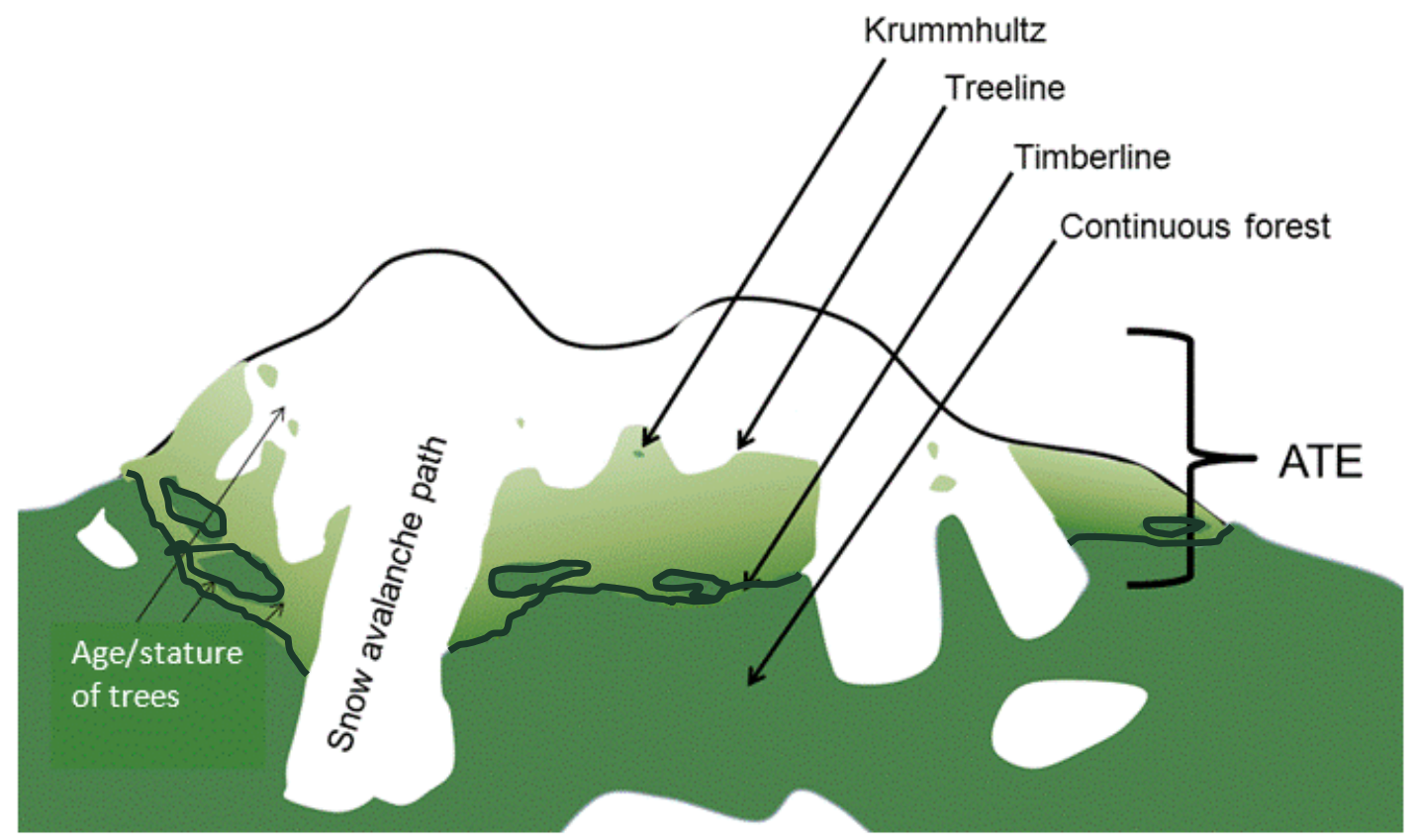

Figure 1. Location of timberline within the alpine treeline ecotone (ATE). 


\title{
Chapter 2:
}

\section{Wood Microsites at Timberline-Alpine Meadow Borders: Implications for Conifer Seedling Regeneration and Alpine Meadow Conifer Invasion*}

\begin{abstract}
The importance of climate warming on forests is recognized worldwide and has increased attention on the significance of both timberline advance and alpine meadow invasion by forests. Successful seedling regeneration in alpine meadows depends on availability of suitable substrates, or microsites, for seedling establishment. I sought to determine whether wood microsites ("nurse logs"), which are regeneration sites in PNW subalpine forests, promoted regeneration at timberline-alpine meadow borders. To determine the ecological role of wood microsites, I examined mechanisms forming wood microsites; compared density, survival, and percent nitrogen content of seedlings growing on wood microsites to adjacent soil substrates; and compared substrate moisture, temperature, and percent nitrogen content. Wood microsites, at 13 of 14 randomly selected sites, were characterized by highly decayed downed wood ( $>75 \%$ decay class five) originating from treefall $(66 \%)$, snow avalanches $(17 \%)$, forest fires $(15 \%)$, and by human cutting (2\%). Although no differences in percent nitrogen content were detected, greater seedling densities, greater seedling survival of both natural and transplanted
\end{abstract}

*Note: Chapter 2 has been published in Northwest Science (Johnson and Yeakley 2013). 
seedlings, higher temperatures, and higher moisture contents were found on wood microsites compared to adjacent soil. I suggest that greater seedling density and seedling survival on wood microsites was associated with factors including heightened moisture and increased temperature. Assuming sustained downed wood input from timberline trees and continued viable seed input, wood microsites are expected to will facilitate accelerated alpine meadow conifer invasion associated with climate warming.

Keywords: regeneration, alpine meadow invasion, disturbance, wood microsites, seedlings

\section{Introduction}

The importance of climate warming on forests is recognized worldwide and has increased attention on the significance of both timberline advance and alpine meadow invasion by forests (Franklin et al. 1971, Rochefort et al. 1994, Körner 2003, Wather 2003, Holtmeier and Broll 2005). Timberline, one of three areas included in the alpine tree ecotone (ATE), represents a line between continuous forest below and area of treeline and krummholtz above (Wardle 1973, Tranquillini 1979, Holtmeier 2003, Hasselquist et al. 2005). Timberline is often adjacent to alpine meadows (upper parklands) having both isolated and groups of seed-generated and clonal-regenerated trees. Seed dispersal, germination, and seedling establishment must occur well in advance of any permanent changes in the spatial distribution pattern of mature forests (Noble 1993, Smith et al., 2003, Zens and Peart 2003). Increase in seed-generated trees and 
viable seed populations in the ATE is associated with climate warming (Franklin et al. 1971, Rochefort et al. 1994, Korner 1998, Kullman 2006), but successful seedling regeneration in alpine meadows may depend on availability of suitable substrates for seed establishment (Woodward et al. 1995, Peterson 1998, Germino et al. 2002).

Microsites are areas of micro relief that help ameliorate local environmental factors limiting seed establishment by providing germinating seedlings with necessary shade, moisture, and temperature (Harper et al. 1961, Eriksson and Ehrlén, 1992, Graae et al. 2011). ATE microsites include convexities, concavities, objects that provide shelter from sun and wind, and substrates composed of wood, mineral soil, or rock (Holtmeier and Broll 1992, Rochefort et al. 1994, Moir et al. 1999, Castro et al. 2002, Maher et al. 2005). Microsites range in size from millimeters to meters in diameter. In drier areas of the world, concavity microsites supply seedlings with needed moisture during periods of drought (Mellmann-Brown 2005, Anschlag et al. 2008). Where night frost is common, rocks and trees may alter wind, sun, and long-wave radiation patterns thereby protecting seedlings (Ball et al. 1991, Germino and Smith 1999). In the Pacific Northwest (PNW) where heavy snowpacks are common, regeneration in alpine meadows typically occurs on convex microsites or small mounds. Longer growing seasons, attributed to early snow melting, are typically found on raised surfaces (Lowery 1972, Rochefort and Peterson 1996). Examples of PNW convex microsites are located in alpine meadows of Mt. Rainier, North Cascade Mountains of Washington, and Mt. Bachelor in Oregon (Lowery 1972, Rochefort and Peterson 1996, Harold Zald, personal communication). There, species including subalpine fir (Abies lasiocarpa) and mountain hemlock (Tsuga 
mertensiana) grow within ericaceous species (e.g., pink mountain heather [Phyllodoce empetriformis], and Cascade blueberry [Vaccinium deliciosum]) where favorable physical conditions (e.g., shade, wind protection, soil type, seed catchment), favorable biological environments (e.g., appropriate mycorrhizal fungi, Perry et al. 1990), and/or areas having lower than normal snowpack provide improved conditions for regeneration (Woodward et al. 1995, Peterson et al. 2002).

Wood microsites, important areas of regeneration below timberline (Christy and Mack 1984, Harmon and Franklin 1989, Gray and Spies 1997, Veblen 1989, Gratzer et al. 1999, Narukawa et al. 2003, Ziolonka and Niklossen 2001, Motta et al. 2006, Baier et al. 2007), may also facilitate regeneration at timberline-alpine borders. Below timberline, factors including wood size, wood decay class, available moisture, and amount of shade determine viability of wood microsites for seedling regeneration (Gray and Spies 1997, Mori et al. 2004, Ziolonka and Niklossen 2001). In lower elevation PNW forests, wood microsites reduce competition, support higher moisture levels, and support longer snowfree periods. These factors enhance germination of western hemlock (Tsuga heterophylla), Pacific redcedar (Thuja plicata), subalpine fir (Abies lasiocarpa), and Engelmann spruce (Picea engelmannii) more than adjacent ground surfaces (e.g., Harmon et al. 1986, Harmon and Franklin 1989, Caza 1993). In mountainous forests of Europe and Japan, wood facilitates Norway spruce (Picea abies), Maries' fir (Abies mariesii), and Veitch's fir (Abies veitchii) generation by reducing destructive effects of snow glide, reducing interspecies competition, increasing mychorrizal populations, and enhancing nutrient concentrations (Eichrodt 1969, Simard et al. 1998, Bauer 2003, Brang 
et al. 2003, Mori et al. 2004, Baier et al. 2007, Baier et al. 2007). In subalpine forests of the Swiss Alps, spruce were found to grow significantly faster on decaying wood (Baier et al. 2007), and seedlings were assumed to profit from earlier snowmelt (Stockli 1995, Smit et al. 2005) and warmer temperatures (Mayer and Ott 1991). I speculated that many of the positive attributes associated with wood microsites in lower elevation forests would also be present at timberline-alpine meadows to support subalpine fir and mountain hemlock seedling regeneration where suitable downed wood exists.

I developed a conceptual model (Fig. 2) to illustrate how alpine meadow conifer invasion on wood microsites likely occurs at PNW timberline-alpine meadows, given four necessary steps: (1) existence of large timberline trees and notable forest disturbances; (2) a climate enabling extensive decay of downed wood; (3) successful germination and survival of seedlings on wood microsites; and (4) growth of trees to maturity. First of all, large trees exist at pristine timberlines. By definition, timberline tree heights range from $6 \mathrm{~m}$ to $>15 \mathrm{~m}$, as compared to treeline, with tree heights $>2 \mathrm{~m}$, but generally $<4$ m (Wardle 1981, Cuevas 2002, Oberhuber 2004). Disturbances including treefall, snow avalanching, and fire are common at PNW timberlines (Franklin et al. 2002, van Mantgem et al. 2009). Trees likely fall or are transported via these disturbances from timberline to adjacent alpine meadows (Fig. 2, step 1). Tree susceptibility to treefall from wind storms is often related to soil water status and whether soil is frozen, storm meteorology, topography, forest type, amount of tree heart rot decay, and stage of forest stand development (Veblen et al. 1991, Everham and Brokaw 1996, Petola et al. 1999, Lindeman and Baker 2001, Baker et al. 2002, Kulakowksi and Veblen 2002, Kramer et 
al. 2004, Mitchell 2012). Wood input is expected to increase with climate warming due to increases in pests, increases in wind disturbance, and decrease in length of time ground is frozen (Edburg et al. 2012, Mitchell 2012). Second, extensive decay of downed wood occurs given adequate moisture, temperature, and time (Sollins 1982, Zielonka and Niklasson 2001; Fig. 2, step 2). Wood decay rate depends on whether trees are partially decayed before falling with climatic attributes facilitating decay of wood including high moisture, warm temperatures, and wood species type (Marra and Edmonds 1996, Chen 1999, Hicks 2000, Yatskov et al. 2003). Wood in contact with the ground may decay $50 \%$ faster than elevated wood (Barber and Van Lear 1984). Reduced snowfall, warmer summer temperatures, decreased summer precipitation, and longer growing seasons (Leung and Wigmosta 1999, Dale et al. 2001, Mote 2003a, Mote 2003b, Mote 2003c, Mote et al. 2005, Westerling et al. 2006, Battin et al. 2007, Markoff and Cullen 2008, Edburg et al. 2012) should increase wood decay rate as long as prolonged droughts do not occur. Third, assuming presence of viable seeds, seedlings germinating on sufficiently rotted wood could establish, given sufficient warmth, moisture, nutrients, and protection from stresses at timberline including wind, frost, and radiation (Hofgaard 1993, Fig. 2 , step 3). Limitations to seedling growth could potentially be ameliorated more by wood substrates than adjacent soil substrates. Finally, if seedlings and saplings growing on wood microsites at timberline-alpine meadow borders reach maturity and subsequently fall into meadows and decay, another cycle of conifer invasion into meadows via wood microsites would ensue (Fig. 2, step 4). Awareness of eco-physical linkages between processes that introduce wood and possible microhabitats created by wood will help to 
elucidate processes by which alpine invasion is occurring. Further, this information should enhance predictions of alpine meadow tree invasion rate and should inform forest management in the ATE.

My study objective was to assess conceptual model steps 1-3 in order to evaluate the ecological role of large downed wood at timberline-alpine meadows borders for facilitating seedling regeneration and enhancing alpine meadow conifer invasion (Fig. 2). From a random selection of timberline sites, I addressed the following questions: (1) How prevalent are wood microsites, what are site characteristics where wood microsites are present, and what are the disturbance processes that introduce downed wood? (2) What are the characteristics of wood and wood decay class supporting most conifer seedlings? (3) Do differences exist in wood and adjacent soil substrate moisture, temperature, and nitrogen content; and do differences exist in density, survival, and nitrogen content of seedlings growing on wood microsites to seedlings on adjacent soil substrates? Lastly, given answers to the previous questions, I assessed the likely rate of tree invasion in alpine meadows and discuss management implications of regeneration on wood substrates.

\section{Study area}

Using a geographic information system (GIS), 14 sites were chosen from the densest point spacing of possible study locations meeting selection criteria described below. The GIS used a regular systematic $1 \mathrm{~km}$ grid of 1600 potential sample points within the Cascade Range of Washington and Oregon that was spatially intersected with 
roads, a 10 meter digital elevation model (DEM), and a landcover grid (Homer et al. 2004, McNab et al. 2005, Gesch 2007). Initial selection criteria reduced potential sample point locations to 300 based on elevation (> $1400 \mathrm{~m}$ ) and close proximity to forest edges (John Chase, personal communication). Because approximately 33\% of these randomlyselected sample points were located in the North Cascade Mts. of northern Washington State, this area was selected as representative of the region for research. Site selection criteria included locating sites at least $1 \mathrm{~km}$ away from roads, but requiring no more than a four-hour hike to reach. These criteria reduced the pool of sites to about 50 point locations. Multiple points on the west side of the Cascade Mts. were eliminated due to road closures and multiple points on the east side were eliminated due to known domestic livestock grazing. The chosen 14 point locations span across the North Cascade Mts. of Washington State in the vicinity of the North Cascades Hwy, and also span the west to east precipitation gradient (Fig. 3).

Of the 14 sites, seven were located within the mountain hemlock (Tsuga mertensiana) zone on the western portion of the North Cascade Mts. (west of longitude $120.700 \mathrm{~W}$ ) and seven were located in the subalpine fir zone on the eastern side of the North Cascade Mtns. (east of longitude 120.7 W). Both zones include subzones of closed forest and upper parkland (Franklin and Dyrness 1979; Fig. 3, Table 2). The mountain hemlock zone includes Pacific silver fir (Abies amabilis) and Alaska cedar (Chamecyparis nootkatensis). The subalpine fir zone was more continental with cooler temperatures, and included Engelmann spruce, lodgepole pine (Pinus contorta), grand fir (Abies grandis), subalpine larch (Larix lyallii), and western white pine (Pinus monticola) 
(Franklin and Dyrness 1979). Upper parkland tree invasion, found at all sites, was primarily by mountain hemlock and subalpine fir (Franklin et al. 1971). The forests are under jurisdiction of the Mt. Baker Snoqualmie National Forest on the west, North Cascades Park Complex in the mid-region, and the Okanogan National Forest on the east side. All of the sites are managed as wilderness areas.

The sites spanned a precipitation gradient from $250 \mathrm{~cm} / \mathrm{yr}$ on the western-most site to $150 \mathrm{~cm} / \mathrm{yr}$ on the east side of the Cascades with summer rainfall averaging $20 \mathrm{~cm}$ on the west side and $10 \mathrm{~cm}$ on the east side. Typical of timberlines, elevation increased with increasing distance from the coast (Arno 1984, Körner 1998, Holtmeier 2009) with timberline elevations ranging from $1585 \mathrm{~m}$ on the west side to $1996 \mathrm{~m}$ on the east side. Mean annual temperature averaged $4.1^{\circ} \mathrm{C}$ on the west side and $3.0^{\circ} \mathrm{C}$ on the east side (Thornton et al. 2012, Table 2). Snow typically covered alpine meadows from midOctober or late-October to late June or early-July with depths exceeding $3.8 \mathrm{~m}$ (USDA, NRCS, SNOTEL 1971-2000).

In general, the geology is volcanic on the west side and sedimentary on the east side, with intrusive volcanics in the mid-range. Soils are well-drained Cryorthods, and have textures ranging from fine sandy loam to sandy gravelly loam. At my sites, organic horizons ranged from 0.5 to $1.0 \mathrm{~cm}$. Total depth of the soil to bedrock ranged from $0.2 \mathrm{~m}$ to $1.0 \mathrm{~m}$ with A-horizons ranging in depth from 0 to $0.2 \mathrm{~m}$ (USDA, NRCS 2008). 


\section{Methods}

Site Characteristics and Disturbance Mechanisms Introducing Wood

At each site, one $60 \mathrm{~m}$ transect was established along the forest-meadow edge of timberline in late-July and August of 2008. Transects typically started at one side of a forest patch and ran along the timberline edge (Fig. 4). At each site, gradient and aspect were recorded. Number, diameter, length, and decay class of wood pieces with diameter $>0.15 \mathrm{~m}$ (Sollins et al. 1987) were noted when the transect line crossed wood pieces on the ground. Disturbance mechanisms introducing downed wood to alpine meadows were determined, and included treefall, snow avalanches, and fire. Treefall included windthrow (uprooted trees with roots exposed), tree snap, and limb breakage due to snow loading on branches. Snow avalanche activity was inferred from presence of open, non-forested, or sparsely forested slopes directly above study areas (Johnson 1987). Fire was indicated by

presence of charcoal.

The 14 sites were placed in short-, medium-, and long-shadow length categories based upon direction of site aspect with respect to tree patch. Short-shadow length sites included locations on south-facing or north-facing slopes having full exposure to the sun due to lack of tree patches. Medium-shadow sites were located upslope of tree patches on south-facing slopes. The high-shadow sites were located downslope of tree patches on north-facing slopes (Table 2). 


\section{Downed Wood Decay Class Supporting Seedlings}

Downed wood was classified into five decay classes as follows: (1) decay class one has branches and twigs present with sound bole; (2) decay class two has sapwood and twigs somewhat decayed, but heartwood and branches may be sound; (3) decay class three has only branch stubs that cannot be pulled out and sapwood that can be broken in chunks; (4) decay class four has decayed heartwood and branch stubs that can be easily pulled out; and (5) decay class five has no structural integrity, decayed heartwood, and branch stubs that have rotted away (Maser et al. 1979, Sollins 1982). To give an estimate of timberline tree age, increment core samples for tree ageing were extracted at a height of $130 \mathrm{~cm}$ above the ground from two or three of the largest trees at each site. Number and species of seedlings growing on downed wood pieces were recorded.

\section{Comparison of Wood and Soil Substrate Temperature, Moisture, Carbon, and Nitrogen} Wood and soil temperatures were measured mid-day in July and August among seedlings growing on wood microsites and also on adjacent soils; both measurements were taken at depths of $10 \mathrm{~cm}$. Subsequent continuous substrate temperature measurements indicated synchronous warming of soils and wood during the day. Generally, the soil measurements were made between 0.3 to $1.0 \mathrm{~m}$ from the wood microsite measurements. These distances ensured that soil temperature measurement were made close, but distant enough from logs to ensure that soil temperature was not influenced by the shade of the $\log$. 
Percent organic carbon, percent nitrogen content, $\mathrm{C}: \mathrm{N}$ ratios, and percent water content of wood and soil were determined for two samples on each of the substrate types at each of the 14 sites to compare substrate quality. These samples, with volumes of $31.1 \mathrm{~cm}^{3}$, were taken with a corer $<5 \mathrm{~cm}$ from clusters of young seedlings ( $<3 \mathrm{yr}$ old $)$ on wood and soil along the $60 \mathrm{~m}$ transects. Samples were weighed, dried for $48 \mathrm{hrs}$ at $75^{\circ} \mathrm{C}$ and then re-weighed to determine change in water content. Dried samples were used for percent carbon content and percent nitrogen content analysis. Percent nitrogen and percent carbon was determined using an automated combustion method (Central Analytical Laboratory Method 9.3) using a LECO model CNS 2000 furnace.

Comparison of Wood and Soil Seedling Density, Survival, and Percent Nitrogen Content A subset of six sites was chosen from the original set of 14 sites to compare density, survival, and carbon and nitrogen content of seedlings growing on wood to seedlings growing on adjacent soil substrates. To minimize site variability, only sites with treefall as the sole mechanism introducing wood to alpine meadows were selected. This ensured that downed wood was generated in situ from the area immediately adjacent timberline edge, as opposed to being transported from a higher elevation by snow avalanches. Of the six sites, three were located on the west side and three were located on the east side of the Cascade Mts. All seedlings observed on wood and adjacent soil were young, approximately one to three years in age. Density of seedlings on wood and adjacent soil was compared by computing the total surface area of wood extending out from the timberline-alpine meadow border along the $60 \mathrm{~m}$ transects (Fig. 4). Then, all seedlings 
growing on the downed wood were divided by the wood surface area as summarized by the equation:

$$
\text { Density }=\Sigma(\mathrm{n} \text { seedlings } /(\text { mean wood width } * \text { length })
$$

Because the narrowest ends of downed trees were generally absent due to extensive decay, I assumed this approximation of area was appropriate. Seedlings per area on the ground surface were determined by a stratified sampling design whereby 15 regularlyspaced $0.25 \mathrm{~m}^{2}$ plots were sampled in the timberline-meadow fringe within the zone of the wood substrates (Fig. 5). At distances of 0, 15, 30, 45, and $60 \mathrm{~m}$, three plots were placed extending out from the timberline into the alpine meadow. The three plots were evenlyspaced on the zone of wood influence along the $60 \mathrm{~m}$ transect. Soil seedling density was determined by dividing all seedlings growing on soil substrates by the total ground area $\left(3.75 \mathrm{~m}^{2}\right)$ as summarized by the equation:

Soil seedlings density $=\Sigma(\mathrm{n}$ seedlings/area ground $)$

At each of the plots, the number, height, species of seedling, dominant species of herbaceous cover, and amount of area inhibiting tree growth such as rock cover were determined.

To compare seedling survival on wood and soil substrates, a total of 324 one-to three-year old seedlings (162 on wood and 162 on adjacent soil) were marked and reassessed for survival after a three-year period. Each of the six sites had three subsamples comprised of wood and adjacent soil substrate pairs. For each pair, nine seedlings were assessed on wood substrates and nine seedlings were assessed on soil 
substrates. The nine seedlings were located in clusters of three and were distributed at three locations having different levels of canopy overstory: (1) at timberline, or (highest level of overstory), (2) at mid-range between timberline edge and outermost region of wood influence in alpine meadows (medium level of overstory), and (3) outermost region of wood influence in alpine meadows (lowest level of canopy overstory).

Healthy seedlings were transplanted from elsewhere within each of the study sites when extra seedlings were needed to complete this study design (Table 3). Out of 162 seedlings on wood, 100 were natural and 62 transplanted, whereas on soil, 49 were natural and 113 were transplanted. Survival assessments were made separately for natural and transplanted seedlings. To differentiate between seedlings, natural seedlings were marked with one toothpick and transplanted seedlings were marked with two toothpicks. Percent survival was determined when seedlings were approximately three- to six-years old.

Total organic carbon, total nitrogen, $\mathrm{C}: \mathrm{N}$ ratios were determined for whole seedlings (all $<3 \mathrm{~cm}$ in ht) growing on wood and soil. At each of the six sites, three to ten whole seedlings were compiled for each of the three locations. Samples were dried for $48 \mathrm{hrs}$ at $35^{\circ} \mathrm{C}$ and then were ground to a fine powder in a Cole-Parmer Analytic Mill (Model 4301). Dried samples were used for percent carbon and percent nitrogen analysis. Percent nitrogen and percent carbon was determined using an automated combustion method (Central Analytical Laboratory Method 9.3) using a LECO model CNS 2000 furnace. 


\section{Estimate of Tree Invasion Rate}

I developed the following theoretical equation to approximate rate of tree invasion on wood microsites in alpine meadows:

$$
\mathrm{TI}=\frac{\mathrm{d}_{\text {seed }}}{\mathrm{W}_{\text {mature }}+\mathrm{W}_{\text {decay }}}
$$

where TI is timberline invasion rate $\left(\mathrm{m}^{*} \mathrm{y}^{-1}\right), \mathrm{d}_{\text {seed }}$ is the distance of a growing seedling in alpine meadow beyond timberline $(\mathrm{m}), \mathrm{W}_{\text {mature }}$ is the time necessary for a seedling to grow into a mature tree and fall into an alpine meadow (y), and $\mathrm{W}_{\text {decay }}$ is the mean time to reach decay class five (y). $\mathrm{D}_{\text {seed }}$ was determined from my field observations and $\mathrm{W}_{\text {mature }}$ was determined from the mean age of standing timberline trees in the vicinity of downed wood. I assumed a $\mathrm{W}_{\text {decay }}$ rate of 150 years, a rate found for extensive decay of wood at high-elevation subalpine forests (Hofgaard 1993). Hypothesized alpine conifer invasion rates given climate warming were estimated using decay rates of both 100 years and 50 years, given found decay rates of 44 to 115 yrs in lower elevation sub-alpine forests (Zielonka and Niklasson 2001, Storaunet and Rolstad 2002). I assumed that tree maturity and input occurred at a rate of 100 years given climate warming incorporated an assumed increased input of trees due to catastrophic winds.

\section{Statistical Analysis}

Parametric one-way analysis of variance (ANOVA) tests and t-tests were conducted as well as nonparametric tests to assess differences in the response variables temperature, 
water content, total carbon, nitrogen, and $\mathrm{C}: \mathrm{N}$ ratio of wood and soil with the independent variables including shadow (three categories), aspect (generalized by four cardinal directions), and eastern and western-most sites (split into eastside or westside categories at longitude $120.700 \mathrm{~W}$, near Rainy Pass, see Table 2). When needed, transformations of data were made in an attempt to meet assumptions of normality and data variability. Unless otherwise noted, all statistical tests conducted were separate oneway analysis of variance (ANOVA), with post-hoc multiple comparison tests (Tukey’s) used when significant differences were detected. If comparisons were between only two groups, a t-test was used. When comparisons of wood and soil were nonparametric, Wilcoxon rank sum tests were conducted. Statistical significance was assessed with $\alpha=$ 0.05 and all statistical analyses were conducted with the R statistics package ( $\mathrm{R}$ Core Development Team 2005).

\section{Results}

\section{Origin and Characteristics of Wood Microsites with Description of Seedlings}

Conifer seedlings grew on downed wood at 13 of 14 randomly selected sites (site 10 had no seedlings on downed wood) at timberline-alpine meadow borders. From the 136

pieces of wood with diameters $>15 \mathrm{~cm}, 41$ had seedlings growing on them. Wood pieces ranged in length from 1.5 to $20 \mathrm{~m}$ ( $7.5 \mathrm{~m}$ average) and wood diameter ranged from 0.15 to $0.80 \mathrm{~m}(0.52 \mathrm{~m}$ average $)$. Standing mature trees at the edge of timberline adjacent to my study area had diameters of $0.63 \mathrm{~m}$ and surpassed 230 years in age. 
Of the 41 pieces of wood with seedlings, more wood was introduced to meadows at each site by treefall (27 pieces) than by snow avalanche ( 7 pieces), fire ( 6 pieces), or human cutting (1 piece). Treefall included tree snap (13 pieces), windthrow (6 pieces), knock over by other trees ( 3 pieces), limb and bole breakage likely due to snow (2 pieces), and other unknown causes (5 pieces). Decay class of wood microsites ranged from two to five with $>75 \%$ of the wood microsites in decay class five.

Of the 325 total seedlings growing on wood substrates, 261 were found on decay class five, 59 on decay class four, four on decay class three, and one on decay class two. Seedling species on nurse logs included Tsuga mertensiana, Abies lasciocarpa, Abies amabilis, Chamecyparis nootkatensis, Picea engelmannii, and western larch (Larix occidentalis). Many of the seedlings were $<2 \mathrm{~cm}$ in height, and determining species of seedlings was difficult. However, I estimate that approximately $75 \%$ of the seedlings regenerating on wood were Abies sp. In general, western sites were dominated by Tsuga mertensiana and Abies sp. seedlings, whereas eastern sites were dominated by Abies sp., Picea engelmannii, and Larix occidentalis seedlings.

Seedlings were found on rotten wood substrates at distances ranging from 0 to 20 $\mathrm{m}$ from timberline edge into alpine meadows. Mean seedling heights and seedling number did not differ significantly by shade category $(p>0.1 ; \mathrm{n}=4,7$, and 3 for shortmedium, and long-shadow categories, repectively; Fig. 6a, b). No significant differences were found for seedling number by aspect $(p=0.98 ; \mathrm{n}=3,6,2,3$, for $\mathrm{N}, \mathrm{S}, \mathrm{E}$, and $\mathrm{W}$, respectively) or by eastside versus westside location $(p=0.66 ; \mathrm{n}=7$ each for east and west locations). 
Comparison of Wood and Soil Substrate Temperature, Moisture, Carbon, and Nitrogen Wood substrates had significantly higher summer percent moisture contents than the adjacent soils $(p<0.01, \mathrm{n}=14$ for each substrate; t-test, means of 38.9 and $17.5 \%$, respectively; Fig. 7a). Comparisons of percent moisture in wood versus soil substrates as described by aspect, by shade category, and by eastside or westside location were all significantly different ( $p<0.01, \mathrm{n}=3$ to 7 per category; Fig. $7 \mathrm{~b}, \mathrm{c}, \mathrm{d})$, but wood substrates on the westside and wood substrates on the eastside did not differ. Post-hoc Tukey tests indicated that wood substrates of the western location category (mean moisture content of $38.9 \%$ ) were wetter than both eastern soil substrates (mean of $15.9 \%$ ) and western soil substrates (mean of 19.0\%) $(p<0.05)$. Also, wood substrates in the medium-shadow category, all south-facing slopes, were significantly wetter than soil substrates of the medium-shadow category $(p<0.01)$. Wood substrates of the shortshadow category, found on north-facing slopes were significantly wetter (mean of 46.6\%) than soil substrates of the medium-shadow category $(p=0.03)$. Post hoc tests indicated that wood substrates on south-facing slopes (mean of $41.2 \%$ ) were significantly wetter than south-facing soil substrates (mean of 16.8\%). Wood substrates on west-facing slopes (mean of $47.9 \%$ ) were significantly wetter than soil substrates on either south or eastfacing slopes (mean of $11.9 \%)(p<0.05)$. In comparing wood substrates only or soil substrates only, no significant differences were found between shadow category, east and west locations, or different aspects $(p>0.05)$.

Wood substrates had significantly higher temperatures than the adjacent soils ( $p=$ $0.016, \mathrm{n}=14$ for each substrate type; t-test, means of 9.9 and $8.3^{\circ} \mathrm{C}$, respectively; Fig. 
8a). These differences were not significantly different on eastside versus westside sites ( $p$ $=0.06, \mathrm{n}=7$ per substrate/shade category, Fig. $8 \mathrm{~b}$ ). When comparing temperature by aspect or shadow length category, no significance differences were found between soil and wood substrates $(p>0.09, \mathrm{n}=$ range of 2 to 6 per category, Fig. $8 \mathrm{c}, \mathrm{d})$.

Significant differences existed between substrates for percent carbon content $(p<$ $0.01, \mathrm{n}=14$ per substrate type, mean soil carbon content $13.4 \%$, mean wood carbon content $47.16 \%)$ and $\mathrm{C}: \mathrm{N}$ ratio $(p<0.001, \mathrm{n}=14$ per substrate type, mean soil 32.2, mean wood 126.5). No difference in percent nitrogen content was detected for wood and soils $(p=0.59, \mathrm{n}=14$ per substrate type; $\mathrm{t}$-test, means of $0.474 \%$ and $0.507 \%$, respectively; Fig 9a). No differences in nitrogen were detected for wood and soils when comparing by aspect or by shadow length category $(p>0.05, \mathrm{n}=3$ to 7 per substrate/aspect or substrate/shadow category, Fig. 9b).

\section{Comparison of Wood and Soil Seedling Density, Survival, and Nitrogen Content}

Mean seedling density of wood was significantly different than soil ( 6.85 seedlings per $\mathrm{m}^{2}$ versus 3.64 seedlings per $\mathrm{m}^{2}$ on soil, $p=0.026, \mathrm{n}=6$ per substrate; Fig. 10a, nonparametric data, Wilkoxon rank sum test). When separating data by shade category, significant differences were detected $(p=0.022)$ and post-hoc Tukey tests indicated significant differences only between seedling density for high-overstory wood microsites and low-overstory soil substrates $(p=0.014$, density means of 11.7 and 2.2 seedlings per $\mathrm{m}^{2}$, respectively). 
Percent survival was significantly greater for natural seedlings growing on wood than for natural seedlings growing on the adjacent soil substrates $(p=0.01, \mathrm{n}=6$ per substrate, means of 88.3 and 72.7, respectively, Fig. 10b, nonparametric data, Wilcoxon rank sum test). Percent survival was significantly greater for transplanted seedlings growing on wood than for seedlings transplanted on soil substrates $(p=0.03, \mathrm{n}=6$ per substrate, means of 18.1 and 12.0, respectively, Fig. 10c, nonparametric data, Wilcoxon rank sum test). Percent survival was greater for seedlings growing on wood at locations closer to timberline than seedlings growing on soil close to timberline.

Percent nitrogen content was similar for seedlings growing in wood and seedlings growing in soil substrates ( $p=0.57, \mathrm{n}=6$ per substrate; t-test, means of 1.23 and 1.17 , respectively). Overall, percent carbon content of whole seedlings growing in soil was significantly higher than seedlings growing on wood $(p=0.042, \mathrm{n}=6$ per substrate; $\mathrm{t}$ test, means of 47.7 and 46.8, respectively, Fig. 10d). No statistical difference was found for $\mathrm{C}: \mathrm{N}$ ratio between seedlings growing on wood and soil substrates $(p=0.47, \mathrm{n}=6$ per substrate; t-test, means of 43.2 and 40.6 , respectively).

\section{Estimate of Conifer Invasion Rate in Alpine Meadows}

Using equation (3), I estimated a current tree invasion rate between 0.005 to $0.05 \mathrm{~m}^{*} \mathrm{y}^{-1}$. This estimate is based on presence of seedlings growing on rotten wood microsites extending between 2 to $20 \mathrm{~m}$ from timberline into alpine meadows, tree maturity and subsequent input of trees to alpine meadows at 250 years, and a wood decay rate of 150 
years. Using climate warming assumptions, a theoretical rate of conifer meadow invasion is increased to $0.13 \mathrm{~m}^{*} \mathrm{y}^{-1}$ (Table 4).

\section{Discussion}

Wood Input from Timberline to Alpine Meadows

Wood input pattern, ultimately affecting wood microsite location, is influenced by factors that will be altered by climate warming (Fig. 2, step 1). Fire, considered the most important disturbance in the Cascade Mountains (Agee 1993, Hemstrom and Franklin 1982, Agee and Skinner 2005, Westerling et al. 2006, Gavin et al. 2007) was apparent at only one study site (located on the eastside of the Cascades), and may have been minimized due to snow avalanches serving as fire breaks (Agee 1993). Although snow avalanches created woody debris trim lines along snow avalanche path borders and deposited wood in alpine meadows, snow avalanches typically transported trees considerable distances downslope. In contrast, wood from timberline trees falling directly into alpine meadows via blowdown and wind snap typically created wood microsites at higher elevation timberline locations.

Mature subalpine fir trees (common at my sites) may have been especially prone to wind snap due to weakening by internal wood decay and infestation with fir engraver beetles (Alexander et al. 1984, Hennon 1995, Lewis and Lindgren 1999, McCarthy 2001). With recent outbreaks of large-scale bark beetle infestations, similar in magnitude to that affected by fire facilitated by climate warming (Edburg et al. 2012) and projected increases in more intense storms, more catastrophic inputs of wood can be expected (Dale 
et al. 2001, Mitchell 2012). Given greater frequency of forest disturbance, a broad band of downed wood will likely be present at timberline-alpine meadow borders in the future.

\section{Decay Characteristics of Wood Microsites at Timberline-alpine Meadows}

My field observations indicate that the extensive wood decay may be necessary to facilitate growth of conifer seedlings may not occur at many locations given climate warming (Fig. 2, step 2). In some areas, particularly in drier regions where trees die standing, wood can become case hardened whereby compressional strength increases and rotting is inhibited (Erickson 1985, Harmon et al. 1995, Pyle and Brown 1998). Case hardening was apparent at some of my eastside sites where a few downed wood pieces were hard and intact or wood was found in piles of brittle fragments near stumps. These sites did not support seedling regeneration. The type of decay present in downed trees may have affected wood decay at my sites. For example, presence of brown rot is associated with deterioration of wood cellulose only, whereas presence of white rot is associated with decay of both wood cellulose and wood lignin (Blanchette 1991). In general, I expect greater decay of wood particularly at westernmost sites where moisture is greater.

\section{Factors Facilitating Seedling Regeneration on Wood}

I speculate that greater seedling densities and greater survival of both natural and transplanted seedlings on wood microsites is attributed, at least in part, to factors including warmer temperature and greater moisture, elements likely to accelerate alpine 
meadow invasion with climate warming assuming continued input of viable seeds (Fig. 2, steps 3 and 4). As indicated by greater survival of transplanted seedlings on wood substrates, wood enables better adaption of seedlings to the harsh alpine meadow environments than soil substrates. Given expected increase in downed wood abundance at timberline-alpine meadow borders, there will be more available substrates for conifer regeneration at shady, protected timberline locations. Here, interrelated factors including higher moisture, lower light, and likely more wind and frost protection enabled successful seedling regeneration. Abies sp. seedlings, tolerant of low light levels with roots able to penetrate thick litter layers (Knapp and Smith 1982), were found at all sites. In contrast, Abies sp. seedlings that may have initially established on wood and soil at lowshadow/low-canopy overstory locations may have been prone to drought and photoinhibition, a common cause of frost-related death for seedlings growing at high elevation with minimal overstory protection (Ball et al. 1991, Germino and Smith 1999, Germino et al. 2002). Lack of substrate moisture, typically limiting seedling growth (Cui and Smith 1991, Smith and Johnson 2007), is ameliorated by wood substrates. Wood microsites are known to serve as reservoirs during periods of drought (Harmon and Franklin 1989, Amaranthus et al. 1989, Cornett et al. 2000), common during summers in the PNW (Rochefort et al. 1994, Peterson et al. 2002) and expected to increase with climate warming (Markoff and Cullen 2008). Enhanced temperature of wood substrates as compared to adjacent soil substrates (covered by vegetation) can be attributed, at least in part, by the lower albedo of dark wood surfaces. Because mean summer temperature surrounding roots is the most basic ecological factor defining the location of timberlines 
(Körner and Paulsen 2004), heat enhancement found on wood microsites may have a positive effect on seedling growth.

I speculate that for seedlings growing on wood microsites, more carbon allocation to root production and more colonization of mycorrhizal fungi, may have compensated for low substrate nutrient status. As indicated by seedling excavations (conducted for seedling survival assessments), roots of seedling in wood appeared longer with more tortuous paths than seedlings growing in soil. More colonization of roots by mycorrhizal fungi allow plants to extract sufficient nutrients and from rotting wood (Baier et al. 2006, Fukasawa 2012). Lack of mycorrhyizal infection has been suggested a factor associated with high conifer seedling mortality rate (Cui and Smith 1991, Hasselquist et al. 2005, Germino et al. 2006). Although nitrate and ammonium, forms of nitrogen used by plants, were not measured, a $\mathrm{C}: \mathrm{N}$ ratio threshold of 25:1 (with $\mathrm{N}$ limitation above and $\mathrm{C}$ limitation below, Chapin et al. 2002) suggests $\mathrm{N}$ limitation for all wood microsites, $\mathrm{N}$ limitation for $66 \%$ of soil substrates, and C limitation for $33 \%$ of soil substrates. Since plants associated with infertile and cold habitats may respond to nutrient stress by maintaining higher nutrient concentrations, nitrogen level is not necessarily a decisive factor in determining growth at timberline (Chapin 1980, Körner 1989, Li et al. 2008). For whole seedlings (excluding roots), I found no difference in percent $\mathrm{N}$ and $\mathrm{C}: \mathrm{N}$ ratio, but slightly higher percent $\mathrm{C}$ content in seedlings growing on soil.

Although not measured in this study, both snow creep and plant completion, minimized on wood microsites as compared to adjacent soil substrates, may have enhanced seedling survival. Snow glide, indicated by downward-sloping toothpicks used 
to mark seedlings, were very common on soils, but not common on wood. Less snow creep on wood microsites has been found in subalpine forests (Baier et al. 2007). The families Poaceae, Ericaceae, and species including Vaccinium sp. and Veratrum viride were commonly found on soil substrates. I speculate that these dense patches of understory foliage at the timberline edge limited survival of conifer seedlings. In contrast, highly decayed wood was commonly devoid of any vegetation besides moss and conifer seedlings.

Wood microsites, important to the survival of young seedlings, are not expected to be important to the survival of older trees. Wood substrates supporting seedlings were highly decayed and often flush with the soil surface. Therefore, I speculate that by the time trees reach maturity wood pieces will be integrated into the soil and wood will not be noticeable. Beyond the $20 \mathrm{~m}$ zone influenced by wood microsites, seedlings growing on soil were both clonal and seed generated. Although both trees growing on wood and trees growing on soils are likely to benefit from the longer seasons associated with climate warming, the trees growing along closest to the edge of timberline, established mostly on wood microsites, will have the advantage of less wind and less frost stress.

\section{Management Implications and Suggestions for Future Work}

My finding of increased seedling regeneration on wood microsites at alpine-timberline borders elucidates mechanisms of conifer regeneration above timberline, timing by which alpine invasion is occurring, and also provides guidance to rehabilitation efforts. My examination of seedling establishment and survival of young seedlings, rather than 
examination of older resilient trees, gives a clearer understanding of current climatic factors affecting tree invasion in alpine meadows. I found better survival of both natural and transplanted seedlings on wood substrates as compared to adjacent soil substrates, and therefore it is likely that microsites providing additional warmth and increased moisture ameliorate current climatic limitations for seedling germination at PNW alpine meadows. Natural alpine invasion on wood microsites likely occurs in other regions typified by large trees at timberline-alpine meadows, high precipitation, mild summers, and lack of forest harvesting. Further, these treeline dynamics provide important feedback mechanisms to the global climate system by altering albedo and carbon storage at high latitudes and high elevations (Leung and Wigmosta 1999, Wilmking et al. 2006, Malanson et al. 2007, Kirdyanov et al. 2012, Wilmking et al. 2012). My investigation indicates that wood microsites provide a feedback loop of increased albedo and also increased carbon storage. Interdisciplinary research in the ATE may help reveal the many interrelated positive and negative feedbacks associated with conifer alpine meadow invasion. Wood microsites, providing moister and warmer substrates can be used in restoration practices. For example, in boreal and alpine areas where histories of fire suppression, forest harvest, and mechanical degradation of alpine meadows have once occurred, newer policies encouraging controlled burns and natural succession processes have benefitted by restoration practices utilizing downed wood and wood fabric (Fattorini 2001, Vanha-Majamaa et al. 2007). At these locations, wood microsites have effectively enhanced rate of plant colonization. My findings indicate that wood substrates may also support restoration in degraded alpine meadows adjacent to high-use recreational trails 
along timberline-alpine meadows. Since predicted increases in insect abundances and catastrophic winds may exacerbate frequency of downed wood loading in alpine meadows, sustainable long-term supplies of downed wood facilitating conifer regeneration will depend on maintenance of timberline tree populations containing at least a portion of young, healthy trees capable of withstanding various disturbances.

To further assess site factors associated with conifer growth on wood microsites as compared to adjacent soil substrates, four factors are suggested for future research: (1) determination of whether wood substrates accelerate snowmelt and extend the growing season, (2) measurements of possible differences in substrate radiative cooling at night related to level of overstory canopy, (3) physiologic measures of active seedling growth, and (4) assessment of root mycorrhyizal associations.

\section{Conclusion}

I determined that conifer seedling regeneration was facilitated more by wood microsites than by adjacent soil substrates at timberline-alpine meadow borders. Wood microsites had greater seedling density, greater seedling survival of both natural and transplanted, and provided warmer and moister substrates than adjacent soil substrates. Highly rotted wood, primarily originating from treefall, supported regeneration particularly for Abies $s p$. Wood has been shown to be a superior site for germinating seedlings, particularly in sites with high shade. I hypothesize that higher seedling density and survival was attributed to greater substrate temperature and moisture, and was also likely supported by mychorryzal associations, less snow glide, and less competition on/in 
wood microsites. Potential conifer invasion into alpine meadows via wood substrates is dependent on three steps: (1) disturbance processes introducing large wood from timberline to meadows, (2) a climate facilitating wood decay, and (3) successful germination and survival of seedlings to maturity. Seedling growth on wood microsites is likely to occur in other regions typified by large trees at timberline-alpine meadows, high precipitation, mild summers, and lack of forest harvesting. 


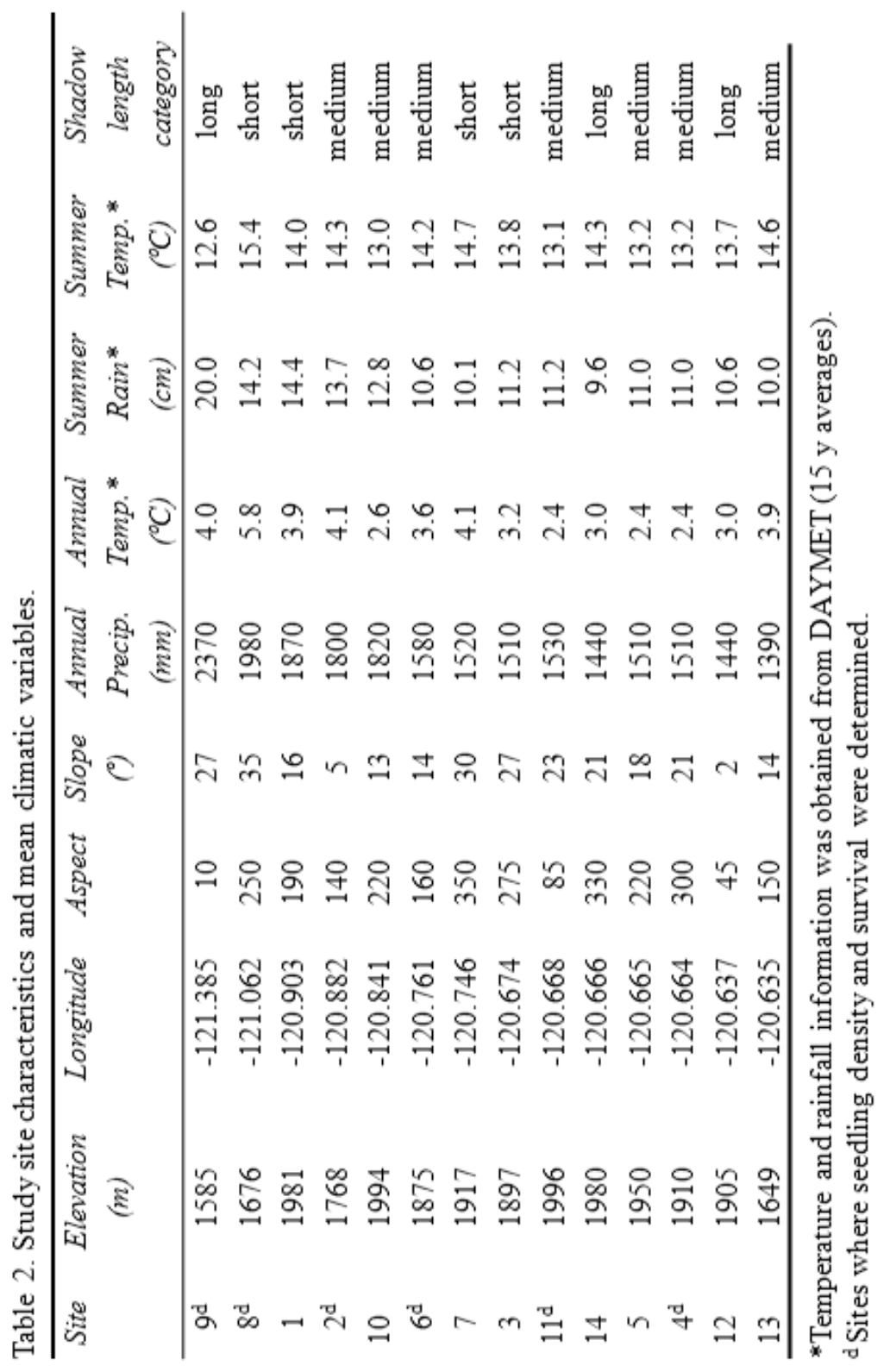


Table 3. Number of natural (and transplanted) seedlings at study sites.

\begin{tabular}{|c|c|c|c|c|c|c|}
\hline \multirow[t]{2}{*}{ Site } & \multicolumn{2}{|c|}{$\begin{array}{c}\text { Edge of } \\
\text { timberline }\end{array}$} & \multicolumn{2}{|c|}{$\begin{array}{l}\text { Mid-distance } \\
\text { out in meadow }\end{array}$} & \multicolumn{2}{|c|}{$\begin{array}{l}\text { Furthest out } \\
\text { in meadow }\end{array}$} \\
\hline & Wood & Soil & Wood & Soil & Wood & Soil \\
\hline$\overline{9}$ & $9(0)$ & $6(3)$ & $9(0)$ & $2(7)$ & $9(0)$ & $1(8)$ \\
\hline 8 & $5(4)$ & $3(6)$ & $5(4)$ & $5(4)$ & 36 & $1(8)$ \\
\hline 2 & $6(3)$ & $4(5)$ & $3(6)$ & $3(6)$ & $1(8)$ & $3(6)$ \\
\hline 6 & $5(4)$ & $0(9)$ & $4(5)$ & $1(8)$ & $0(9)$ & $0(9)$ \\
\hline 11 & $9(0)$ & $2(7)$ & $9(0)$ & $2(7)$ & $9(0)$ & $1(8)$ \\
\hline 4 & $8(1)$ & $5(4)$ & $6(3)$ & $6(3)$ & $0(9)$ & $4(5)$ \\
\hline
\end{tabular}


Table 4. Estimates of conifer alpine invasion rate on wood microsites using equation (3), $\frac{\mathrm{d}_{\text {seed }}}{\mathrm{W}_{\text {mature }}+\mathrm{W}_{\text {decay }}}$.

\begin{tabular}{lcccc}
\hline $\begin{array}{l}\text { Climate } \\
\text { scenarios }\end{array}$ & $\begin{array}{c}\text { Seedling distance } \\
\text { in alpine } \\
\text { meadow, } d_{\text {seed }}(m)\end{array}$ & $\begin{array}{c}\text { Time to tree } \\
\text { maturity/input, } \\
W_{\text {mature }}(y)\end{array}$ & $\begin{array}{c}\text { Decay rate, } \\
W_{\text {decay, }}(y)\end{array}$ & $\begin{array}{c}\text { Resulting alpine } \\
\text { invasion rate, } \\
T I\left(m^{*} y^{-1}\right)\end{array}$ \\
\hline Current & 20 & 250 & 150 & 0.05 \\
Warmer & 20 & 100 & 100 & 0.10 \\
Much warmer & 20 & 100 & 50 & 0.13 \\
\hline
\end{tabular}




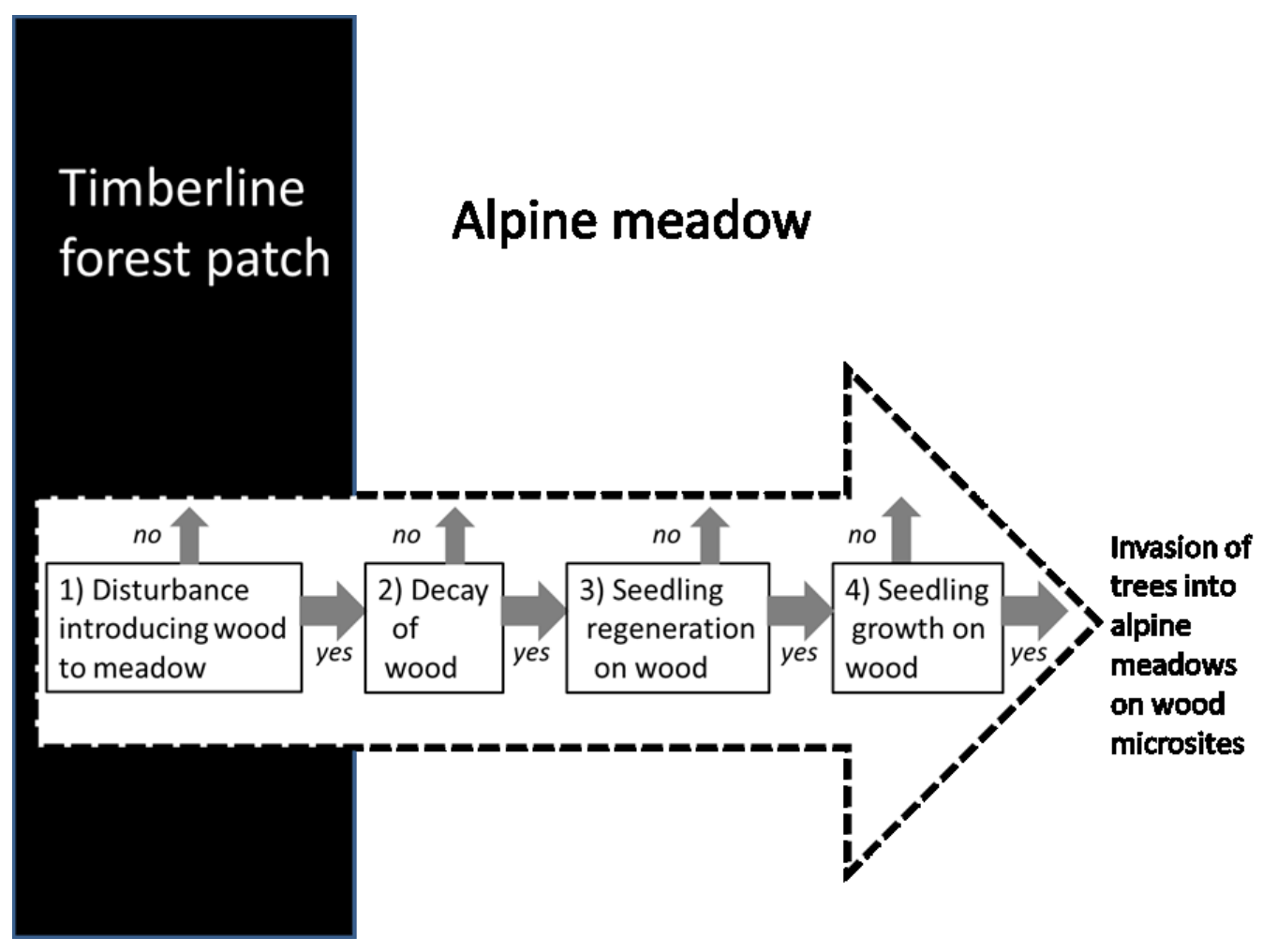

Figure 2. A conceptual model describing wood input, wood decay, seeding regeneration, and seedling growth and invasion of trees in alpine meadows. 


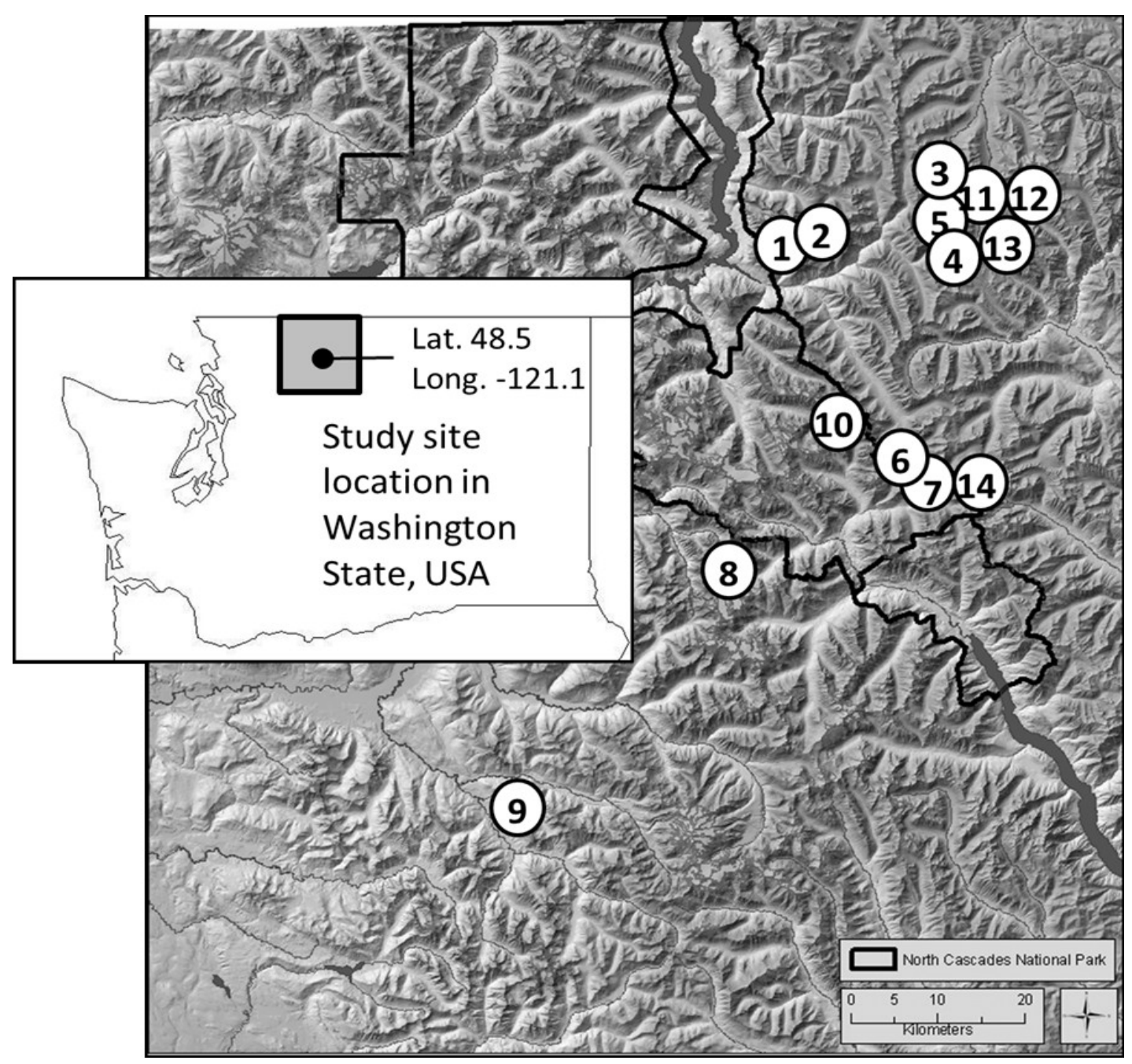

Figure 3. Study site locations in Washington State, USA. Western sites are the seven sites located west of site 14 and eastern sites are all sites east of site 7 . 


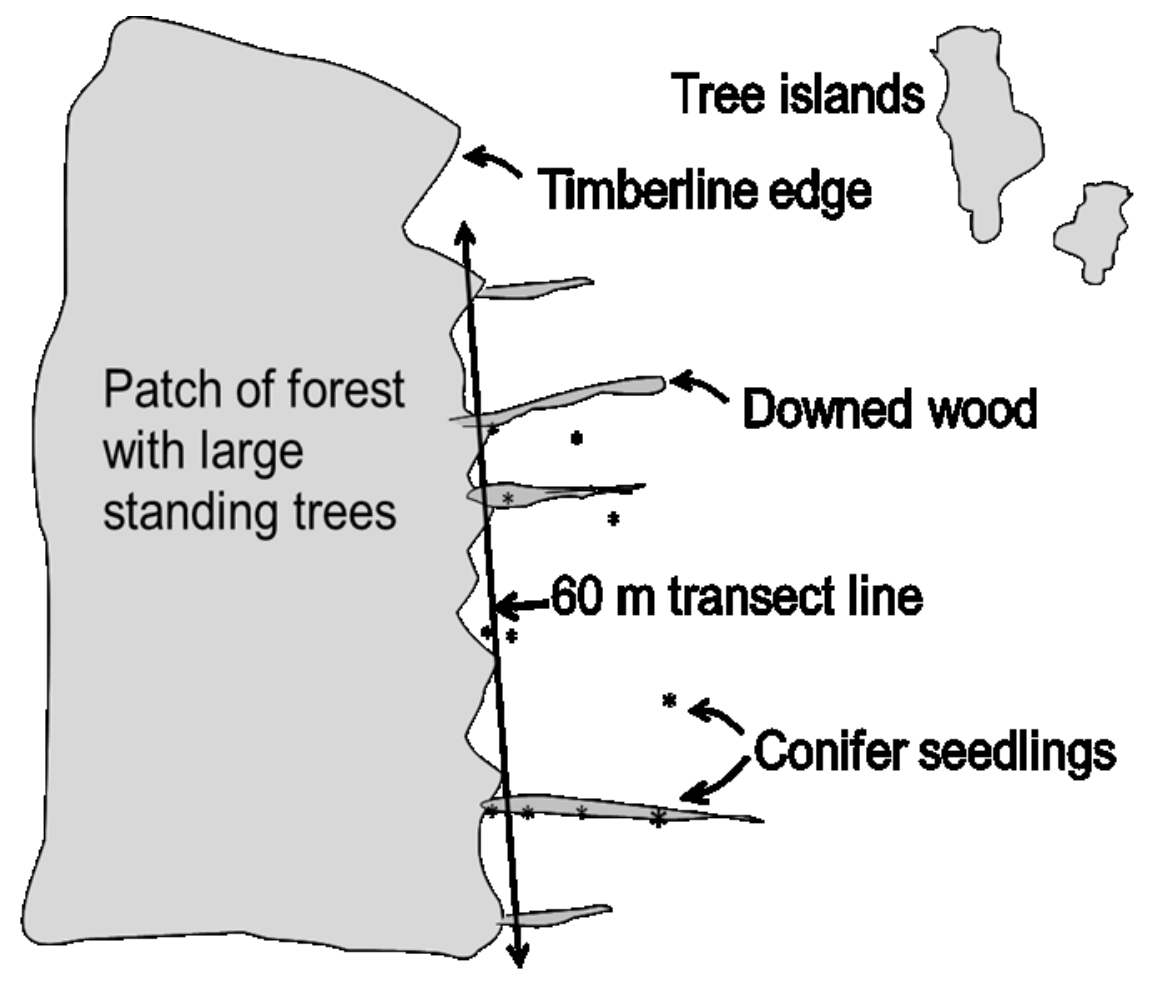

Figure 4. A typical study site having a forest patch, adjacent alpine meadow, downed wood, and seedlings. 


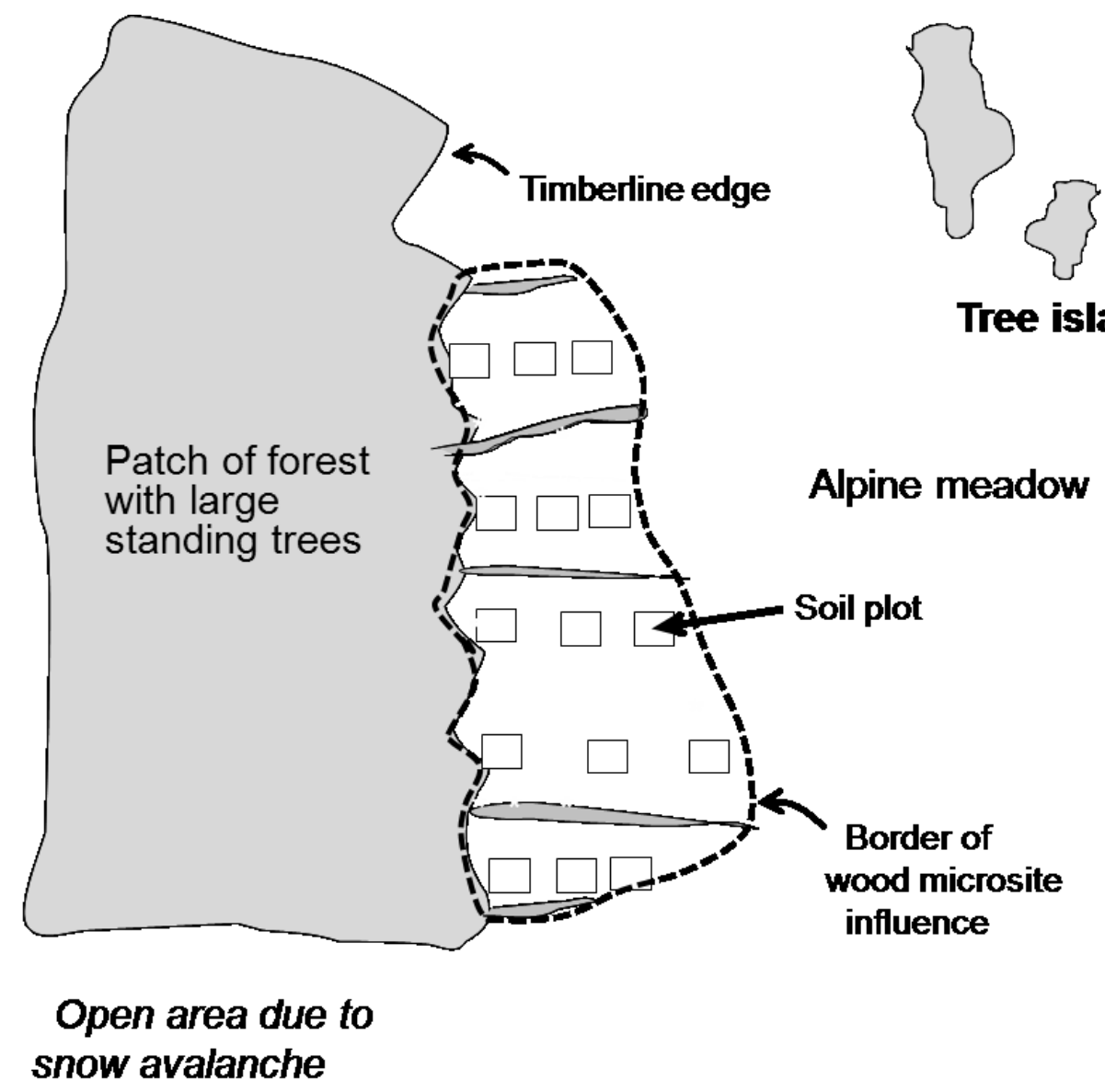

Figure 5. Stratified sampling used to evaluate seedling density on soil. 


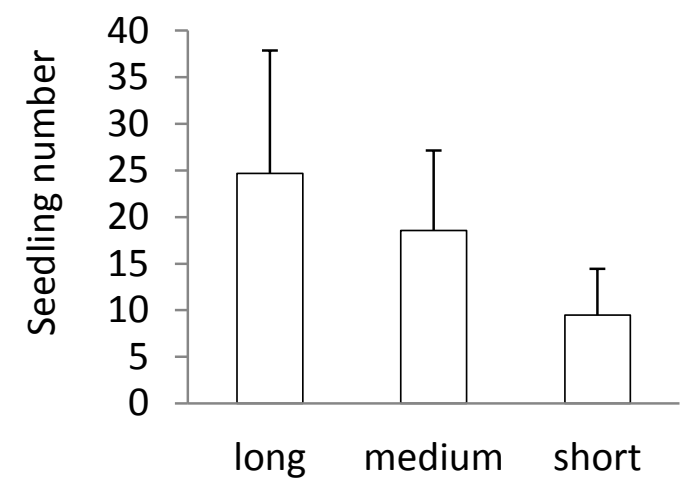

Wood substrate shadow category

a)

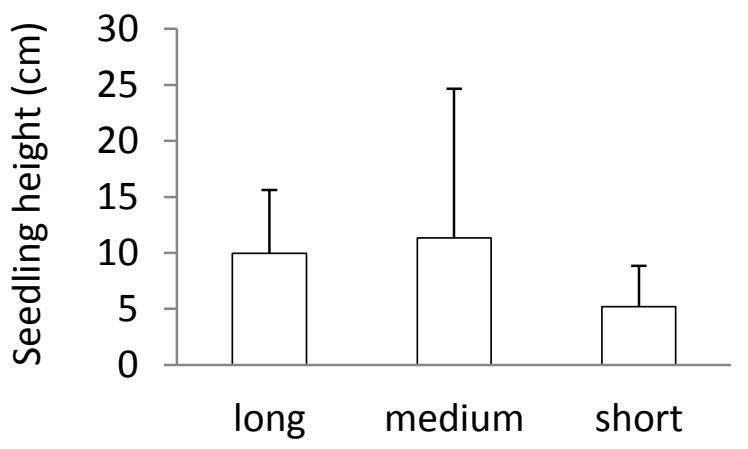

b)

Wood substrate shadow category

Figure 6. Barplots of seedling number and height on wood microsites. Means for 14 sites with $95 \%$ confidence intervals for: a) seedling number on wood substrates by shade category and $b$ ) seedling height by shade category. (for both a and $b: n=4,7$, and 3 for short-, medium-, and long- shadow categories, respectively). Short-, medium-, and longshadow length categories were based upon direction of site aspect with respect to tree patch (see Methods for further description). No significant differences were found for seedling number or seedling height by shade. 


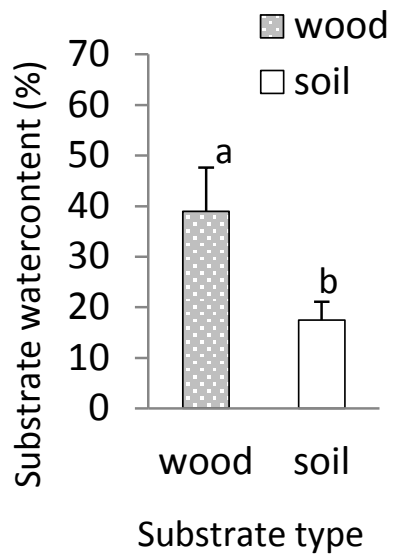

a)

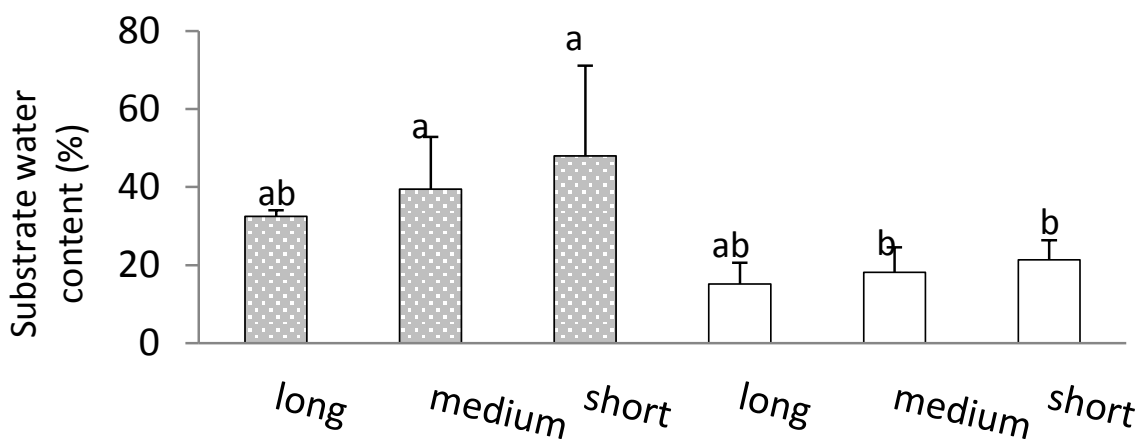

c)

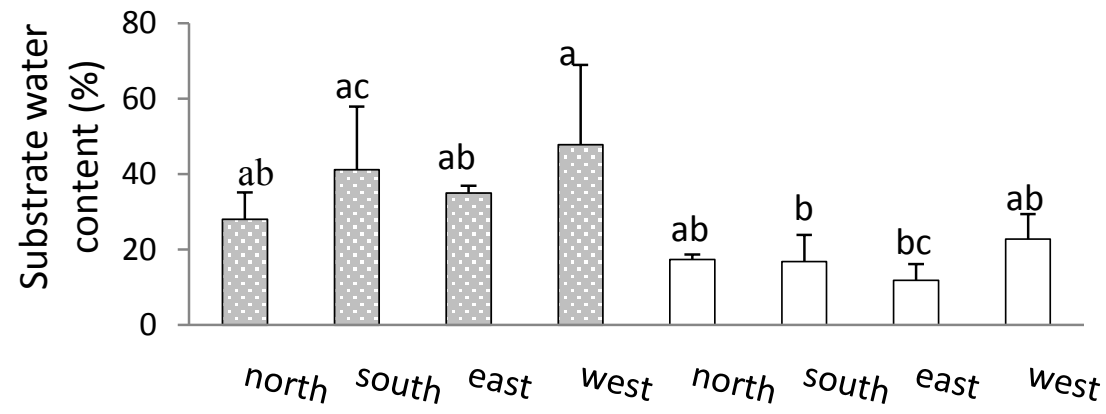

d)

Substrate type by aspect

Figure 7. Barplots of wood and soil moisture content. Means and 95\% confidence intervals for a) wood and soil substrates $(n=14$ per bar), b) substrate type and eastside or westside location ( $\mathrm{n}=7$ per bar, see Fig. 1 for description), c) substrate and shadow category $(\mathrm{n}=$ range of 3 to 7 per bar), and d) substrate and aspect (four directions, $\mathrm{n}=$ range of 2 to 6 per bar). Wood microsites are indicated by shaded bars and soil is indicated by open bars. Tukey results are indicated by letters above barplots. If one of the letters is the same, no statistical difference is indicated. If letters are different, significant differences exist $(p<0.05)$. 


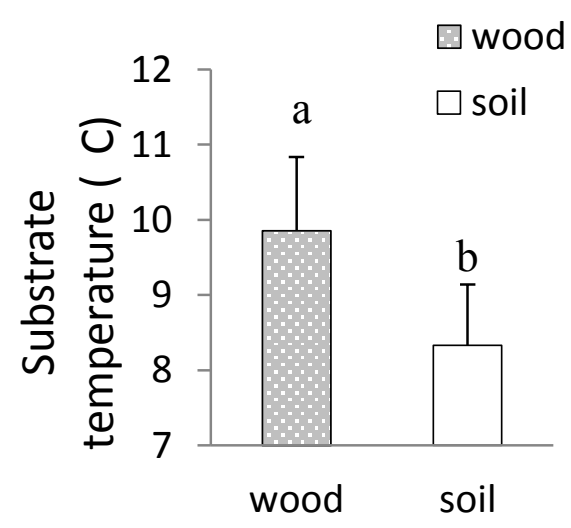

a)

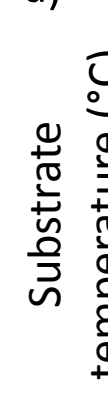

Substrate tvpe

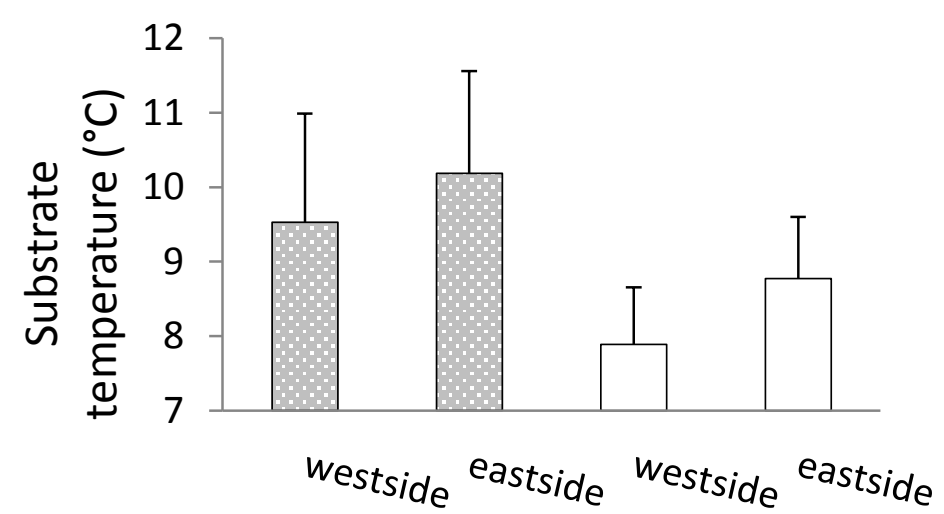

b)

c) Substrate type by shade category
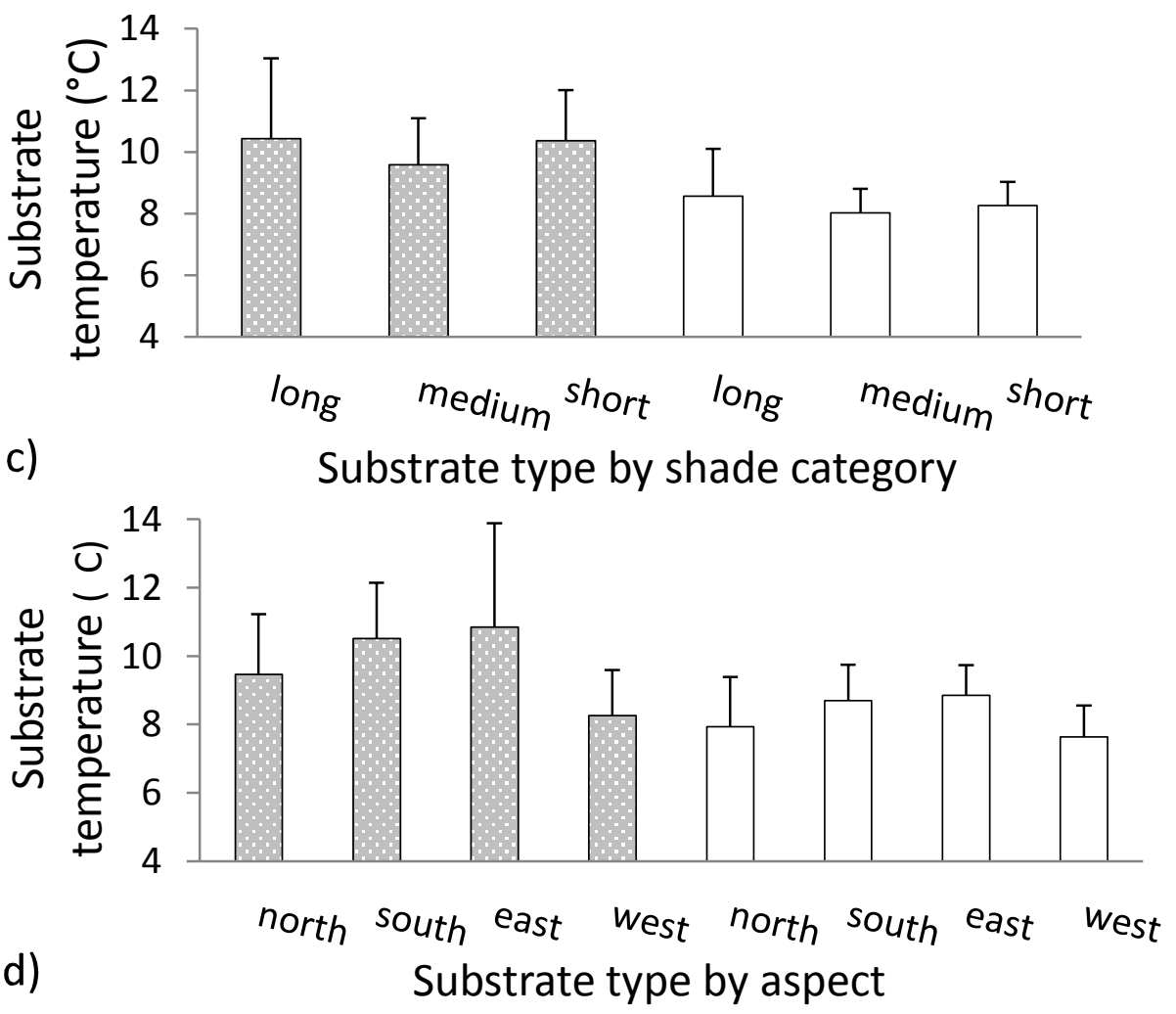

Figure 8. Barplots of wood and soil temperature. Means and $95 \%$ confidence intervals for: a) wood and soil substrates $(n=14)$, b) substrate type and eastside or westside location ( $\mathrm{n}=7$ per bar, see Fig. 1 for description), c) substrate and shadow category ( $\mathrm{n}=$ range of 3 to 7 per bar), and d) substrate and aspect (four directions, $n=$ range of 2 to 6 per bar). Wood microsites are indicated by shaded bars and soil is indicated by open bars. Tukey results are indicated by letters above barplots. If one of the letters is the same, no statistical difference is indicated. If letters are different, significant differences exist $(p<$ $0.05)$ 

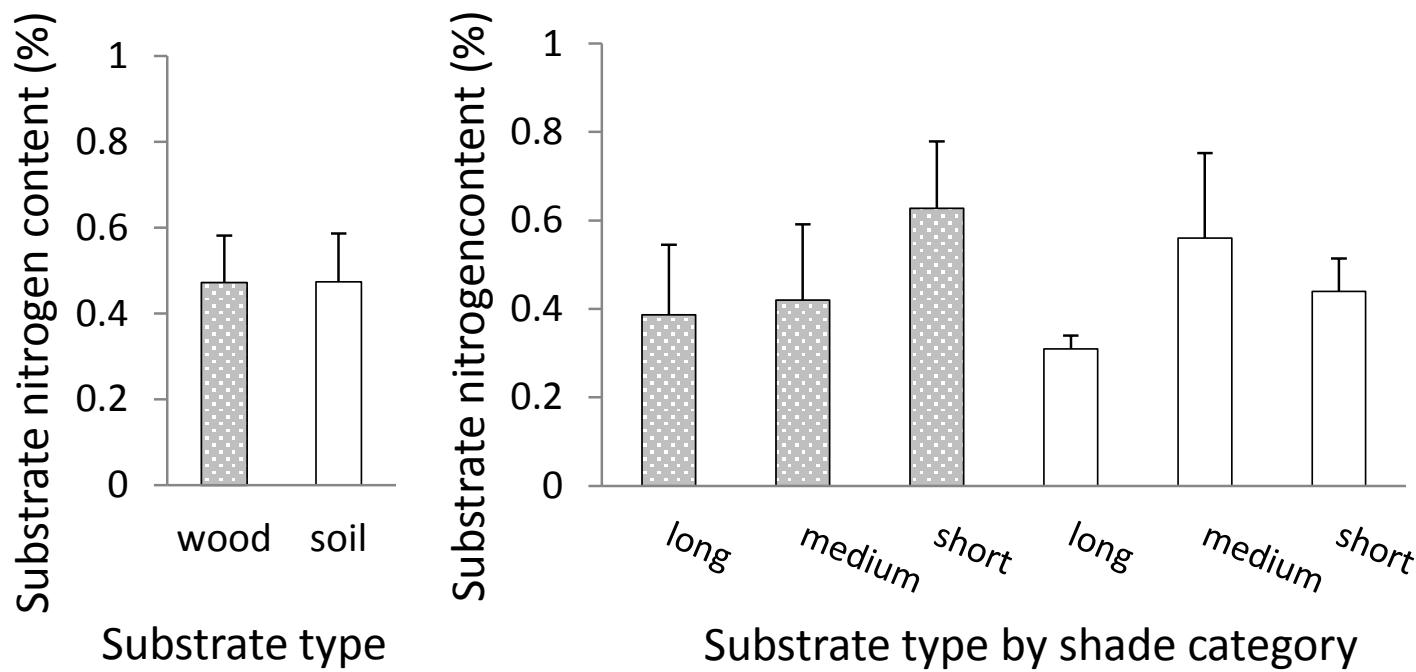

a)

b)

Figure 9. Barplots of wood and soil substrate nitrogen content. Means and 95\% confidence intervals for: a) wood and soil substrates $(\mathrm{n}=14)$, and $\mathrm{b})$ substrate and shadow category $(n=3$ to 7 per bar). Wood microsites are indicated by shaded bars and soil is indicated by open bars. No significant differences were found for nitrogen content in wood and soil substrates. 


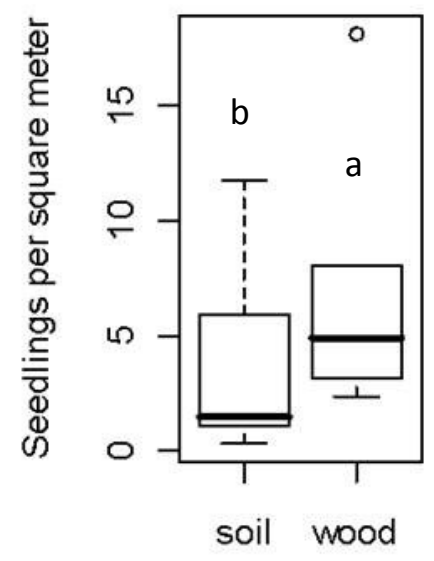

a)

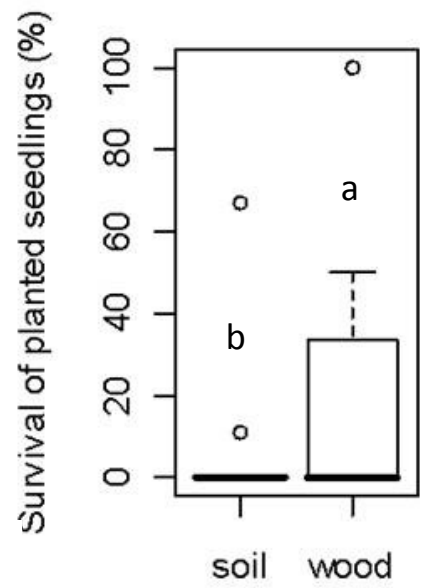

c)

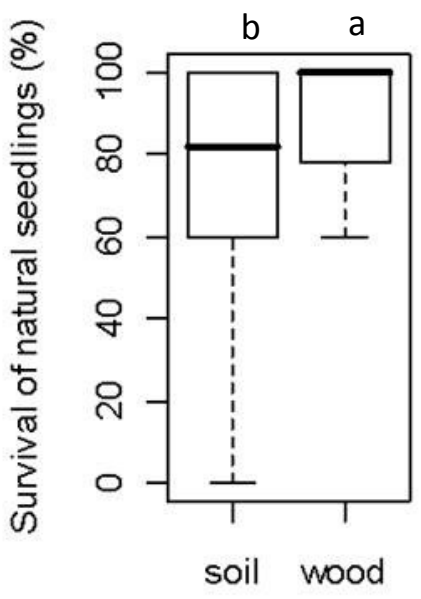

b)

Substrate type

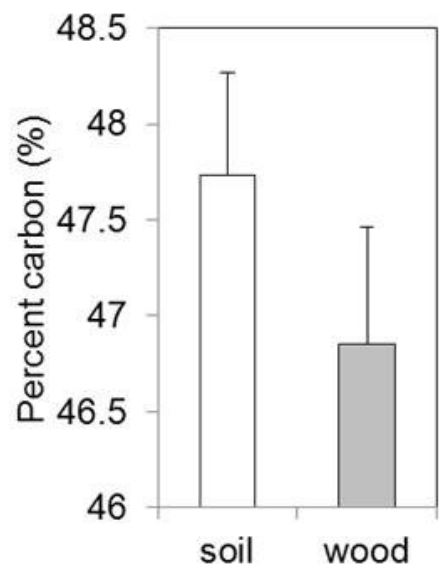

d)

Substrate type

Figure 10. Boxplots and barplots of density, survival, and carbon content of seedlings on wood and soil. Boxplots for: a) seedling density ( $\mathrm{n}=6$ per box $)$, and $\mathrm{b}$ ) natural seedling survival $(\mathrm{n}=6$ per box), $\mathrm{c}$ ) transplanted seedling survival ( $\mathrm{n}=6$ per box). Note: Data were non-parametric and significant differences were found for density and survival. In the boxplot, the central line in the box indicates the median, the box includes $50 \%$ of the data, the top of the box indicates $75^{\text {th }}$ percentile (upper quartile) of the data, the bottom of the box indicates the $25^{\text {th }}$ percentile, and the vertical lines extend to the upper and lower deciles $\left(90^{\text {th }}\right.$ and $10^{\text {th }}$ percentiles). Barplots for $\left.\mathrm{d}\right)$ total percent carbon $(\mathrm{n}=6$ per bar). Significant differences are indicated by letters above boxplots and barplots $(\mathrm{p}<0.05)$. 


\title{
Chapter 3:
}

\section{Radiation and Associated Temperature and Moisture Effects on Wood and Soil Substrates Supporting Conifer Regeneration at Timberline-Alpine Meadow Borders}

\begin{abstract}
Although warmer substrates associated with climate warming are expected to facilitate seedling regeneration above timberline, probable drought and high radiation suggest limited regeneration sites availability at alpine treeline ecotones (ATE). Wood microsites of the Pacific Northwest timberline-alpine meadow borders ameliorate stresses for growing seedlings as evidenced by my previous findings of greater substrate moisture and temperature, greater seedling densities, and greater survival of natural and transplanted seedlings as compared to adjacent soil substrates (Chapter 2). To better understand the range of site factors favoring seedling growth over the entire growing season, this study evaluated influence of percent transmitted radiation on wood and soil adjacent substrates at six sites in the North Cascade Mts. Measurements included substrate temperature, timing of spring thaw and fall freeze, mean annual temperature, mean summer temperature, and mean summer growing degree hours (GDH) for substrate temperatures $>7^{\circ} \mathrm{C}$. Substrate volumetric water content (VWC) was also measured three times during the growing season. Wood did not thaw earlier and had a lower annual mean temperature than soil, but had a warmer summer temperature, greater number of GDH, and greater VWC $\left(6.78^{\circ} \mathrm{C}\right.$ versus $6.55^{\circ} \mathrm{C}, p=0.016 ; 51.8 \mathrm{GDH}$ versus 46.4 GDH, $p<0.001 ; 22.9 \%$ versus $16.5 \%, p<0.001$; respectively). As evidenced by
\end{abstract}


higher seedlings densities, substrates most advantageous to seedling regeneration at timberline-alpine meadow borders had higher moisture (> $16 \% \mathrm{VMC})$. Wood substrates, as compared to soil substrates, more commonly provided these conditions. These results suggest that with climate warming, seedling regeneration will be limited by substrate moisture availability. Research suggests that presence of rotten wood microsites, particularly in locations with lower percent incoming radiation, will continue to provide suitable sites for Abies sp. regeneration up to a threshold. Beyond this threshold, water uptake requirements for seedlings will likely not be available limiting potential upward forests advance in some locations.

Keywords: wood microsites, nurselogs, overstory canopy, alpine meadow invasion, temperature

\section{Introduction}

The alpine treeline ecotone (ATE), stretching from the upper limit of continuous forest canopy (timberline) to tree limit (Holtmeier 2003, Korner 1998) is associated with major changes in stresses effecting tree growth (Fig. 11). Timberline-alpine meadow boundaries generally mark a transition from a micro-climate moderated by dense forest to an open alpine meadow environment having more wind, greater radiation, increased frost stress, and more extremes in temperature (Tranquillini 1979, Holtmeier 2009). Above timberline, alpine meadows (i.e. upper parklands) having both isolated and groups of seed-generated and clonal-regenerated trees are often present (Franklin et al. 1971, Kearney 1982, Holtmeier 2009). Conifer invasion into adjacent alpine meadows depends 
on successful germination, growth, and maturity of trees. Recent seed-generated conifer invasion of meadows is associated with climate warming (Franklin et al. 1971, Magee and Antos 1992, Rochefort et al. 1994, Kullman 2007).

Although factors including radiation and drought are important limiters to alpine meadow invasion assuming viable seed input (Germino et al. 2002), substrate temperature has been suggested as the key environmental factor in determining the transition from forests to alpine shrub and grassland (Körner and Paulsen 2004, Wieser and Tausz 2007). Specifically, a soil threshold temperature of approximately $7^{\circ} \mathrm{C}$ is associated with tree root growth (Havranek 1972, Körner 1998, Körner and Paulsen 2004, Alvarez-Uria and Körner 2007). Locally, other factors determining forest distribution include moisture availability, solar radiation, wind, snow cover, geomorphic processes, animal predation, and human influence (Holtmeier and Broll 2005).

Depending on microsite association and amount of shade, temperatures may vary dramatically (Rochefort et al. 1996, Holtmeier and Broll 2007). Wood microsites in Pacific Northwest (PNW) forests, formed mostly from tree fall at alpine-timberline borders, were found to have higher temperatures and greater moisture than the adjacent soil (Chapter 2). Wood microsites, typically located in shady locations, supported greater seedling densities and greater survival of both natural and transplanted seedlings (Chapter 2). In subalpine forests of the Swiss Alps, spruce were found to grow significantly faster on decaying wood (Baier et al. 2007) where seedlings were assumed to profit from earlier snowmelt (Stockli 1995, Smit et al. 2005) and warmer temperatures (Mayer and Ott 1991). Comparative measurements of wood and soil throughout the growing season sites 
could enhance understanding of possible differences in substrate temperature, moisture, shade relationships influential to the growth of seedlings.

A systematic examination of seedling density and site conditions would elucidate factors most favorable to seedling growth above timberline. Abies lasciocarpa and Abies amabilis, the seedling species most commonly found at PNW timberline sites (Chapter 2) typically experience high mortality due to low moisture conditions and effects of photoinhibition (Cui and Smith 1991, Germino et al. 2003). Seedlings may benefit from the moisture provided by wood microsites.

As far as I know, no studies have systematically compared radiation, temperature, and moisture on wood microsites and adjacent soil substrates at timberline-alpine meadow borders. Although wood substrates in subalpine forests were presumed to facilitate early melting of snow due to low albedo provided by dark wood surfaces (Eichrodt 1969), this phenomenon has not been scientifically quantified. If wood microsites melt snow faster and provide warmer substrates, the increased growing season length as well as added warmth and moisture during the growing season could enhance growth of seedlings on wood substrates as compared to adjacent soil substrates if sufficient moisture is available.

The goal of this study was to assess various measures of temperature, radiation, and moisture associated with density of seedling density of $<3$ yr Abies $s p$. seedlings. This objective was met by assessing four specific hypotheses for wood and soil substrates having low, medium, and high radiation categories: 
Ho 1: No difference in timing of spring thaw and fall freeze,

Ho 2: No difference in mean annual temperature, mean growing season temperature, or mean moisture,

Ho 3: No difference in growing degree hours (GDH) as defined by substrate temperature $>7^{\circ} \mathrm{C}$, and

Ho4: No difference in seedling density by temperature or moisture.

\section{Study Area}

A set of six sites, chosen earlier from the data set of 14 sites (Chapter 2), met additional site selection criteria including lack of snow avalanching impacts at the timberline sites and no notable impacts by forest fire. The six sites extended from the west side to the east side of the Cascade Mountains of Washington state. The sites were all chosen to have a four or less hours' hike from roads and had no forest harvest (Fig. 12).

Of the six study sites, three were located within the Tsuga mertensiana Zone on the western portion of the North Cascades (west of longitude -120.7), three were located in the Abies lasciocarpa Zone on the eastern side of the Cascades (east of longitude -120.7), and both zones include subzones of closed forest and upper parkland (Franklin and Dyrness 1979; Fig. 12, Table 5). The Tsuga mertensiana Zone includes Abies amabilis and Chamecyparis nootkatensis. The Abies lasciocarpa Zone is more continental with cooler temperatures, and includes Picea engelmannii, Pinus contorta, Abies grandis, Larix lyallii and Pinus monticola (Franklin and Dyrness 1979). Upper parkland tree invasion is primarily by Tsuga mertensiana and Abies lasciocarpa 
(Franklin et al. 1971). Seedling species on nurse logs included Tsuga mertensiana, Abies lasciocarpa, Abies amabilis, Chamecyparis nootkatensis, Picea engelmannii, and Larix occidentalis (Chapter 2). Many of these seedlings were $<2 \mathrm{~cm}$ in height; identification species of seedlings was sometimes difficult, however, at least $90 \%$ of the seedlings were Abies lasciocarpa and Abies amabilis. In general, western sites were dominated by Abies $s p$. with some Tsuga mertensiana seedlings, whereas eastern sites were dominated by Abies sp. with fewer Picea engelmannii seedlings. In this study I refer to conifer species as Abies sp., a reasonable generalization considering that Abies sp. was dispersed evenly throughout sites and had greatest survival. At our sites the herbaceous families Poaceae, Ericaceae, and species including Vaccinium $s p$. and Veratrum viride were commonly found on soil substrates whereas on wood microsites, plants occurrence consisted solely of limited to conifer seedlings and/or moss (Chapter 2). The forests are under jurisdiction of the Mt. Baker Snoqualmie National Forest on the west, North Cascades Park Complex in the mid-region, and the Okanogan National Forest on the east side. All of the sites are managed as wilderness areas.

The sites span a yearly precipitation gradient from $250 \mathrm{~cm} / \mathrm{yr}$ on the western-most site to $150 \mathrm{~cm} / \mathrm{yr}$ on the east side of the Cascades with summer rainfall (June, July, and August) $20 \mathrm{~cm}$ on the west side and $10 \mathrm{~cm}$ on the east side. Timberline elevations range from $1585 \mathrm{~m}$ on the west side to $1996 \mathrm{~m}$ on the east side. Mean annual temperature averages $4.1^{\circ} \mathrm{C}$ on the west side and $3.0^{\circ} \mathrm{C}$ on the east side (DAYMET; Table 5).

In general, the geology is volcanic on the west side and sedimentary on the east side, with intrusive volcanics in the mid-range. Soils are well-drained Cryorthods, and 
have textures ranging from fine sandy loam to sandy gravelly loam. At my sites, organic horizon depths ranged from 0.5 to $1.0 \mathrm{~cm}$. Total depth of the soil to bedrock ranged from $0.2 \mathrm{~m}$ to $1.0 \mathrm{~m}$ with A-horizons ranging in depth from 0 to $0.2 \mathrm{~m}$ (USDA, NRCS 2008).

Each site had at least four pieces of large woody debris that extended up to $20 \mathrm{~m}$ from timberline into alpine meadows. These wood pieces were very decayed (decay class five, see Sollins 1987). Seedlings on wood ranged in height from 1 to $15 \mathrm{~cm}$.

\section{Methods}

Overstory canopy measurements radiation

Wood and adjacent soil substrates were assessed by low, medium, and high percent transmitted radiation categories, areas initially described by three levels of overstory canopy. Categories of overstory canopy were determined for each site; each site had three subsamples: (1) high canopy category was located directly under timberline trees, (2) medium canopy areas were approximately $3-10 \mathrm{~m}$ beyond the timberline edge, and (3) open area was generally located 5 to $20 \mathrm{~m}$ beyond the timberline edge into alpine meadows and were characterized by locations with downed wood having the least shading by overstory canopy. Measures of overstory were estimated with photographs taken skyward from the forest floor with a $180^{\circ}$ hemispherical (fisheye) lens mounted on a Nikon digital camera to produce circular images of forest overstory. The camera image was initially analyzed for percent open sky at each of the six sites by Gap Light Analyzer (GLA, Frazer et al., 1999) (Fig. 13, Table 6). 
To calculate percent incoming radiation using GLA, additional parameters used included latitude, longitude, elevation, aspect, slope, growing season start and stop date, clear sky transmission, solar constant, and cloud index. Calculation of percent incoming radiation took into account the tracking of the sun on the horizon through openings in overstory canopy and the area of open sky through the canopy. I assumed clear sky transmission (\% of clear sky over extra-terrestrial radiation) of 0.65 (Frazer et al. 1999, used for Vancouver, WA, in the summer), a solar constant (amount of incoming solar electromagnetic radiation per unit area indicant on a plane perpendicular to the rays) of $1365 \mathrm{~W} / \mathrm{m}^{2}$, and a cloudiness index (\% of the mean daily extraterrestrial radiation arriving at the ground as global solar radiation, Frazer et al. 1999) of 0.5 for the west sites and 0.7 for the east sites. Considering a mean snow free period generally occurring between mid-June and mid-July (USDA, NRCS, SNOTEL 2000-2011), I used a growing season of July 1 to September 30 for calculations (this assumption was later verified by temperature data and visits to the field sites). Percent transmitted radiation calculations per each site, pooled and averaged for each overstory category, indicate general similarity between level of overstory and level of transmitted radiation (Table 6). The resulting tree categories of transmitted percent radiation were all significantly different as indicated by ANOVA tests $(p<0.001)$. Three levels of transmitted percent radiation; low, medium, and high were used in evaluation of site temperature and moisture. 


\section{Substrate temperature}

Air, soil, and wood temperature were monitored with i-Button data loggers (IButtonLink, LLC, East Troy, Wisconsin, USA) for nearly two years. The i-Buttons were installed in both substrates in the midst of seedlings at depths of $6 \mathrm{~cm}$ in the high, medium, and low percent transmitted radiation categories (Table 6, Fig. 14). Air temperature was measured with i-Buttons placed approximately $2 \mathrm{~m}$ above ground in large trees and shaded by sun. A sample rate measurement interval of 4.25 hours was used that produced 2048 possible sample points in one year.

Timing of fall freeze, spring thaw, and summer growing season temperature was evaluated for both soil and wood substrates having low, medium, and high percent transmitted radiation categories at all six sites. To separate site by higher and lower precipitation, sites were separated into west side and east side sites. Sites 1, 2, and 3 were considered west side locations and sites 4, 5, and 6 were considered east side locations (separated by longitude $120.7 \mathrm{~W}$ ). Fall freeze date was assumed to be the first $>24 \mathrm{hr}$ that period substrates $\leq 0^{\circ} \mathrm{C}$ and spring thaw was assumed to be the first $>24 \mathrm{hr}$ period with temperatures $>0^{\circ} \mathrm{C}$. Summer temperature was evaluated for July, August, and September as this was the time period that is generally snow-free (USDA, NRCS, SNOTEL 2000-2011).

\section{Estimate of growing degree hours}

Growing degree hours (GDH), a measure of heat accumulation necessary for growth (Prentice et al. 1992) was used. 


$$
\mathrm{GDH}=\Sigma\left(\mathrm{T}_{\mathrm{A}}-\mathrm{T}_{\mathrm{O}}\right) \mathrm{dt}
$$

GDH was adapted by using a base soil temperature, $\mathrm{T}_{\mathrm{O}}$, of $7^{\circ} \mathrm{C}$; by temperature measurement intervals, $\mathrm{dt}$, of $4.25 \mathrm{hrs}$; and by substrate temperature, $\mathrm{T}_{\mathrm{A}}$, as opposed to measures of air temperature. For the period with $T_{A}>T_{O}$, temperature increments were accumulated for each day. For each substrate/shade category, temperature and GDH were pooled and averaged. For the entire study period when at least one substrate was $>7^{\circ} \mathrm{C}$, comparisons were made of mean daily GDH.

\section{Substrate moisture}

Substrate volumetric water content (VWC) was measured three times during the growing season within each of the three percent transmitted radiation categories with a Field Scout TDR Soil Moisture Meter (Spectrum, Technologies, Plainfield, IL). Measurement periods were early (mid-July), mid-way (mid-August), and late (mid-September) during the growing season. The moisture meter was calibrated for sand-silt loams on soil substrates. On wood substrates, the device was calibrated following an experiment whereby 10 known volumes of water were added to a known volume of rotten wood. This procedure was conducted three times and the results were averaged to determine a suitable VWC relationship (Spectrum, Technologies, Plainfield, IL; personal communication).

\section{Seedling survival}

Density of $<3$ yr seedlings was related to substrate type by percent transmitted radiation categories, substrate temperature trends, and moisture measurements. Seedling density, 
assessed previously (see Chapter 2 for methodology), was allocated to low, medium, and high percent transmitted radiation categories.

\section{Statistical analysis}

Nested ANOVA tests, t-tests, and linear regressions were used to assess significant differences of response variables (substrate temperature, volumetric water content, and seedling density) associated with wood microsites and soil substrates. When needed, data transformations were made in an attempt to meet assumptions of normality and data variability. Post-hoc multiple comparison tests (Tukey's) were used when significant differences were detected. When comparisons of wood and soil were nonparametric, Wilcoxon rank sum tests were conducted. Statistical significance was assessed with $\alpha=$ 0.05 and all statistical analyses were conducted with the $\mathrm{R}$ statistics package ( $\mathrm{R}$ Core Development Team 2005). Visual inspection of microsite-climate relationships associated with high seedling density, including volumetric water content, substrate density, and categorical variables such as radiation class, west side or east side, and substrate type were conducted with classification regression trees (CART).

Factors not tested in this research also having implications to survival of seedlings included animal trampling, predation, and plant competition. Further south in the Cascade Mts., it has found that reduced dense herbaceous vegetation abundance, typically found at tree meadow borders, was required before small seedlings of Abies procera could become established at meadow borders (Magee and Antos 1992). Wood in my study locations likely had a similar effect on reducing competition at forest edges. 
Observations of hoof prints from deer and goats at timberline-alpine meadow borders also suggest mechanical damage of seedlings and herbaceous vegetation, particularly on high radiation soil substrates.

\section{Results}

\section{Spring thaw and fall freeze}

Timing of mean thaw date was not significantly different between wood and soil substrates assessed alone ( $p=0.69, \mathrm{n}=36$ per substrate), by radiation category ( $p=$ $0.48)$, or by location ( $p=0.10, \mathrm{n}=18$, Fig. 15a). Date of substrate thaw ranged from June 8 to July 18 . When substrates were combined, mean substrate thaw date was June 30. Combining wood and soil substrates together by west side and east side location, mean thaw date was June 27 for west sites and July 4 for eastside sites $(p=0.017, \mathrm{n}=36$, Fig. 15b).

Date of substrate fall freeze, not significantly different for wood and soil $(p=$ $0.22, \mathrm{n}=36$ ), ranged from October 1 to December 21 with a mean combined freeze date of November 2. There were no significant differences in substrate freeze date by radiation category $(p=0.7)$. Freeze date between substrates by location was not different ( $p>$ $0.05, \mathrm{n}=18$ ), but mean date of west side soil freeze was approximately one month later than eastside soils and eastside wood substrates (November 20 versus October 23 for eastside wood and eastside soil, $p=0.017$ and $p=0.02$, respectively; Fig. $15 \mathrm{c}$ ). Combining wood and soil substrates, mean freeze date was November 10 for west side sites and October 23 for eastside sites ( $p=0.009, \mathrm{n}=36$, Fig. 15d). 
Although no differences were found in freeze and thaw dates by substrate and radiation level, overall substrates had a significantly shorter period of unfrozen ground for east side locations than west side locations (wood and soil combined). Later substrate thaw dates and earlier freeze dates resulted in 25 less days of non-frozen substrates on west side locations than east side locations.

Annual substrate temperature comparisons Annual mean temperature was lower for wood microsites than for soils $\left(1.56^{\circ} \mathrm{C}\right.$ versus $1.62^{\circ} \mathrm{C}, \mathrm{n}=35019, p<0.001$, respectively, Fig. 16a). By substrate-radiation category, low-radiation wood microsites had significantly lower annual temperatures than respective low-radiation soil substrates $\left(1.34^{\circ} \mathrm{C}\right.$ versus $1.59^{\circ} \mathrm{C}, \mathrm{n}=11673, p<0.001$; Fig. 16b). There was no difference between the annual temperature of wood and soil substrates having medium and high radiation $(p=0.11, p=0.22$, respectively). Mean annual temperatures of west side wood microsites were colder than west side soil substrates $\left(1.75^{\circ} \mathrm{C}\right.$ versus $\left.1.85^{\circ} \mathrm{C}, p<0.001\right)$ and east side wood substrate temperatures were not significantly different from east side soil substrates $(p=0.2)$.

On the west side, wood substrates in low and medium radiation sites had lower mean annual temperatures than soil substrates and high radiation sites were not significantly different $\left(1.76^{\circ} \mathrm{C}\right.$ versus $1.93^{\circ} \mathrm{C}, p<0.001 ; 1.6^{\circ} \mathrm{C}$ versus $1.78^{\circ} \mathrm{C}, p=0.002$; and $p=0.99$; respectively; Fig. 16c). On the east locations, low radiation sites were cooler; high radiation sites were warmer; and medium radiation sites were not 
significantly different than respective soil substrates $\left(0.87^{\circ} \mathrm{C}\right.$ versus $1.24^{\circ} \mathrm{C}, p<0.001$; $1.78^{\circ} \mathrm{C}$ versus $1.48^{\circ} \mathrm{C}, p<0.001 ; p=1.0$ respectively; $\mathrm{n}=3891$; Fig. $\left.16 \mathrm{c}\right)$.

\section{Summer substrate temperature comparisons}

Mean summer substrate temperature was significantly higher for wood microsites than adjacent soil substrates $\left(6.76^{\circ} \mathrm{C}\right.$ vs. $6.53^{\circ} \mathrm{C}, p=0.001, \mathrm{n}=4848$, Fig. 17a). Wood substrate temperature was significantly greater than soil substrates temperature for high radiation sites, but not different for comparisons of medium radiation or low radiation sites $\left(7.53^{\circ} \mathrm{C}\right.$ versus $6.80^{\circ} \mathrm{C}, p<0.001 ; p=0.51 ; p=0.78$, respectively; $\mathrm{n}=1616$; Fig. $17 b)$.

Wood temperature was significantly greater than soil substrates in July but not in August or September $\left(5.13^{\circ} \mathrm{C}\right.$ versus $4.57^{\circ} \mathrm{C}, p=0.0016, p=0.99, p=0.99$, respectively). In July, wood substrates in the high radiation category were warmer, but low and medium radiation categories were not different $\left(6.1^{\circ} \mathrm{C}\right.$ versus $4.8^{\circ} \mathrm{C}, p<0.001$, $p=0.9, p=0.9$, respectively, Fig. $17 \mathrm{c})$.

Overall, wood was warmer than soil on east side locations and substrates did not differ on west side locations $\left(6.13^{\circ} \mathrm{C}\right.$ versus $5.89^{\circ} \mathrm{C}, p<0.028 ; p=0.80$, respectively, $\mathrm{n}=$ 2424, Fig. 18a). On the west side, wood microsites with high radiation categories were warmer than soil substrates and low and medium radiation substrates were not different $\left(7.9^{\circ} \mathrm{C}\right.$ versus $7.4^{\circ} \mathrm{C}, p=0.04, p=0.99, p=1.0$, respectively). As compared to respective soil sites, east side wood microsites having low radiation were cooler, wood microsites having high radiation were warmer, but medium radiation categories were not different 
$\left(5.1^{\circ} \mathrm{C}\right.$ versus $5.85^{\circ} \mathrm{C}, p=0.001,7.13^{\circ} \mathrm{C}$ versus $6.25^{\circ} \mathrm{C}, p<0.001, p=0.058$, respectively, Fig. 18b).

On the west side in July, low radiation sites wood sites were cooler $\left(5.83^{\circ} \mathrm{C}\right.$ versus $7.12^{\circ} \mathrm{C}, p<0.001$ ) and no differences were found for medium and high radiation sites ( $p=1.0, p=0.12$, respectively). In August, low, medium, and high radiation categories were not different $(p=0.1, p=0.99, p=0.19$, respectively. In September, low radiation wood microsites were warmer $\left(7.4^{\circ} \mathrm{C}\right.$ versus $\left.6.78^{\circ} \mathrm{C}, p=0.007\right)$, medium radiation sites were not different $(p=0.54)$, and high radiation sites were warmer $\left(7.44^{\circ} \mathrm{C}\right.$ versus $\left.6.25^{\circ} \mathrm{C}, p<0.001\right)$.

On the east side in July, low radiation wood substrates were cooler than soil substrates $\left(3.2^{\circ} \mathrm{C}\right.$ versus $\left.3.8^{\circ} \mathrm{C}, p=0.008\right)$, medium radiation wood substrates were warmer than soil substrates $\left(5.1^{\circ} \mathrm{C}\right.$ versus $\left.4.2^{\circ} \mathrm{C}, p<0.001\right)$, and high radiation was not different than soil substrates $(p=0.98)$. In August, low radiation wood temperature was cooler than the respective soil sites $\left(7.6^{\circ} \mathrm{C}\right.$ versus $\left.8.7^{\circ} \mathrm{C}, p<0.001\right)$, medium radiation sites were not different $(p=0.78)$, and high radiation wood microsite were warmer than respective soil microsites $\left(9.9^{\circ} \mathrm{C}\right.$ versus $\left.8.8^{\circ} \mathrm{C}, p<0.001\right)$. In September, low radiation wood microsites were cooler than respective soil substrates $\left(5.4^{\circ} \mathrm{C}\right.$ versus $6.0^{\circ} \mathrm{C}, p=$ $0.014)$, high radiation wood microsites were warmer $\left(6.4^{\circ} \mathrm{C}\right.$ versus $\left.5.1^{\circ} \mathrm{C}, p=0.01\right)$, and medium radiation wood microsites were not different $(p=0.09)$. 
Growing degree hours (GDH)

Overall, mean daily growing degree hours (GDH) were greater for wood microsites than soil substrates with 51.8 versus $46.4 \mathrm{GDH}$, respectively ( $p<0.001, \mathrm{n}>1490$, Fig. 19a). Medium-radiation wood microsites had more GDH than medium-radiation soil substrates and no differences were found in mean GDH for comparisons between low-radiation sites and high-radiation $(p=0.04,48.3$ versus $40.7 ; p=0.7 ; p=0.4 ;$ respectively; $\mathrm{n}>\mathrm{F} 470$ ig. 19b).

East wood had more GDH than and east soil substrates (43.2 versus 37.2, $p=$ 0.035 , Fig. 19c), but west wood did not have significantly different GDH than west soil $(p=0.052)$. In July, August, and September on west side locations, wood did not have differing GDH than soil ( $p=0.99, p=0.15, p=0.99$, respectively). In July, August, and September on east side locations, wood did not have differing GDH than soil ( $p=0.8, p$ $=0.9, p=0.9$, respectively, Fig. 19d).

For west side, low, medium, and high radiation sites were did not have different $\mathrm{GDH}$ ( $p=0.9, p=0.99, p=0.8$, respectively). For east sites, medium radiation, wood sites had more GDH (49.0 versus 35.0, $p<0.001$ ), but low and high radiation sites were not different ( $p=1.0$ and $p=0.89$, respectively, Fig. 19e).

\section{Volumetric moisture content (VMC)}

VMC for wood was greater soil (22.9\% for wood and $16.5 \%$ for soil, $p<0.001)$.

Moisture content was greater for wood microsites in the low, and medium radiation categories, but not for the high radiation category $(p<0.001, p=0.015, p=0.059$, 
respectively, $\mathrm{n}=53$ to 84 , Fig. 20a). Moisture content was greater for wood substrates than soil substrates during July and September summer sampling periods, but not during the August sampling period (July, 31.1\% versus 19.2\%, $p<0.001$; August, $22.5 \%$ versus $16.9 \%, p=0.057$; September, $20.3 \%$ versus $12.6 \%, p=0.028)$.

VWC of wood was greater than soil on both west side and east side locations ( $28.3 \%$ versus $19.6 \%, p<0.001 ; 21.9 \%$ versus $15.1 \%, p<0.001$; respectively). On the west side, low radiation wood had greater VWC than both medium and high radiation soil sites $(30.7 \%$ versus $20.9 \%, p=0.004 ; 30.7 \%$ versus $14.2 \%, p=0.008$; respectively; $n=18$ to 43 , Fig. 20 b). On the east side, low radiation wood microsites locations had greater VWC than low radiation soils, medium and high radiation sites were not significantly different than respective soil substrates, and medium radiation wood substrates had greater VWC than low radiation soil substrates $(p=0.01,21.7 \%$ versus $15.0 \% ; p=0.12$ and $p=0.11 ; 21.7$ versus $18.0, p=0.002$; respectively, Fig. 20b).

Seeding density, seedling survival, and site characteristics of seedlings

Density of $<3$ yr-old seedlings growing on wood and soil substrates was not significantly different by radiation category or by west side or east side location $(p=$ $0.17, p=0.05$, respectively). Mean density of seedlings on wood in low and medium radiation sites combined was greater than density of seedlings on soil in high radiation sites $(p=0.047)$. Regressions of seedling density by substrate temperature by radiation category indicated no significant relationships ( $p>0.06$, Fig. 21a). Density of seedlings 
on wood microsites at east side locations were negatively associated with increase in substrate temperature ( $p=0.047, \mathrm{r}^{2}=0.38$, all other $p$-values were $>0.09$, Fig. $\left.21 \mathrm{~b}\right)$.

For all sites combined, mean VWC decreased significantly with increase in temperature ( $p=0.0002, \mathrm{r}^{2}=0.32$ ). Density of $<3$ yr seedlings was not related to VWC for west side wood or west side soils, but was positively related to VWC for east side wood microsites and east side soil substrates, but was not significantly related to VWC on west side wood or soil ( $p>0.09$ for west side substrates; $p=0.024, \mathrm{r}^{2}=0.48 ; p=$ $0.048, r^{2}=0.37$; respectively, for east side substrates, Fig. 22a, b).

Regressions of VWC versus substrate temperature indicate significant negative relationships for soil substrates in medium radiation categories only $\left(p=0.04, \mathrm{r}^{2}=0.6\right.$, Fig. 23a). For substrates by location, negative relationships between VWC and substrate temperature were found for west wood substrates, west soil substrates, and east soil substrates $\left(p=0.46,0.03\right.$, and 0.002 , respectively; $\mathrm{r}^{2}=0.38,0.31,0.73$, respectively, Fig. 23b). Soil substrates with densities of $<1$ seedling per $\mathrm{m}^{2}$ had significant decreases in substrate VWC with increase in temperature ( $p=0.004, \mathrm{r}^{2}=0.68$, Fig. 23c).

Classification and regression trees (CARTs) classified the dependent variable, seedling density by percent incoming radiation and VWC (with CP first and second splits of 0.15 and $0.07,0.14$ and 0.09 , respectively; Fig. 24a, b). 


\section{Discussion}

Temperature conditions and seedling regeneration

Study results indicate that wood microsites, as compared to adjacent soil substrates, while not extending growing season, did provide heightened substrate temperature during the growing season. The finding of cooler early spring and late fall temperatures is partially in contrast to conclusions of researchers in subalpine forests in the European Alps who suggest that wood substrates facilitate early melting and subsequent temperature enhancement in the early growing season (Eichrodt 1969, Mayer and Ott 1991, Stockli 1995, Smit et al. 2005, Baier et al. 2007). Although wood may have facilitated earlier snow melting and late arrival of snow cover, the associated lack of snow providing insulation (Marchand 1996) at my study locations above timberline likely made wood colder than soil during periods when air temperature was $<0^{\circ} \mathrm{C}$ in late June and late September.

GDH as defined by the months of July, August, and September and a base temperature of $7^{\circ} \mathrm{C}$, proved to be useful in assessing heat accumulation differences for wood and soil substrates and in assessing relative influence of percent transmitted radiation on heat accumulation pattern. On west side Cascade Mtn. locations, wood microsites did not accumulate significantly more daily heat than adjacent soil substrates for any level of percent incoming radiation. On the east side, wood microsites having medium levels of percent transmitted radiation had more GDH than soil. Although wood was warmer in high radiation areas, high diurnal temperature fluctuations found at these sites resulted in less GDH due to colder nighttime temperatures, particularly at east side 
sites. These results suggest that radiation has a more pronounced effect on heat accumulation on east side sites than at west side locations and that wood microsites with medium levels of radiation maximize heat gain during the day and minimize heat loss at night.

\section{Conifer invasion of alpine meadows}

Greater seedling densities were found at sites having greater moisture; locations having a variety of light levels, but generally not locations with the highest substrate temperature. These results partly support the postulation that Abies $s p$. seed germination and seedling survival in the ATE is strongly dependent on specific light, water, and temperature requirements met only within certain microsites (Germino et al. 2003). In addition, my results indicate that seedling generation occurred in areas with both high and low radiation given presence of moist substrates. This research also determined relative importance of these site factors by Mediterranean (western sites) and more continental climates (eastern sites) in the PNW (Peterson 1998). Based on this research, I suggest that for western-most sites where moisture is abundant, wood microsites are beneficial to seedlings by providing both heightened temperature and moisture. At eastern sites, moisture provided by substrates appeared more important to seedling survival than heightened temperature. At eastern sites, greater potential for alpine meadow conifer invasion is suggested for wood microsites with moderate levels of transmitted raditation given greater VWC (than soil substrates in low radiation sites) assocaited greater seedling densities. At both east and west sites, it is likely that the water stored in decaying wood 
in the winter provided moisture to help pioneering plants become established (Amaranthus et al. 1989). Greater substrate moisture provided by wood is likely associated with better alpine meadow seedling adaption, an advantage indicated by greater natural and transplanted seedling survival (Chapter 2).

It appeared that photoinhibition was not as much of a threat to PNW seedlings as it is to Rocky Mtn. seedlings. Photoinhibition, an inactivation or damage to photosystem II reaction center in the chloroplast, may result in loss of a plant's ability to photosynthesize (Long et al. 1994, Taiz and Zeiger 2006). Photoinhibition, commonly damaging trees in open alpine areas, is associated with periods of night frost followed by clear sky days (Ball 1991). Although level of sky exposure was very similar at PNW sites and Rocky Mtn. locations (Germino et al. 2002) (87.3\% cover versus $86.5 \%$ cover for low radiation sites and $66.9 \%$ versus $67.6 \%$ cover in high radiation sites, respectively), healthy seedlings were found at PNW high percent transmitted radiation sites, in contrast to the Rocky Mtn. sites. Differences in photoinhibition negative effects between these locations were likely due to differences in number of nights having $<0^{\circ} \mathrm{C}$ temperatures that were followed by clear sky days (Ball et al. 1991, Germino 2002). Colder eastern-most sites in this PNW study had eight or fewer days of $<0^{\circ} \mathrm{C}$ temperatures during the growing season as compared to 18 days of $<0^{\circ} \mathrm{C}$ nighttime temperatures at the Rocky Mts (Germino et al 2002). Differences in temperature pattern are also attributed to elevation differences (PNW sites with $<2,000 \mathrm{~m}$ timberlines and $>$ 3,000 m timberline locations in the Rocky Mts.). Typical of more maritime timberlines, PNW timberline sites were lower in elevation than the more continental Rocky Mtn. sites 
(Arno 1984). These elevation differences are primarily attributed to difference in location of the mean substrate temperature facilitating growth of seedlings (Körner 1998, Körner and Paulsen 2004).

Alpine meadow invasion, climate change, and management-related implications

Study results illuminate the importance of making suitable spatial and temporal analysis choices for research aimed at building inferences for seedling regeneration in the ATE. Differences in wood and soil substrate temperature depended on increment of time period assessed. Although annual mean temperature was lower for wood microsites, mean summer growing season temperature was greater, particularly for areas having high incoming radiation. Use of a precipitation gradient (east side and west side locations) and measures of increasing radiation (three categories) in my analysis were vital for highlighting relative importance of substrate temperature, substrate moisture, and effects of increased radiation. Although overall temperature pattern increased with increasing percent transmitted radiation, it was moisture abundance that proved to be the environmental factor most associated with highest densities of seedlings in PNW timberlines. Wood microsites VWC was significantly greater, particularly in high radiation areas. Given greater VWC and greater seedling survival on wood microsites in open alpine meadows, it is expected that wood microsites will facilitate timberline advance more than adjacent soil substrates.

Classification of seedling density by site characteristics including radiation, VWC, substrate temperature, aspect, and elevation by classification and regression trees 
(CART) was informative in quantifying important site thresholds influencing seedling density at my PNW sites. CART identified two important site thresholds: (1) a VWC of $15.9 \%$ splitting sites into groups either positively or negatively affected by increased site temperature, and (2) a radiation level of $19.44 \%$ dividing sites into groups dependent on higher VWC for higher seedling densities.

My research suggests that drought will significantly limit regeneration above timberline in the PNW, and likely at other timberlines, in the future. Moisture availability, although not a feature strictly associated with altitude per se (Körner 2007), is certainly associated with local moisture gradients expected to change with climate warming (Markoff and Cullen 2008). Although climate warming is expected to increase photosynthesis in general, reduction in net photosynthesis will occur in regions where temperature it is already close to the optimum and/or warming accentuates water stress (Saxe et al. 2000). Because areas of lower VWC also had higher temperature and decreased seedling density were also associated with decreased survival of natural and transplanted seedlings (Chapter 2), it is suggested that timberline locations are already close to optimum temperatures, given availability of water during the growing seasonparticularly at eastern Cascade Mtn. sites. My research results therefore propose that wood microsites, by providing more moisture, will facilitate survival of seedlings up to threshold whereby the added moisture found in rotten wood will not compensate for young seedling moisture requirements. 


\section{Suggestions for future research}

As a result of this research, two research directions were suggested for future investigation: (1) physiologic measures of young conifers regenerating on wood and soil at locations having low, medium, and high incoming radiation to test the theory that photoinhibition damage is low at PNW timberlines and (2) comparisons of microsites at timberlines throughout the world to relate microsite type to dominant climatic factors.

\section{Conclusion}

Substrate temperature and moisture pattern was evaluated by level of percent transmitted radiation at timberline-alpine meadow borders to determine possible advantages for seedling regenerating on wood and soil microsites. Although wood did not thaw earlier and had a lower annual mean temperature, summer wood microsite temperature, number of substrate growing degree hours above $7^{\circ} \mathrm{C}(\mathrm{GDH})$, and volumetric water content (VMC) were significantly greater than adjacent soil soil substrates.

Study results suggested substrate conditions likely to support Abies $s p$. seedling regeneration at timberline-alpine meadow borders. Soil moisture, rather than soil temperature or level of radiation, was most associated with increased density of $<3 \mathrm{yr}$ seedlings. Regeneration of seedlings at sites having mean summer substrate temperatures $<8^{\circ} \mathrm{C}$ and moisture contents $>12 \%$ appeared to be of primarily importance to young seedings. Temperatures greater than about $8^{\circ} \mathrm{C}$ were associated with lower substrate moisture and lower seedling densities. With climate warming and associated increase in 
drought, sites having more moisture and less radiation (cooler sites) will likely facilitate regeneration of conifers better than warmer, drier higher radiation sites. 
Table 5. Characteristics of six study sites and mean climatic variables.

\begin{tabular}{|c|c|c|c|c|c|c|c|c|}
\hline $\begin{array}{l}\text { Site } \\
{\left[{ }^{1}\right]}\end{array}$ & $\begin{array}{c}\text { Ele- } \\
\text { vation } \\
(m)\end{array}$ & $\begin{array}{l}\text { Longi- } \\
\text { tude }\end{array}$ & $\begin{array}{r}\text { Aspect } \\
\text { (०) }\end{array}$ & $\begin{array}{c}\text { Slope } \\
\left({ }^{\circ}\right)\end{array}$ & $\begin{array}{c}\text { Mean } \\
\text { Annual } \\
\text { Precip } \\
\text { (mm) }\end{array}$ & $\begin{array}{c}\text { Mean } \\
\text { Annual } \\
\text { Temp. }{ }^{*} \\
\left({ }^{\circ} \mathrm{C}\right)\end{array}$ & $\begin{array}{c}\text { Mean } \\
\text { Summer } \\
\text { Precip. }{ }^{*} \\
\text { (mm) }\end{array}$ & $\begin{array}{c}\text { Mean } \\
\text { Summer } \\
\text { Temp. } * \\
\left({ }^{\circ} \mathrm{C}\right)\end{array}$ \\
\hline $1,[9]$ & 1585 & -121.385 & 0 & 21 & 2370 & 4.0 & 200 & 12.6 \\
\hline $2,[8]$ & 1676 & -121.062 & 250 & 35 & 1980 & 5.8 & 142 & 15.4 \\
\hline $3,[2]$ & 1768 & -120.882 & 140 & 5 & 1800 & 4.1 & 137 & 14.3 \\
\hline $4,[6]$ & 1875 & -120.761 & 160 & 14 & 1580 & 3.6 & 106 & 14.2 \\
\hline $6,[11]$ & 1996 & -120.668 & 85 & 23 & 1530 & 2.4 & 112 & 13.1 \\
\hline $5,[4]$ & 1910 & -120.664 & 300 & 21 & 1510 & 2.4 & 110 & 13.2 \\
\hline
\end{tabular}

*Temperature and rainfall information was obtained from DAYMET (15 y averages).

${ }^{1}$ Site numbers used in Chapter 2. 
Table 6. Location of i-Buttons in association with canopy closure and percent transmitted radiation at each site.

\begin{tabular}{llccccl}
\hline Site & $\begin{array}{l}\text { Forest } \\
\text { Overstory } \\
\text { Type }\end{array}$ & $\begin{array}{c}\text { Percent } \\
\text { Canopy } \\
\text { Closure }\end{array}$ & $\begin{array}{c}\text { Canopy } \\
\text { Closure } \\
\text { Category }\end{array}$ & $\begin{array}{c}\text { Mean percent } \\
\text { Transmitted } \\
\text { Radiation } \\
(\text { PTR) }\end{array}$ & $\begin{array}{l}\text { Pooled } \\
\text { Site PTR } \\
\text { Standard } \\
\text { Error }\end{array}$ & $\begin{array}{l}\text { Radiation } \\
\text { Level } \\
\text { Category* }\end{array}$ \\
\hline \multirow{2}{*}{1} & Timberline & 90.8 & high & 12.9 & 0.9 & Low \\
& Mid-distance & 82.0 & med & 17.9 & 2.5 & Low \\
& Meadow & 69.2 & open & 36.3 & 0.4 & Med \\
\hline \multirow{2}{*}{2} & Timberline & 90.9 & high & 11.0 & 3.3 & Low \\
& Mid-distance & 83.2 & med & 19.6 & 5.1 & Med \\
& Meadow & 71.3 & open & 41.4 & 3.1 & High \\
\hline \multirow{3}{*}{3} & Timberline & 86.9 & high & 19.2 & 7.2 & Med \\
& Mid-distance & 71.9 & med & 52.9 & 4.5 & High \\
& Meadow & 63.3 & open & 63.6 & 6.0 & High \\
\hline \multirow{2}{*}{5} & Timberline & 86.9 & high & 15.6 & 7.9 & Low \\
& Mid-distance & 77.9 & med & 26.0 & 8.0 & Med \\
& Meadow & 65.9 & open & 61.8 & 10.1 & High \\
\hline \multirow{2}{*}{6} & Timberline & 85.5 & high & 16.1 & 6.4 & Low \\
& Mid-distance & 81.1 & med & 32.2 & 11.2 & Med \\
& Meadow & 72.3 & open & 49.0 & 3.8 & High \\
\hline & Timberline & 83.9 & high & 15.5 & 2.8 & Low \\
& Mid-distance & 76.7 & med & 22.8 & 8.1 & Med \\
& Meadow & 60.0 & open & 60.0 & 7.1 & High \\
\hline
\end{tabular}

*Note: Percent canopy closure measures canopy above the camera and does not use site specific measurements including aspect, location, slope, cloud index; parameters used to calculate percent transmitted radiation at each study site location. At each of the six sites, three subsamples of each site class were averaged. For transmitted radiation categories are as follows: $<18 \%$ is low, 18 to $40 \%$ is medium, $>40 \%$ is high. ANOVA results indicate significant differences between radiation categories $(p<0.001)$. 


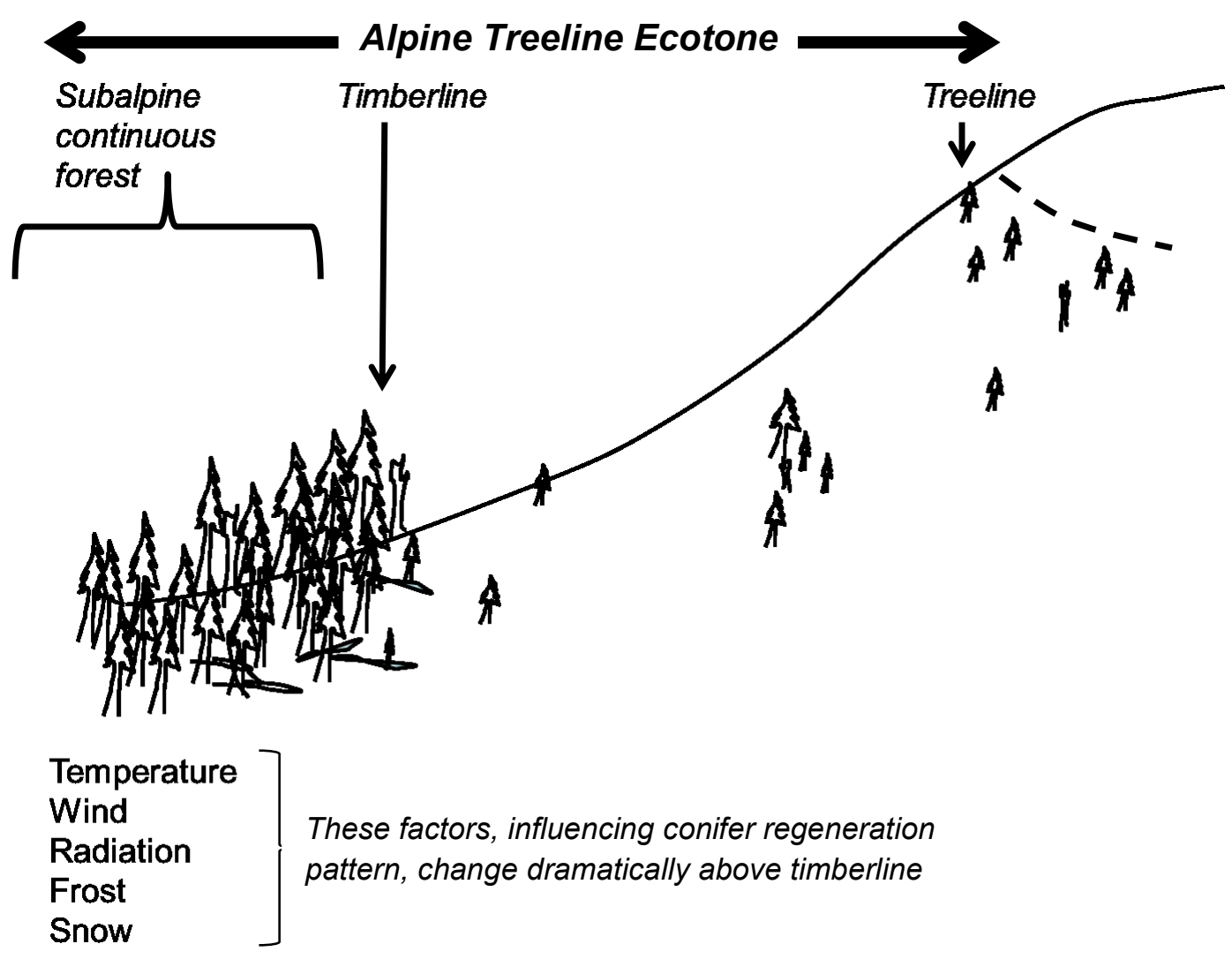

Figure 11. A typical Pacific Northwest timberline location within the alpine treeline ecotone with common stresses indicated. 


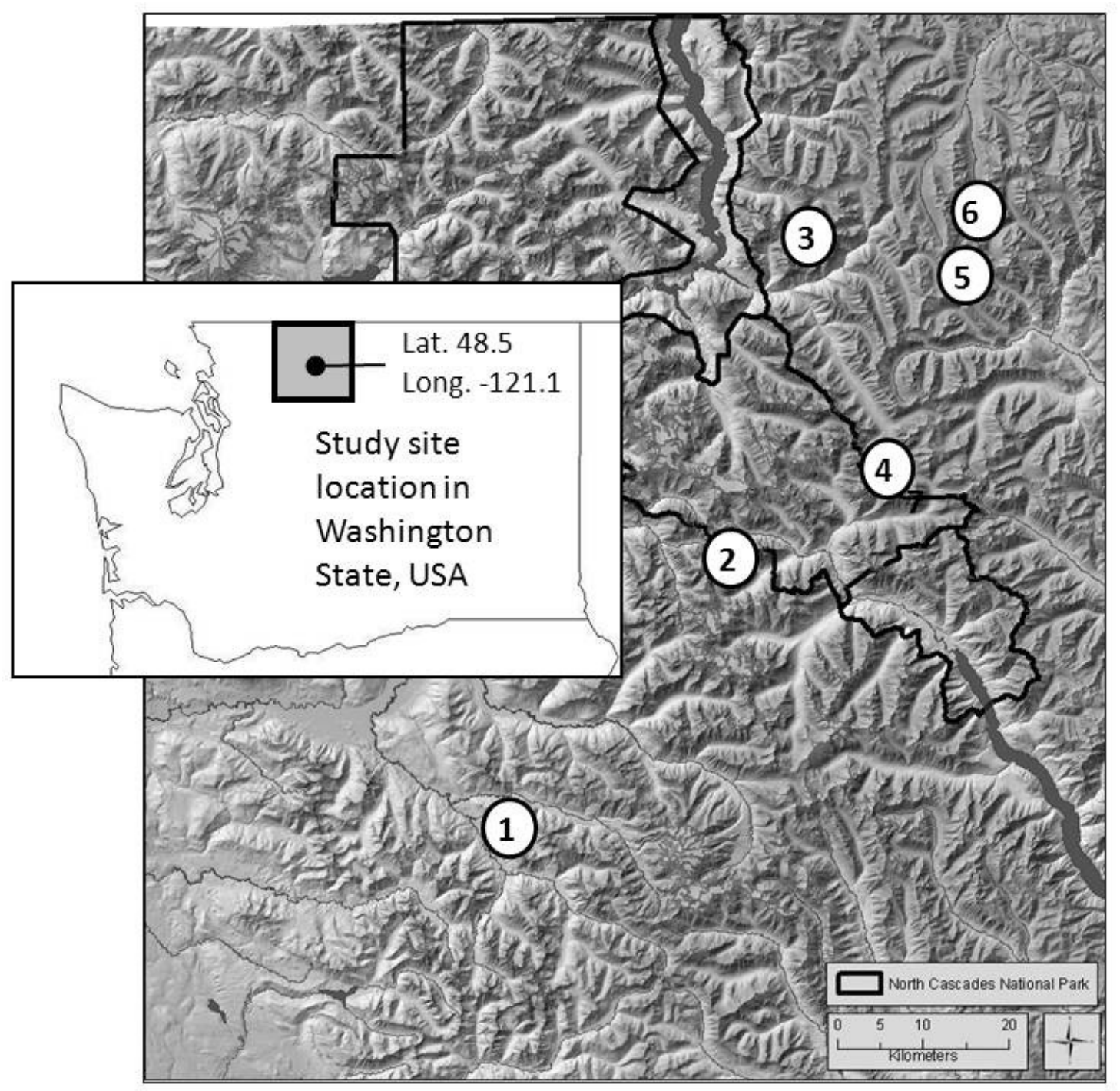

Figure 12. Location of the six study sites in Washington State, USA. 


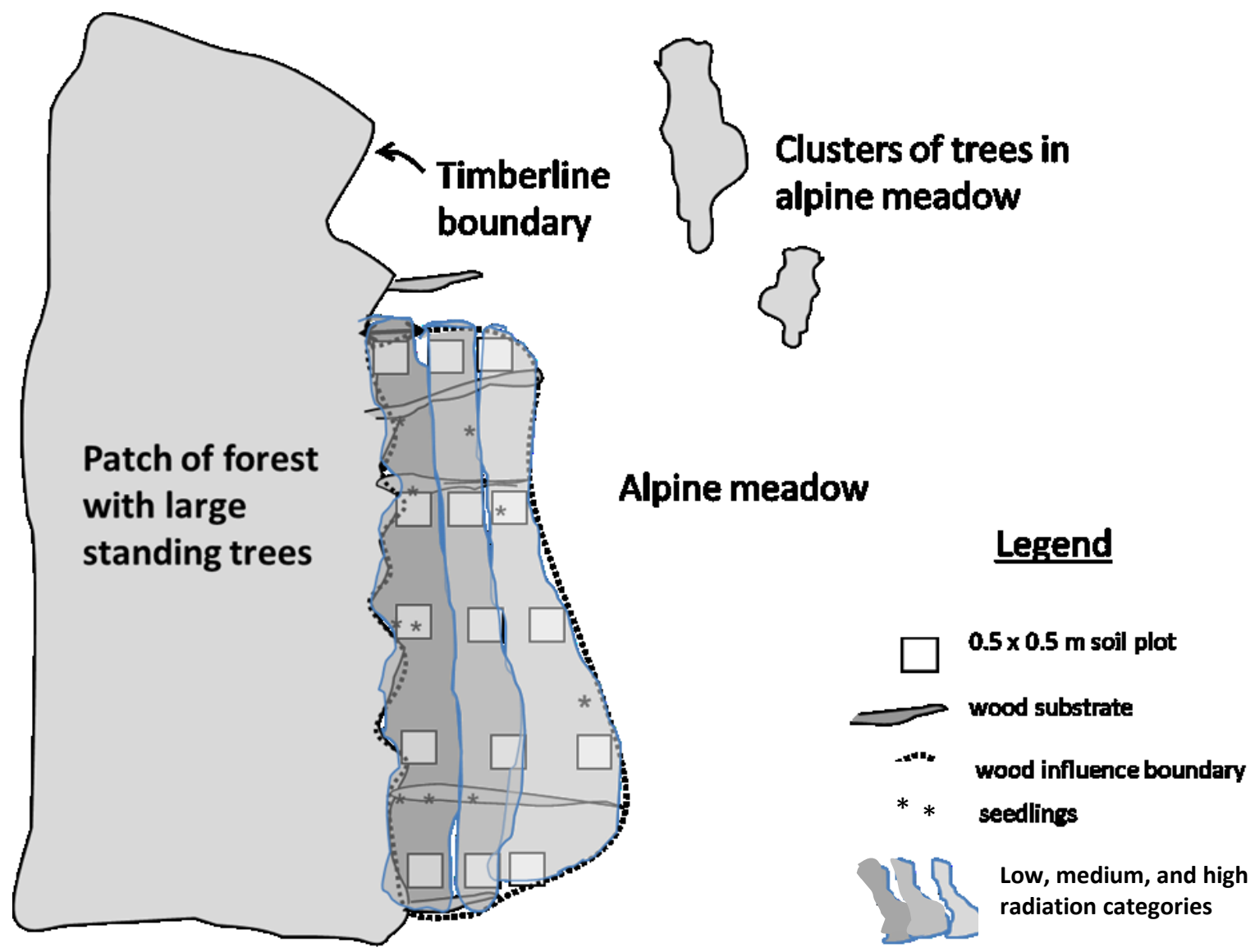

Figure 13. Wood substrates, soil plots, and overstory canopy categories. The overstory categories were generally related to incoming radiation categories (see Table 6). 


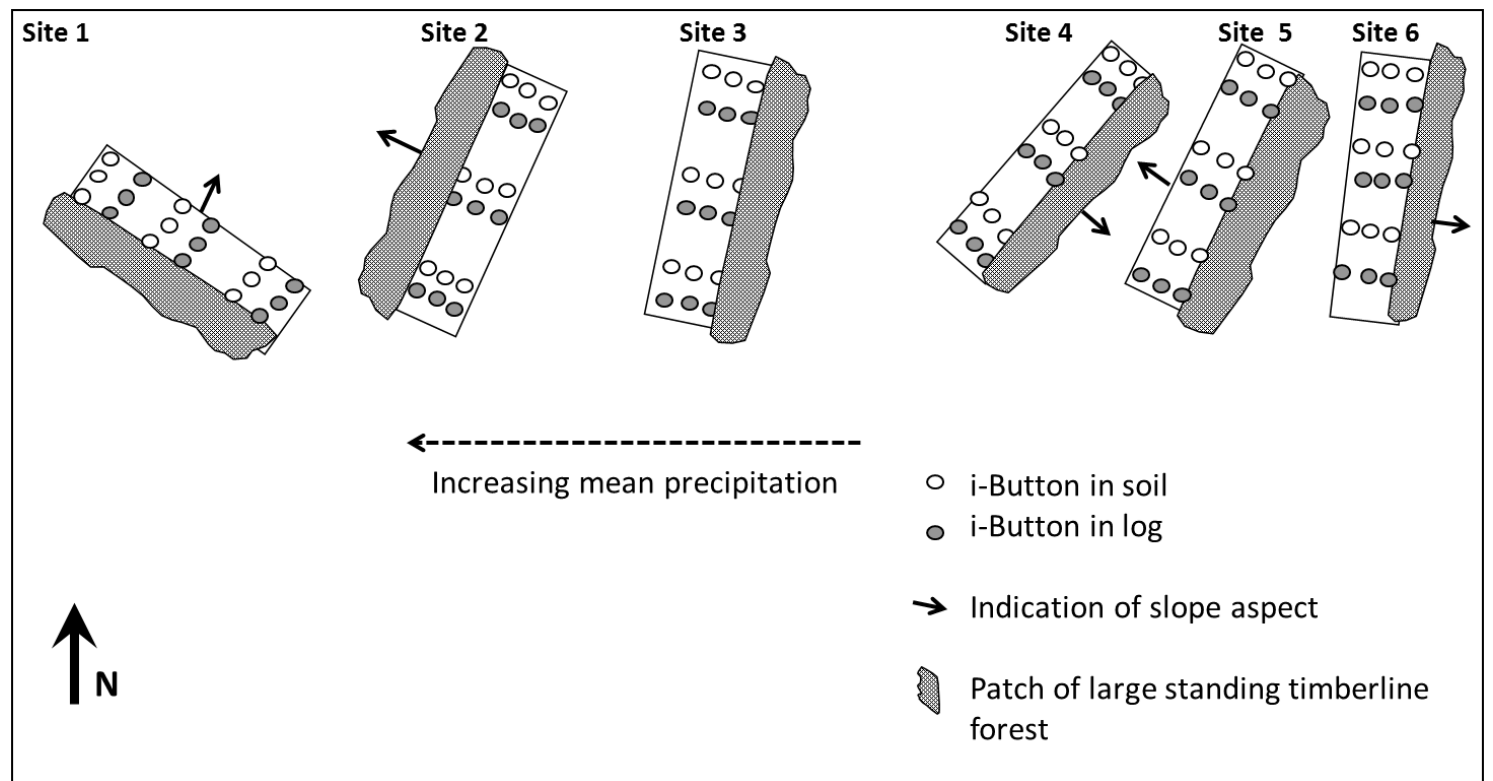

Figure 14. Site aspect and location of i-buttons in wood and adjacent soil with respect to each patch of large standing timberline trees at the six study sites. 

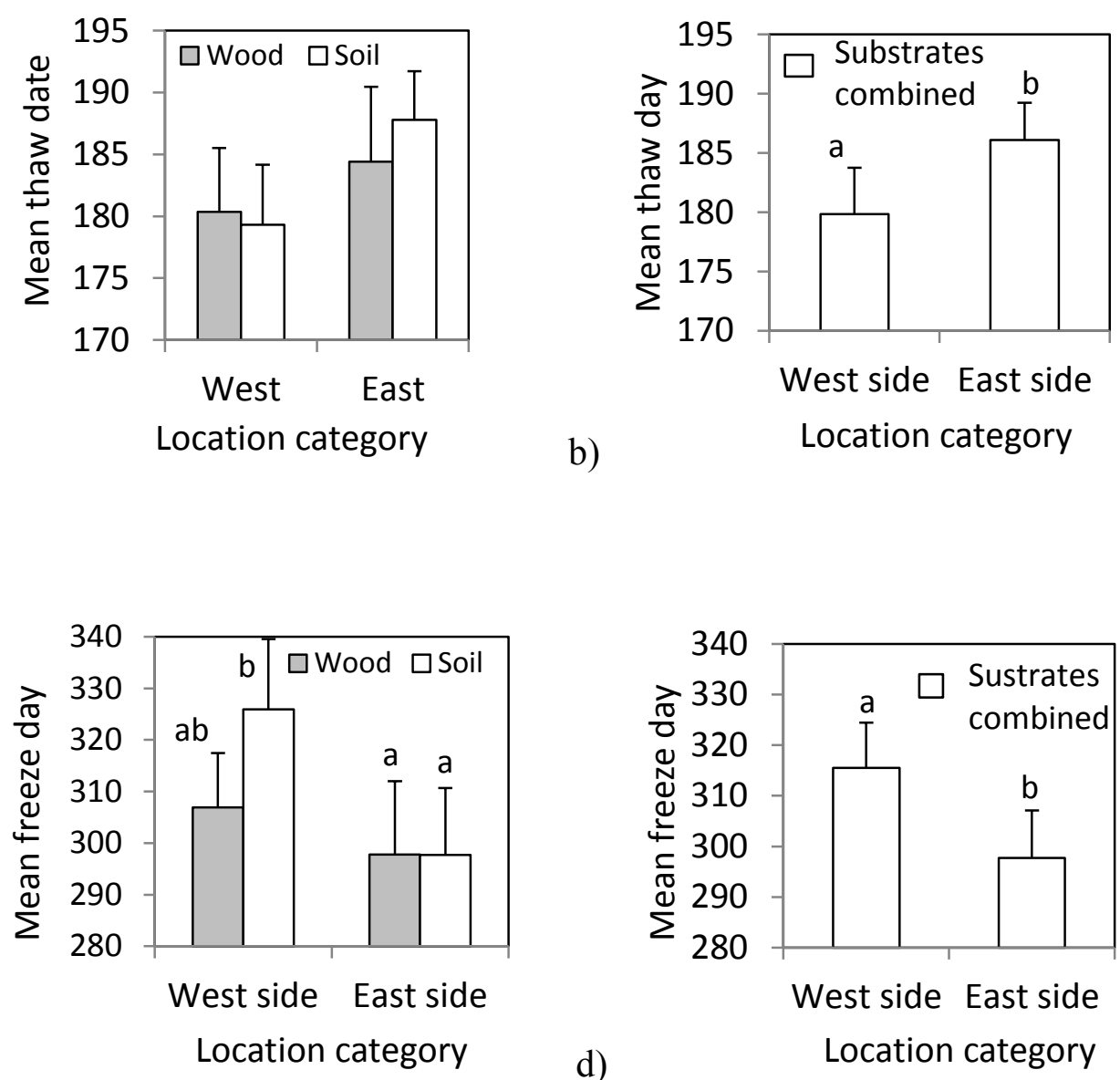

Figure 15. Barplots of spring thaw and fall freeze date for wood and soil substrates. Means for six sites (each having three radiation categories) and 95\% confidence intervals indicated for: a) spring thaw by substrate and location $(n=18$ per bar), b) thaw date for combined substrates by location $(n=36$ per bar, mean thaw of June 27 and July 4, respectively for west side and east side, $p=0.02)$, c) freeze date by substrate and east side or west side location ( $\mathrm{n}=18$ per bar, $p=0.02)$, and $\mathrm{d}$ ) freeze date for combined substrates by location $(\mathrm{n}=36$ per bar, mean freeze of November 10 and October 23, respectively for west side and east side, $p=0.009$ ). 


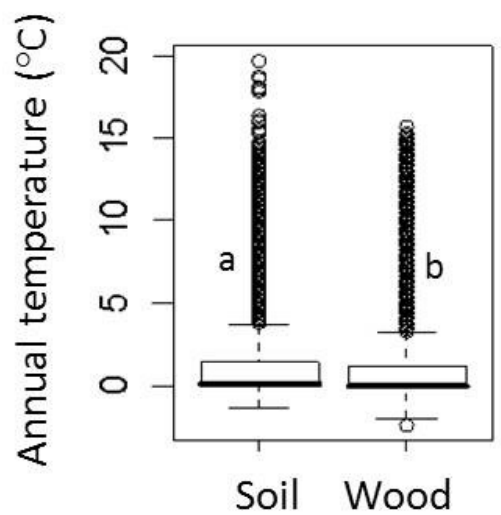

Substrate

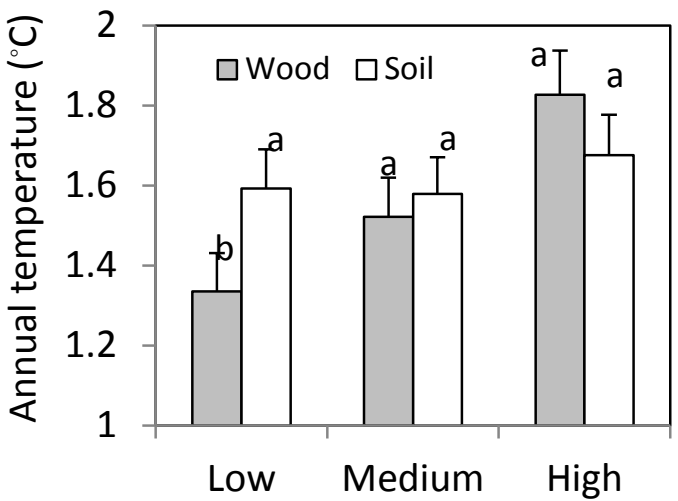

Radiation category

a)

b)

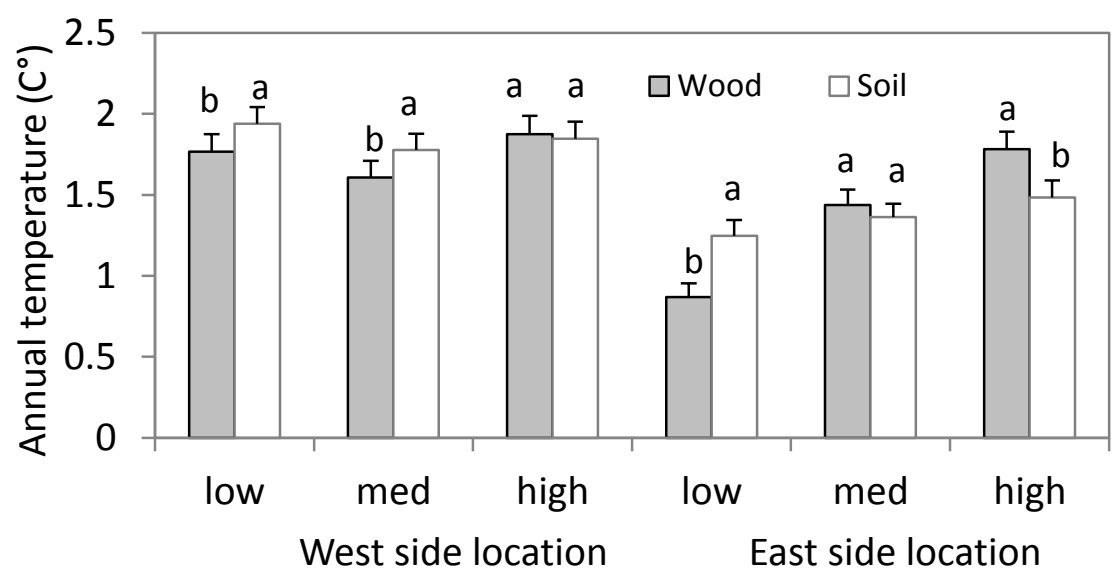

c)

Figure 16. Boxplots and barplots of wood and soil substrate mean annual temperature for six sites. Boxplot sof: a) wood and soil $(\mathrm{n}=35019$ per bar, $p<0.001)$ with central line in box indicating the median, box includes $50 \%$ of data, top of box indicates $75^{\text {th }}$ percentile (upper quartile) of data, bottom of box indicates $25^{\text {th }}$ percentile, and vertical lines extending to upper and lower deciles $\left(90^{\text {th }}\right.$ and $10^{\text {th }}$ percentiles $)$. For barplots, means for sites (each having three radiation categories) and $95 \%$ confidence intervals indicated for: b) wood and soil by radiation category ( $\mathrm{n}=11673, p<0.001$ for low radiation), and c) wood and soil by shade and location $(\mathrm{n}=3891$ per bar; $p<0.001$ and $p=0.002$ for low and medium on west locations and $p<0.001$ and $p<0.001$ for low and high radiation east side sites). Note: for comparisons were made between wood and soil substrates having similar radiation categories only. For these pairs, significant differences are indicated by different letters. 

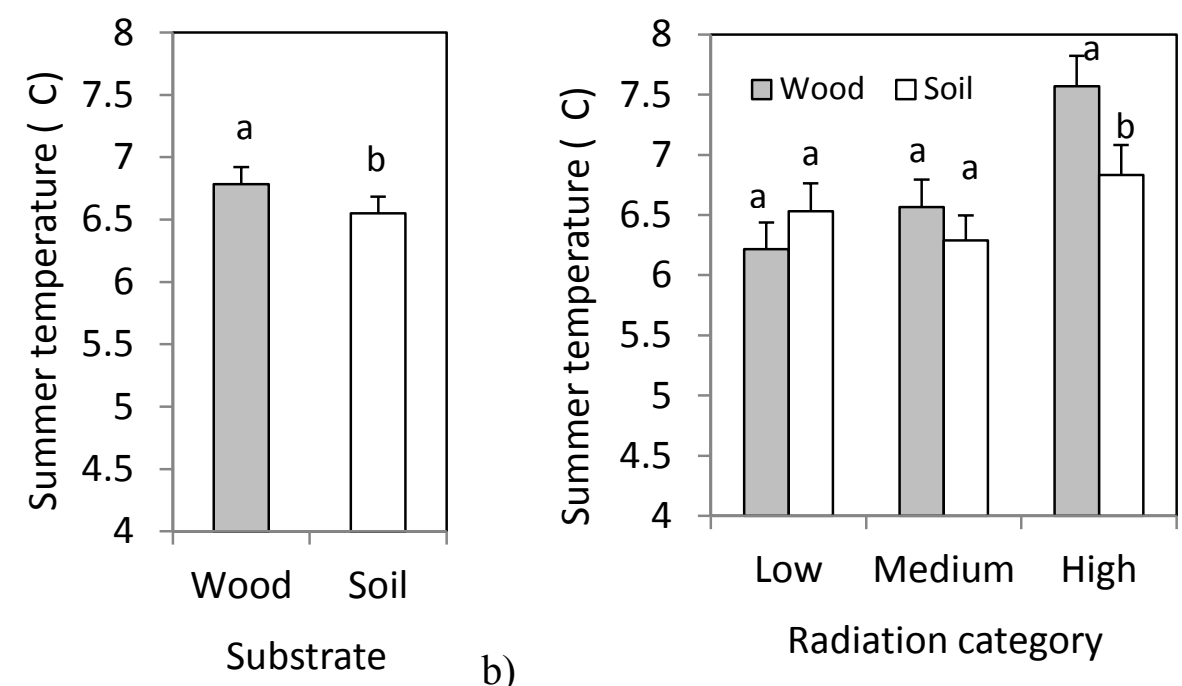

a)

Substrate

b)

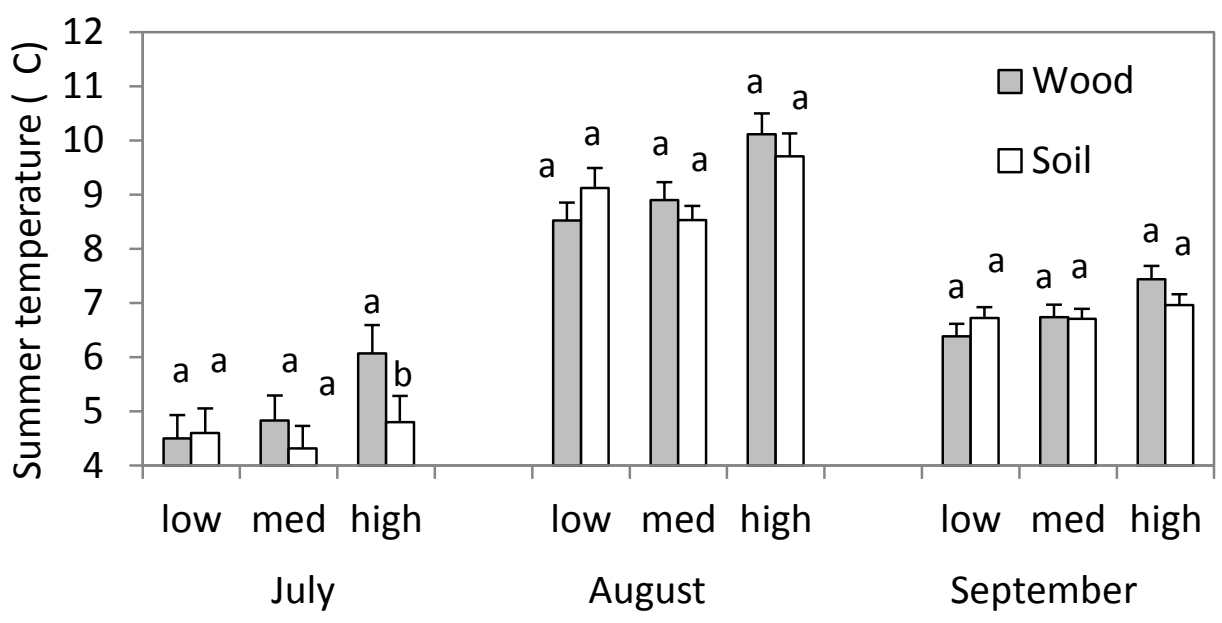

c)

Figure 17. Barplots of summer wood and soil temperature. Means for six sites (each having three radiation categories) and $95 \%$ confidence intervals for a) wood and soil (n $=4848$ per bar, $p=0.0013), \mathrm{b})$ for wood and soil by radiation category $(\mathrm{n}=1616$ per bar; $p<0.001$, wood is warmer than soil for high radiation sites only), and c) wood and soil by percent transmitted radiation category and summer month $(n=566$ per bar for July, $n$ $=372$ per bar for August, $\mathrm{n}=678$ per bar for September; wood is warmer than soil at high radiation sites during the month of July only, $p<0.001)$. Note: comparisons were made between wood and soil substrates having similar radiation categories only. For these pairs, significant differences are indicated by different letters. 

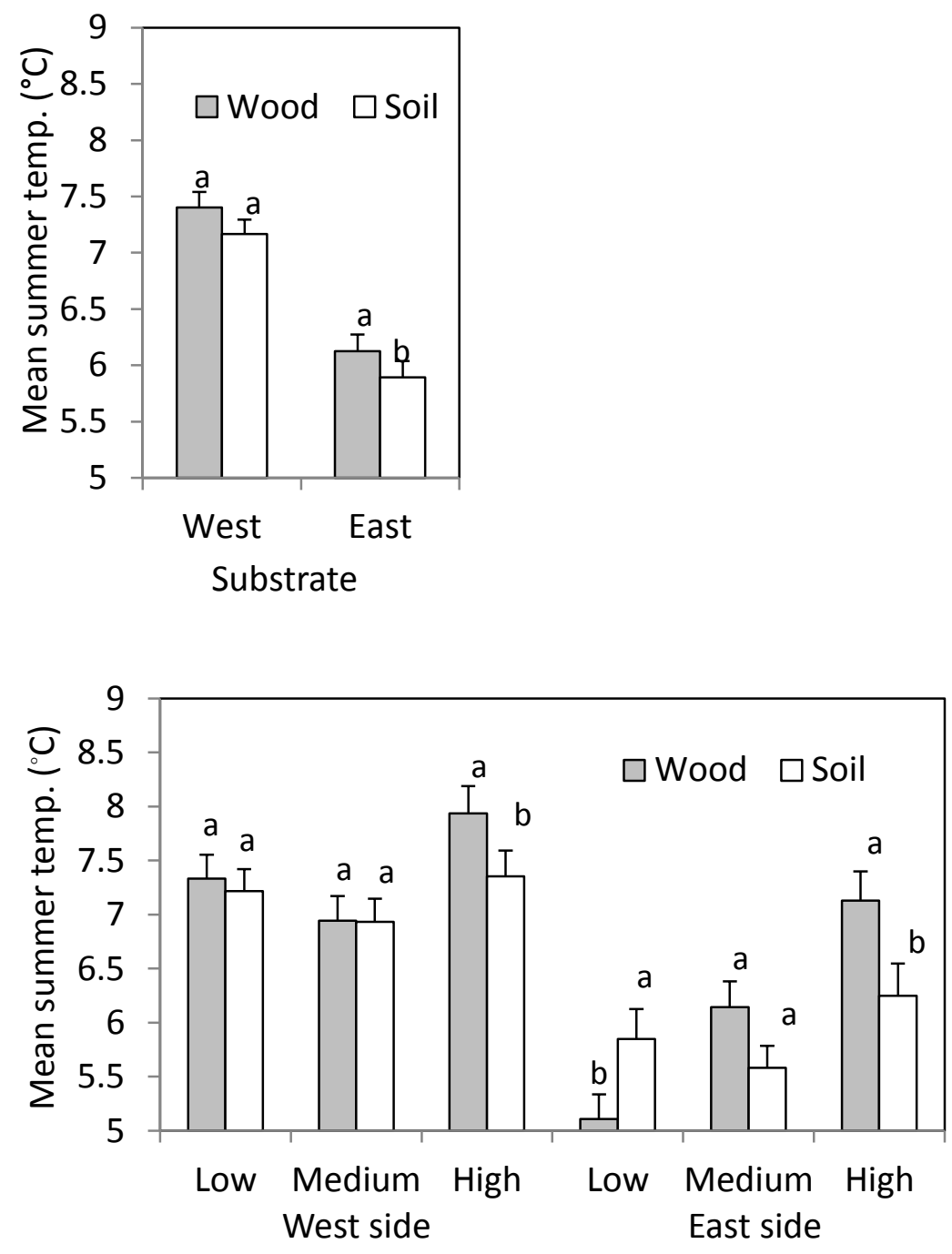

Figure 18. Barplots of substrate summer temperature by west side or east side locations. Means for six sites (each having three radiation categories) and 95\% confidence intervals for a) wood and soil ( $\mathrm{n}=2424$ per bar; wood is warmer than soil on east side, $p=0.028$ ) and $b)$ wood and soil by radiation category $(n=808$ per bar; on west side, wood is warmer than wood at high radiation sites, $p=0.04$; on east side wood is cooler than soil at low radiation sites and warmer than soil in high radiation sites, $p<0.001, p<0.001$, respectively). Note: comparisons were made between wood and soil substrates having similar location category or radiation categories only. For these pairs, significant differences are indicated by different letters. 


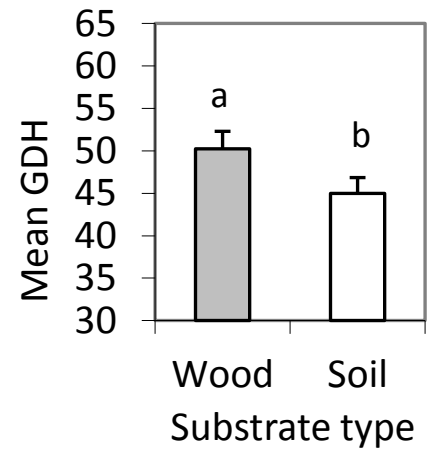

a)

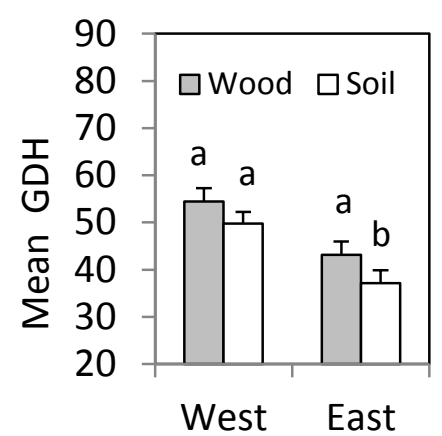

c)

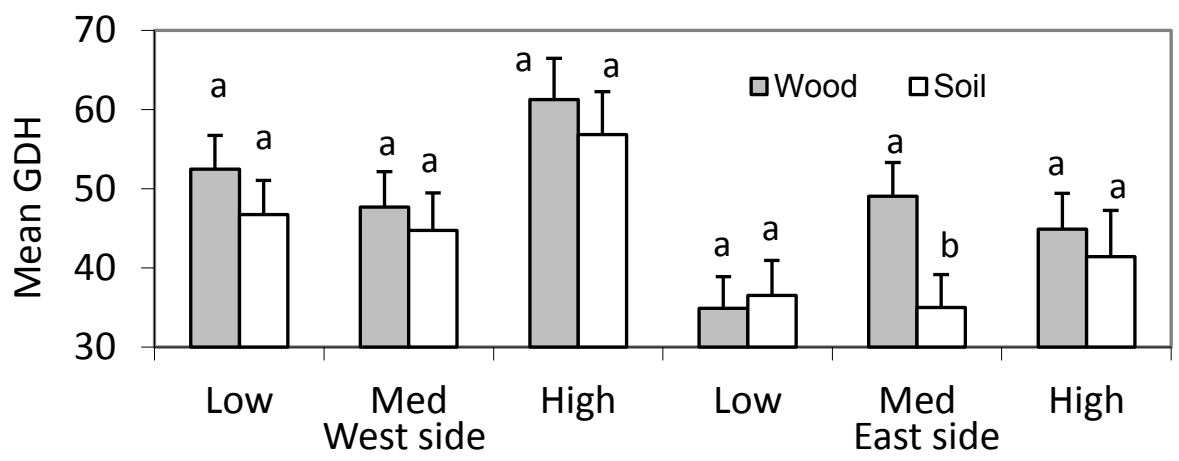

e)
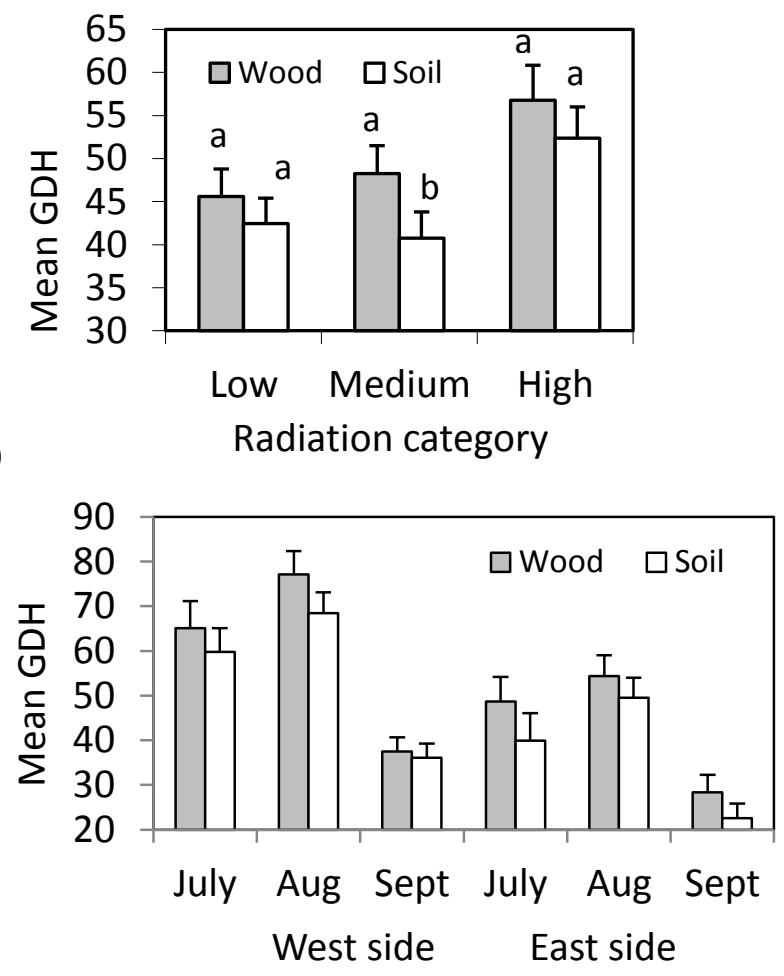

Figure 19. Barplots of wood and soil summer growing degree hours (GDH). Means for six sites (each having three radiation categories) and $95 \%$ confidence intervals by a) substrate type ( $\mathrm{n}=1540$ wood, 1490 soil, $p=0.0002), \mathrm{b})$ radiation category $(\mathrm{n}=$ a range of 470 to 535 per bar, wood has more GDH than soil at medium radiation sites, $p=0.04$ ), c) substrate by east and west location ( $\mathrm{n}=964$ and 926 west side; 576 and 563 east side for wood and soils, respectively); wood at east sites had more GDH than soil $(p=0.035)$, d) substrate type by time period and west and east location $(\mathrm{n}=$ a range of 136 to 385 per bar), and e) substrate type by shade category by west or east side $(\mathrm{n}=$ a range of 136 to 360 per bar); wood with medium radiation has more GDH $(p=0.0002)$. Note:

comparisons were made between wood and soil substrates having similar location categories or radiation categories only. For these pairs, significant differences are indicated by different letters. 


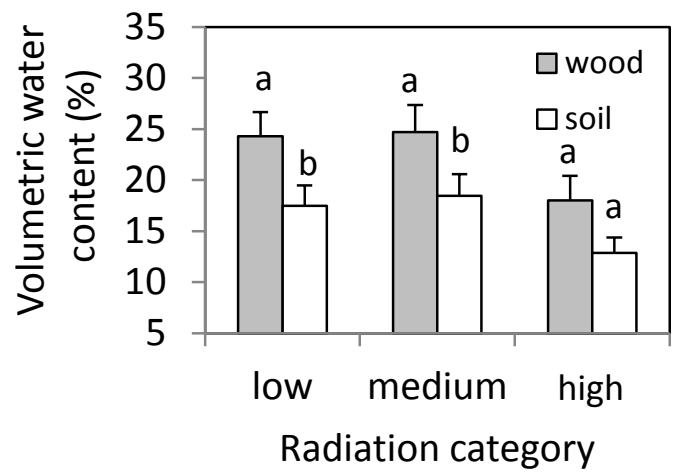

a)

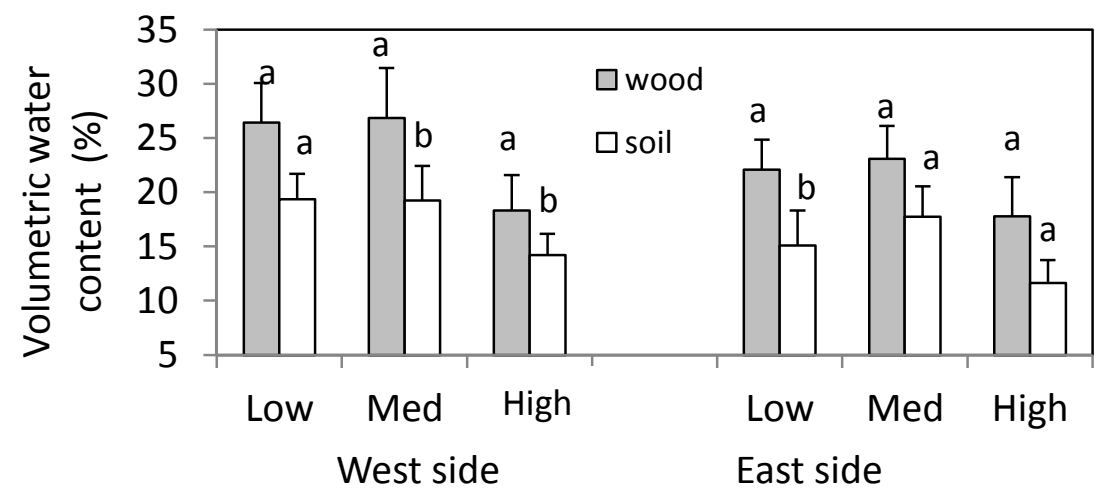

b)

Figure 20. Barplots of wood and soil volumetric water content (VWC). Means for six sites (each having three radiation categories) and 95\% confidence intervals for a) substrate and radiation category $(\mathrm{n}=$ range of 53 to 84 per bar; wood had greater VWC than soil for low and medium radiation, $p=0.0009, p=0.015$, respectively) and $\mathrm{b}$ ) west side and east side radiation category $(\mathrm{n}=$ a range of 18 to 43 per bar; on west site wood VWC is greater for medium and high radiation sites, on east side wood has greater VWC at low radiation sites only $p=0.004, p=0.008, p=0.01$, respectively. Note: comparisons were made between wood and soil substrates having similar radiation categories only. For these pairs, significant differences are indicated by different letters. 

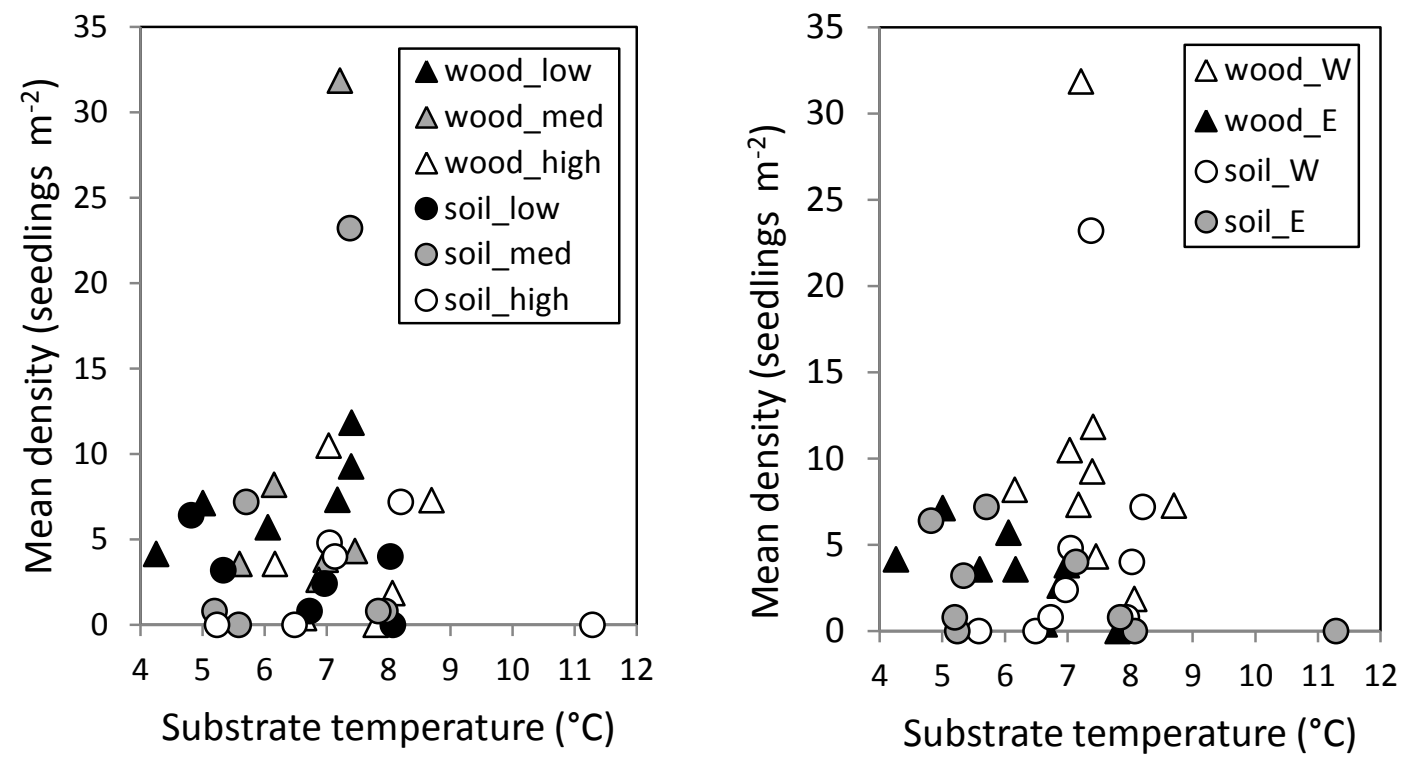

a)

b)

Figure 21. Density of $<3$ yr old seedlings versus wood and soil substrate temperature. Density versus mean substrate temperature for six sites (each having three radiation categories) by: a) radiation category (no significant relationships) and b) location (significant decreases in seedling density at east locations for wood substrates with increases in mean substrate temperature, $p=0.047, \mathrm{r}^{2}=0.38$ ). 


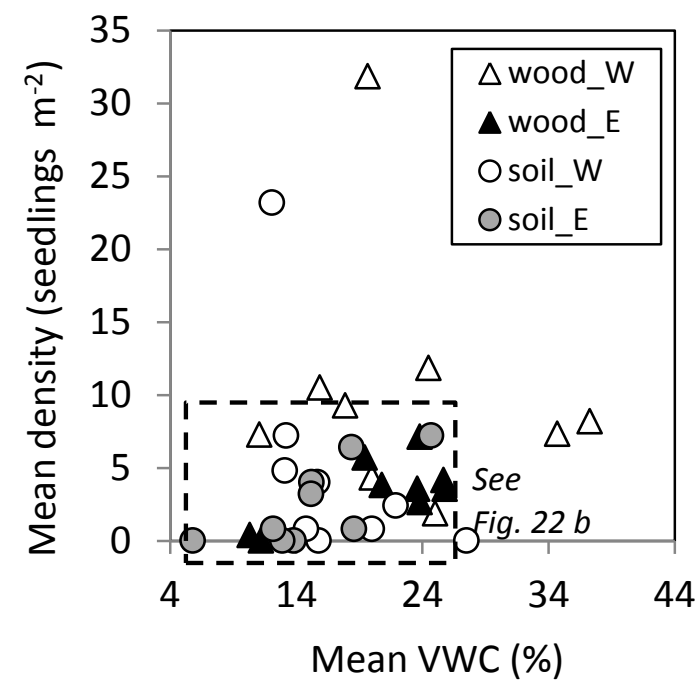

a)

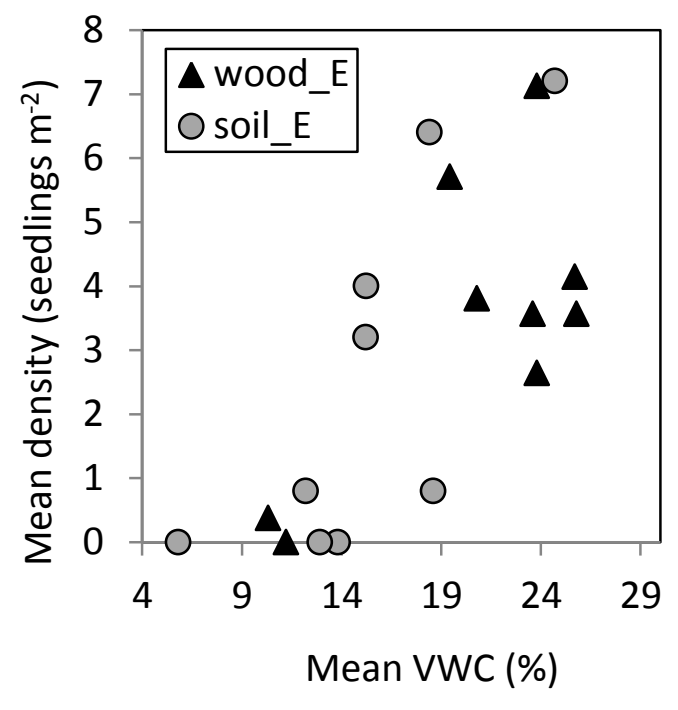

Figure 22. Seedling density versus mean volumetric water content (VWC) on wood and soil substrates. Density is indicated for a) both west side and east side locations (six sites each having three radiation categories) and $b$ ) east side locations (three sites with three radiation categories each) alone where a significant increases in seedling density are associated with increases in mean VWC (eastside wood $p=0.03, \mathrm{r}^{2}=0.42$; east side soil $p$ $=0.01, \mathrm{r}^{2}=0.51$, for west side $p=0.1$ for wood and 0.07 for soil). 


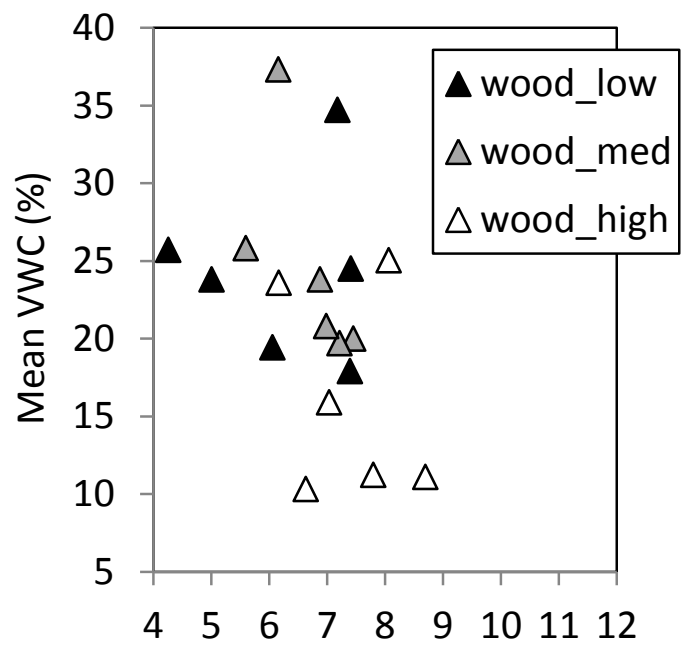

a)

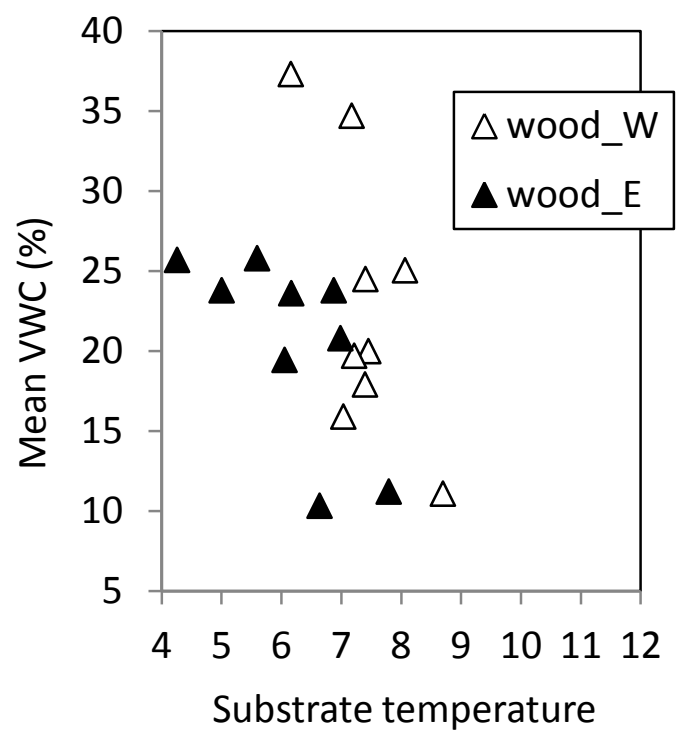

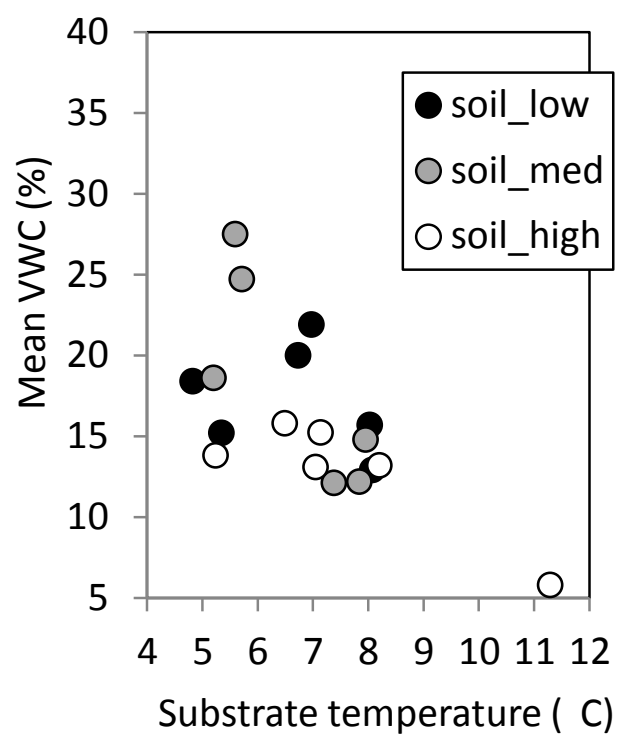

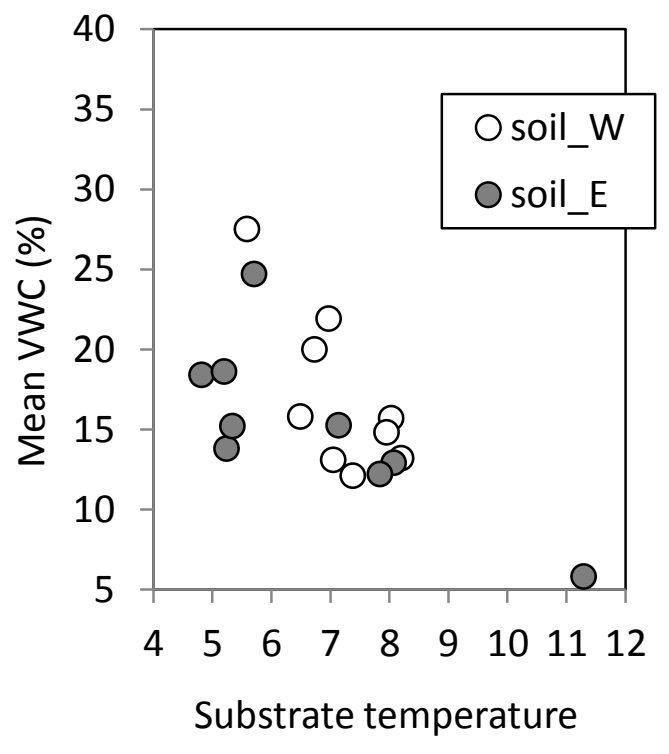

Figure 23. Mean volumetric water content (VWC) versus mean temperature for wood and soil substrates. Regressions of: a) wood substrates by radiation level, b) soil substrates by radiation level (medium radiation sites, $p=0.04, \mathrm{r}^{2}=0.6$ ), and c) wood substrates by east side and west side location (wood west, $p=0.046, \mathrm{r}^{2}=0.38$, and d) soil substrates by west side and east side location (soil west, $p=0.03, \mathrm{r}^{2}=0.31$; east, $p=$ $\left.0.002, r^{2}=0.73\right)$. Data represents six sites each having three radiation categories. Unless noted, $p>0.05$. 


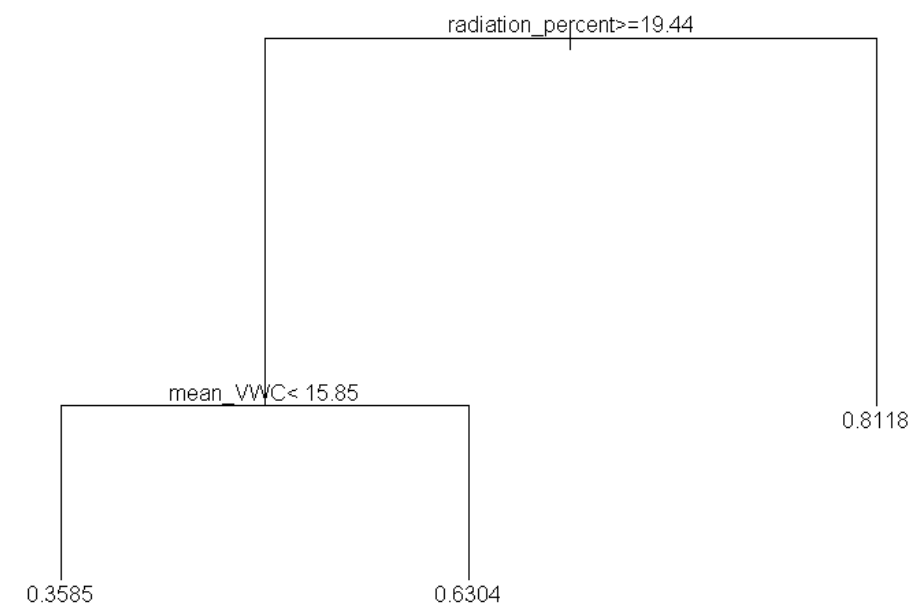

a)

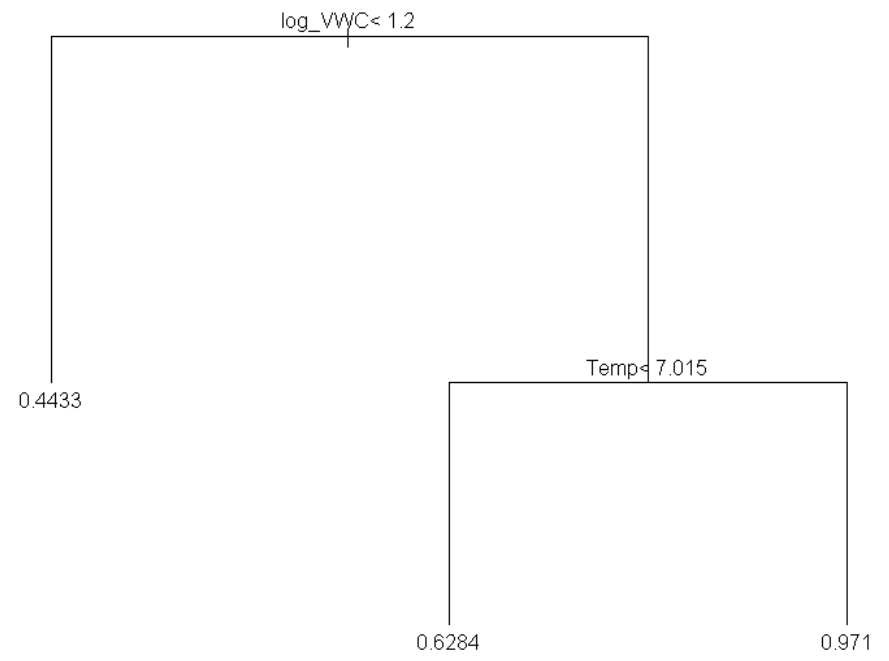

b)

Figure 24. Seedling density as classified by classification and regression trees (CARTs). Labels on these CARTs indicate splitting to the left side. CART indicate: a) decreases in seedling density associated with radiation $\geq 19.44$ and further density reductions with with volumetric water content $(\mathrm{VWC})<15.85$ and $\mathrm{b}$ ) greatest seedling density is classified by VWC $(\log$ transformed $)>1.2$ and substrate temperature $>7.012^{\circ} \mathrm{C}$. 


\title{
Chapter 4:
}

\section{Comparison of Plant Water Relations for Seedlings Growing on Wood Microsites and Soil Substrates at Timberline-Alpine Meadow Borders}

\begin{abstract}
Temperature, moisture, and shade conditions associated with microsites control successful seedling establishment and, thus, should be important determinants of the distributional and successional pattern observed for adult trees in the alpine treeline ecotone (ATE). Wood microsites with advanced decay, originating from large trees at the edge of timberline-alpine meadow borders, were found to provide warmer and moister substrates having higher seedling density and greater survival than adjacent soil substrates (Chapters 2 and 3). Further, comparisons of substrate temperature by radiation level, for both rotten wood microsites and adjacent soil substrates, indicated that mean summer temperature and mean growing degree hours $>7^{\circ} \mathrm{C}$ were significantly greater for wood microsites than soil (Chapter 3). To relate these positive abiotic factors to measures of active growth, the goal of this study was to compare stomatal conductance, water potential, and chlorophyll a content of seedlings growing on wood and soil substrates. Measurements were made in July, August, and September at four sites in the North Cascades of Washington. For the full data set, I found significant differences in water potential, but no differences in stomatal conductance or chlorophyll a content. When examining substrates (wood and soil together) with $>25 \%$ incoming radiation,
\end{abstract}


stomatal conductance measurements were significantly greater on moister substrates. This outcome suggests two important findings: (1) seedlings growing on more moist substrates in high radiation areas appear well adapted and (2) photoinhibition, a major cause of mortality in high radiation sites such as the Rocky Mts, may not be as important in the PNW. As indicated by seedling density, substrate moisture, as opposed to substrate temperature, appeared to be the greatest growth limitation for $<4 \mathrm{~cm}$ seedlings in the PNW. Given predictions for increased frequency of summer drought with climate warming, rotten wood substrates are likely to enhance growth of seedlings more than soil substrates at timberline-alpine meadow borders.

Keywords: wood microsites, stomatal conductance, water potential, volumetric water content.

\section{Introduction}

Assuming dispersal of viable seeds, temperature, water relations, and shade conditions associated with microsites may help control successful seedling establishment and thus, may determine the distributional and successional pattern observed for adult trees in the alpine treeline ecotone (ATE) (Cui and Smith 1991, Balisky and Burton 1995, Smith et al. 2003, Li and Yang 2004, Holtmeier 2009). Seedlings are likely to profit from warmer conditions, particularly substrate temperature $>7^{\circ} \mathrm{C}$ (Tranquillini 1979 , Körner and Paulsen 2004, Alvarez-Uria and Körner 2007) as long as sufficient soil moisture is available from the upper soil horizons (Cui and Smith 1991, Germino et al. 
2002). In some timberline areas, principally those associated with continental and Mediterranean climates, moisture rather than temperature is the most limiting resource for seedlings (Peterson 1998, Daniels and Veblen 2002).

Sites with highly decayed wood originating from blowdown, snow avalanches, and forest fires at timberline-alpine meadow edges simultaneously provide both higher temperatures and greater moisture contents (Chapters 2 and 3). Further, wood microsites with radiation above $40 \%$, have significantly more growing degree hours (GDH) (Chapter 3, GDH defined by accumulation of hours substrate is of above a baseline of $7^{\circ} \mathrm{C}$ ). An understanding of the potential positive value of these abiotic attributes for growing seedlings would be gained through comparative measurements of active seedling growth for seedlings growing on wood microsites and seedlings growing on soil substrates.

Although seedlings growing in areas with less overstory canopy benefit from having warmer substrates, increased likelihood of exposure to intense solar radiation may make seedlings prone to photoinhibition (Cui and Smith 1991, Germino and Smith 1999, Germino et al. 2002). Photoinhibition occurs when excess excitation caused by high levels of light radiation arriving at the photosystem II reaction center in the chloroplast leads to its inactivation and damage (Long et al. 1994) thereby inhibiting photosynthesis (Taiz and Zeiger 2006). Photoinhibition, typically occurring when periods of nighttime freezing are followed by clear days, has been repeatedly observed in tree seedlings growing near alpine treelines (Ball et al. 1991). Low chlorophyll a content may be an indicator of photoinhibition damage (He et al. 2006). Chlorophyll a content is also an 
indication of nitrogen content and is therefore useful in the examination of nutrient limitation for growing seedlings. In my previous study (Chapter 3), it appeared that damage of seedlings by photoinhibition could be less common at Pacific Northwest (PNW) sites than locations having more continental climates.

Measurements of stomatal conductance and water potential are used to understand water limitation for growing trees. Stomatal conductance, an indicator of respiration assuming evaporative demand is constant, is equivalent to the amount of water plants can acquire from belowground sources (Collatz et al. 1991, Wullschleger et al. 1998). Plant water potential is an indicator of moisture stress (Kramer 1995), particularly pre-dawn water potential, serving as an indicator of soil water availability in the zone of roots (Donovan et al. 2003).

Physiological aspects of seedlings regenerating on wood have been studied relatively little either at low or high elevation sites. One exception was a study of plant physiology of $>100 \mathrm{~cm}$ tall Rhododendron calophytum in a subalpine $3000 \mathrm{~m}$ elevation conifer forest in China which showed increased seedling growth and increased stomatal conductance on severely decomposed wood substrates (Ran et al. 2010). Studies linking abiotic factors (including temperature, moisture, and nutrient availability) to physiologic trends for young seedlings $(<4 \mathrm{~cm})$ growing on wood appear to be absent from the literature.

As far as I know, no studies have evaluated seedling tree physiology on wood substrates at the timberline-alpine meadow fringe. The goal of this study was to determine if the greater temperature and greater moisture of wood microsites, as 
compared to adjacent soil substrates (Chapters 2 and 3), provided enhanced measures of active growth for seedlings. For this study, physiologic measures of plant growth activity and plant stress included measurements of stomatal conductance and water potential. Further, this study aimed to determine whether photoinhibition damage to seedlings was common. To quantify potential effects of photoinhibition, leaf chlorophyll a content and total nitrogen content were measured on Abies sp. in the North Cascade Mountains of Washington State. For this examination, three main hypotheses were tested to compare seedlings on wood and soil substrates for low, medium, and high radiation categories:

$\mathrm{Ho}_{1}$ : No difference in stomatal conductance for seedlings on wood and soil substrates, $\mathrm{Ho}_{2}$ : No difference in plant water potential for seedlings on wood and soil substrates, and $\mathrm{Ho}_{3}$ : No difference in total chlorophyll a for leaves of seedlings.

In addition, site attributes most influential for predicting stomatal conductance were assessed. Site attributes included substrate temperature, moisture, leaf temperature, and percent transmitted radiation.

\section{Study Sites}

Four sites were selected in the North Cascades of Washington State. These sites were chosen from a subset of those described in Chapter 3 (Fig. 25). Site selection criteria, described in earlier chapters (Chapters 2 and 3), included $<$ three-hour hiking 
distance from roads, notable seedling regeneration, lack of forest harvesting, and lack of recent forest fires.

Of the four sites, two were located within the Tsuga mertensiana Zone on the west and two were located in the Abies lasciocarpa Zone on the east, and both zones include subzones of closed forest and upper parkland (Franklin and Dryness 1979). The Tsuga mertensiana Zone, includes Abies amabilis and Chamecyparis nootkatensis. The Abies lasciocarpa Zone is more continental with cooler temperatures and includes Picea engelmannii, Pinus contorta, Abies grandis, Larix lyallii and Pinus monticola (Franklin and Dryness 1979). I estimate that at least $90 \%$ of the seedlings were Abies lasciocarpa and Abies amabilis, therefore, I refer to conifer species as Abies $s p$. in this study. The herbaceous families Poaceae, Ericaceae, and species including Vaccinium $s p$. and Veratrum viride were commonly found on soil substrates, whereas on wood microsites plants were limited to conifer seedlings and moss (Chapter 2). Throughout much of the Cascade Mountains Abies lasciocarpa grows as a shade-intolerant, seral species and is gradually replaced by more shade-tolerant associates such as Abies amabilis, Abies grandis, and Tsuga mertensiana (Franklin and Mitchell 1967).

The sites spanned a precipitation gradient from nearly $250 \mathrm{~cm} / \mathrm{yr}$ on the western most site to $150 \mathrm{~cm} / \mathrm{yr}$ on the east side of the Cascades with site timberline elevations ranging from 1585 on the west side to $1996 \mathrm{~m}$ on the east side. Mean annual temperature averaged $4.1^{\circ} \mathrm{C}$ on the west side and $3.0^{\circ} \mathrm{C}$ on the east side (Table 7, Fig. 25).

In general, the geology is volcanic on the west side and sedimentary on the east side, with intrusive volcanics in the mid-range. Soils are well-drained Cryorthods, and 
have textures ranging from fine sandy loam to sandy gravelly loam. At my sites, organic horizon depths ranged from 0.5 to $1.0 \mathrm{~cm}$. Total depth of the soil to bedrock ranged from $0.2 \mathrm{~m}$ to $1.0 \mathrm{~m}$ with A-horizons ranging in depth from 0 to $0.2 \mathrm{~m}$ (USDA, NRCS 2008).

\section{Methods}

Measurements of water potential, stomatal conductance, leaf temperature, and substrate moisture were taken on rain-free days during three time periods during the 2011 growing season: early (mid-July), mid-way (mid-August), and late (mid-September). For each site for the each of the three sampling periods, three measurements of stomatal conductance, volumetric water content, and leaf temperature (mid-August only) were taken within each of the three percent transmitted radiation categories (Figs. 26, 27; see Chapter 3 for description of percent transmitted radiation categories for each substrate type). For each visit per each radiation category, only one measurement of water potential was made for a randomly selected seedling to minimize destructive sampling of the seedlings. Because of possible variation in physiologic measures for different species of seedlings, care was taken to select species of Abies sp., the species most dominant at all sites.

To measure plant water potential, a Pump-up Pressure Chamber (Plant Moisture Stress Instruments, Albany, OR) was used to measure pre-dawn water potential. Plant water potential measurements were made by placing a seedling specimen in the pressure chamber with the cut stem sealed and protruding from the chamber to atmospheric pressure, sealing, pressurizing the vessel, and noting the pressure at which the sap first 
exudes from the xylem of the plant. Bark removal from the seedlings eliminated confusion with phloem exudes (Plant Moisture Stress Instruments, personal communication). Plant water potential measurements were taken on three $<3 \mathrm{~cm}$ seedlings on and off of wood microsites in each radiation class (Figs. 26, 27; described in Chapter 3). Water potential was made in the early morning (giving an indication of soil moisture). Stomatal conductance measurements were made mid-day. Plant water potential was also made later in the day in conjunction with measures of stomatal conductance.

Stomatal conductance was quantified with a porometer (Decader Devices, Pullman,WA). Newly growing clusters of needles extending from the apical meristem of seedlings were placed in the stomatal conductance chamber. Once equilibrium of water content was reached, measurements were made. Effort was made to make measurements on similar aged seedlings having approximately the same number of needles (generally, 3 or 4) in the chamber.

Leaf chlorophyll a content was determined for seedlings growing at low, high, and high radiation categories at the four sites. Several seedlings were clipped within each radiation category and were placed on ice until lab analyses could be conducted. In the lab, needles were removed, samples were ground in a mill, $200 \mathrm{mg}$ samples were put into a solution of $90 \%$ acetone and $10 \%$ DI water, and placed in a freezer overnight to extract the chlorophyll (Bowden et al. 1992). Sample were then centrifuged at $1500 \mathrm{rpm}$ for 20 minutes and fluorescence of the supernatant was measured on a fluorometer (Turner Designs, TD-700, Sunnyvale, CA) using a chlorophyll a filter set (Tett et al. 1975). 
Wood and soil temperatures were measured at the same time as stomatal conductance measurements among seedlings growing on wood microsites; both measurements were taken at depths of $7 \mathrm{~cm}$. Generally, the soil measurements were made between 0.3 to $1.0 \mathrm{~m}$ from the wood microsite measurements. These distances ensured that soil temperature measurement were made sufficiently close, yet distant enough from logs to ensure that soil temperature was not influenced by the shade of the log.

To assess temperature of surfaces undergoing stomatal conductance, leaf temperature was taken with a mini infrared thermometer having a $\mathrm{D}: \mathrm{S}$ ratio of $1: 1$ (measures a $1 \mathrm{~cm}$ area at $1 \mathrm{~cm}$ distance; Dwyer Instruments, Inc., Michigan City, IN). Leaf temperature was measured only during the August sampling period.

Volumetric water content was measured in substrates in the vicinity of the plant measurements with a Field Scout TDR Soil Moisture Meter (Spectrum, Technologies, Plainfield, IL) during the same time periods as the stomatal conductance measurements. The device was calibrated for sand-silt loams on soil substrates and had rod lengths of 7.2 cm (3 in). On wood substrates, the device was calibrated following an experiment whereby 10 known volumes of water were added to a known volume of rotten wood. To develop a suitable volumetric water content relationship, this procedure was conducted three times and the results were averaged (Spectrum, Technologies, Plainfield, IL; personal communication). 


\section{Statistical analysis}

Nested analysis of variance (ANOVA) tests were conducted for associations between temperature, moisture, plant water stress, and stomatal conductance for the three levels of overstory canopy. For each of the four sites (replicates), three subsamples for each shade type were averaged for each of the three measurement time periods. For wood and soil substrates combined, one-way ANOVA tests were conducted for assessments of stomatal conductance by radiation level and for stomatial conductance by subsrate moisture level. If significant, subsequent Tukey analysis were conducted $(p=$ 0.05). Regression analysis of plant water stress measurements was used to decipher the role of one or more variables for predicting stomatal conductance. These predictors include total chlorophyll, substrate water content, substrate temperature, site radiation, leaf temperature, and water potential.

Differences in plant water conditions and site temperature and moisture conditions were tested between eastern most sites and western most sites with t-tests. Subsamples taken within each shade class were averaged for each of the four sites. All statistical analyses were performed using R 2.7 (R Development Core Team, 2008).

\section{Results}

\section{Stomatal conductance}

No differences were found for mean stomatal conductance of seedlings growing on wood and soil substrates or for seedlings growing on wood and soil substrates having low, medium, or high radiation ( $p=0.30, \mathrm{n}=17$ to 55 per substrate/shade category, Fig. 28). 
There was significant increase of stomatal conductance with increasing VWC for seedlings growing on wood only for areas with high radiation $\left(p=0.03, \mathrm{r}^{2}=0.24 ; \mathrm{p}<0.1\right.$ for all other regressions; Fig. 29a). No significant differences were found for low $(<14 \%)$, medium $(14-20.9 \%)$, or high $(>22 \%)$ VWC for the two substrates $(p=0.58, \mathrm{n}$ $=2$ to 10 per substrate/VWC category, Fig. 29b). Stomatal conductance increased significantly with increasing VWC in September when combining wood and soil substrates in areas having $>25 \%$ incoming radiation $\left(p=0.004, \mathrm{r}^{2}=0.44\right.$; Fig. 30).

No significant relationship was found for stomatal conductance versus wood or soil temperature $(p=0.7)$. No difference in stomatal conductance was found for low $(<$ $\left.7^{\circ} \mathrm{C}\right)$, medium $\left(7-9^{\circ} \mathrm{C}\right)$, or high $\left(>9^{\circ} \mathrm{C}\right)$ categories of substrate temperature for sites combined or by sites in the high percent transmitted radiation category $(p=0.84, \mathrm{n}=0$ to 29 for substrate/termperature categories).

For the month of August for wood and soil substrates together, stomatal conductance was negatively related to leaf temperature $\left(\mathrm{r}^{2}=0.16, p=0.0007\right.$, Fig. 31a). Combining wood and soil substrates, greater stomatal conductance was found for medium radiation sites than high radiation sites $(\mathrm{p}=0.008 ; \mathrm{n}=32,33$, and 9 for low, medium, and high radiation categories, repectively). For combined wood and soil substrates categorized by a $14^{\circ} \mathrm{C}$ threshold, greater stomatal conductance was found for leaf temperatures less than $<14^{\circ} \mathrm{C}$ indicated differences in stomatal conductance (117.7 versus $71.6 \mathrm{mmol} \mathrm{m}-2 \mathrm{~s}-1, p<0.001 ; \mathrm{p}=35$ and 28 for $<14$ and $>14$, respectively; Fig. 31c). 
A classification and regression tree (CART) for classifying stomatal conductance indicated major splits at elevation, VWC, and substrate temperature (CP values of 0.1, 0.07, and 0.03, respectively; Fig. 32).

\section{Water potential}

Early morning seedling water potential was less negative for wood than soil $(p=0.007$, $n=69$ for wood and 54 for soil, -4.9 and -6.1 , respectively, Fig. 33a) and water potential for wood was less negative than soil in July, August, and September $(p \leq 0.02$ for all comparisons, $\mathrm{n}=$ to 22 to 25 for wood and 15 to 21 for soil). Seedling water potential decreased significantly over the sampling period for seedlings growing on both wood and soils $(\mathrm{p}<0.05)$. Water potential was not significantly different for radiation categories of wood and soil ( $p=0.89, \mathrm{p}=14$ to 30 for wood and 18 to 24 for soil, Fig. 33b). There was no significant relationship between water potential and volumetric water content $(p>$ $0.05)$.

\section{Seeding leaf chlorophyll a content}

No significant differences were found between leaf chlorophyll a content of seedlings growing on wood and leaf chlorophyll content for seedling growing on soil substrates ( $p$ $=0.85, \mathrm{n}=11$ and 8 for wood and soil substrates, respectively) or by substrate and by low, medium, and high percent transmitted radiation $(p=0.1693, \mathrm{n}=1$ to 5 per substrate/radidaiton category). Chlorophyll a level did not have a positive relationship with nitrogen level $(p=0.99)$. 


\section{Discussion}

\section{Stomatal conductance and plant water potential}

This study elucidated possible advantages of wood substrates given increase in drought stress associated with warmer substrate temperatures. My measurements of stomatal conductance and early-morning water potential on 3-to 6-yr old seedlings $(<4 \mathrm{~cm})$ at timberline-alpine meadow borders indicated that Abies sp. seedling growth was not limited by substrate temperature, as indicated by active stomatal conductance for substrates having temperatures below $5^{\circ} \mathrm{C}$. Further, stomatal conductance was not significantly less in areas having low or high radiation. Overall, stomatal conductance was greatest at sites with moderate levels of radiation. For east side sites, moderate levels of radiation were also associated with more growing degree hours for wood than soil (accumulated substrate temperature $>7^{\circ} \mathrm{C}$, Chapter 3 ). Stomatal conductance was significantly higher at sites having higher VWC, sites generally located in low or moderate radiation sites. When comparisons of stomatal conductance were made at high radiation sites (sites having low to high VWC), significant increases in stomatal conductance were associated with increase in VWC. Because higher densities of seedlings with access to more moisture were typically found on wood microsites, it can be presumed that seedlings growing on wood substrates have an advantage.

Sites with a wide range of VWC were most helpful in deciphering the effects of moisture on plant activity. Although water potential of seedlings growing on rotten wood at the timberline edge was less negative than water potential of seedlings growing on soil, this difference did not demonstrably enhance stomatal conductance. As found elsewhere, 
plant water potential rarely became less negative than -1.5 bar for seedlings older than two yrs (Picea engelmannii and A. lasiocarpa; Johnson et al. 2004) and measures of plant activity did not respond to changes in plant water above this water status (Maher et al. 2005).

My finding of significant increases in seeding stomatal conductance on wood substrates within drier locations of the PNW is similar, by not nearly as dramatic as the results found for seedlings growing on wood in a colder and drier climate. In high elevation subalpine forests of Dawadang Mtn., China, greater stomatal conductance for Rhododendron calophytum saplings growing on rotten wood was attributed to higher moisture and more nutritious substrate than adjacent soil (Ran et al. 2010). Although my study and the study on Dawadang Mt both had abundant downed wood and similarity in mean forest tree height $(20 \mathrm{~m})$, my sites had warmer mean annual temperatures and mean warmest month $\left(2.4-5.8\right.$ versus $1.5^{\circ} \mathrm{C} ; 12.6-15.4$ versus $6^{\circ} \mathrm{C}$; mean annual temperature and mean warmest month, respectively), more rainfall $(150-240 \mathrm{~cm}$ versus $86 \mathrm{~cm})$, and different rainfall timing (most precipitation occurs from November to June in the PNW and from May and August at Dawadang Mtn.). Differences in apparent role of wood for seedling growth may also be attributed to species type, height, and water uptake requirements $(<3 \mathrm{~cm}$ conifers in my study versus deciduous species $>100 \mathrm{~cm}$ in height). Although it has been suggested that increasing soil temperatures are likely to advance timberlines due to better growing potential of trees (Saxe et al. 2001), my study did not show any increases in stomatal conductance with increased soil temperature. In contrast, results of this study suggest that increasing temperatures are associated with 
increases in drought. These increases are also associated with reduced seedling densities and reduced survival of natural and transplanted seedlings (Chapters 2 and 3). Insight into the role of drought on stomatal conductance was gained at my high radiation locations during the month of September. During this time, sites had the least moisture with moderate temperature levels. Because stomatal conductance was higher at sites having additional moisture during this time, it can be surmised that given a range of moisture availability, sites with both plenty of light and plenty of water will have enhanced measures of plant activity.

\section{Chlorophyll a content}

Like others, I found no significant differences in leaf chlorophyll a concentrations or leaf $\mathrm{N}$ concentration growing on wood and soil substrates. Elsewhere, non-significant differences in chlorophyll a pigment concentrations have been attributed to small variation in water availability between different substrates (Ran et al. 2010). As suggested in Chapter 3, lack of difference in chlorophyll a and $\mathrm{N}$ content at sites with varying levels of radiation suggests that photoinhibition is not as important a phenomenon at PNW timberline locations as it is in other locations such as the Rocky Mts. 


\section{Conclusion}

This study evaluated potential differences in seedling growth activity for 3-to-5 yr old seedings growing on rotten wood and soil substrates. Measurements included stomatal conductance, water potential, and leaf chlorophyll a content. Although there were no differences in stomatal conductance overall, evaluation of sites having the greatest of three percent transmitted radiation categories indicated significantly greater stomatal conductance with increased volumetric water content. Early morning water potential of seedlings growing on rotten wood at the timberline edge, found to be significantly less negative than water potential of seedlings growing on soil, did not demonstrably enhance stomatal conductance. Lack of difference in chlorophyll a and $\mathrm{N}$ content for seedlings growing at sites with varying levels of radiation suggests that photoinhibition is not as important a phenomenon at PNW timberline locations as it is in other high elevation continental ATE locations.

This assessment of possible physiological advantages of wood microsites at the upper limit of subalpine forests contributes to a larger body of literature suggesting the importance of wood microsites for seedling regeneration. In a climate characterized by increasing droughts, wood microsites at timberline-alpine meadow borders may facilitate seedling growth of germinating seedling better than adjacent soil substrates due to greater water content. 
Table 7. Characteristics of four study sites and mean climatic variables.

\begin{tabular}{r|cccccccc}
\hline $\begin{array}{l}\text { Site } \\
{[1]}\end{array}$ & $\begin{array}{c}\text { Ele- } \\
\text { vation } \\
(\mathrm{m})\end{array}$ & $\begin{array}{c}\text { Longi- } \\
\text { tude }\end{array}$ & Aspect & $\begin{array}{c}\text { Slope } \\
\left({ }^{\circ}\right)\end{array}$ & $\begin{array}{c}\text { Annual } \\
\text { Precip. } \\
(\mathrm{mm})\end{array}$ & $\begin{array}{c}\text { Annual } \\
\text { Temp. } \\
\left({ }^{\circ} \mathrm{C}\right)\end{array}$ & $\begin{array}{c}\text { Summer } \\
\text { Rain } \\
(\mathrm{cm})\end{array}$ & $\begin{array}{c}\text { Summer } \\
\text { Temp. } \\
\left({ }^{\circ} \mathrm{C}\right)\end{array}$ \\
\hline $1,[9]$ & 1585 & -121.385 & 0 & 21 & 2370 & 4.0 & 20.0 & 12.6 \\
$2,[8]$ & 1676 & -121.062 & 250 & 35 & 1980 & 5.8 & 14.2 & 15.4 \\
$4,[6]$ & 1875 & -120.761 & 160 & 14 & 1580 & 3.6 & 10.6 & 14.2 \\
$5,[11]$ & 1996 & -120.668 & 85 & 23 & 1530 & 2.4 & 11.2 & 13.1 \\
\hline
\end{tabular}

*Temperature and rainfall information was obtained from DAYMET (15 y averages).

${ }^{1}$ Site numbers used in Chapter 2. 


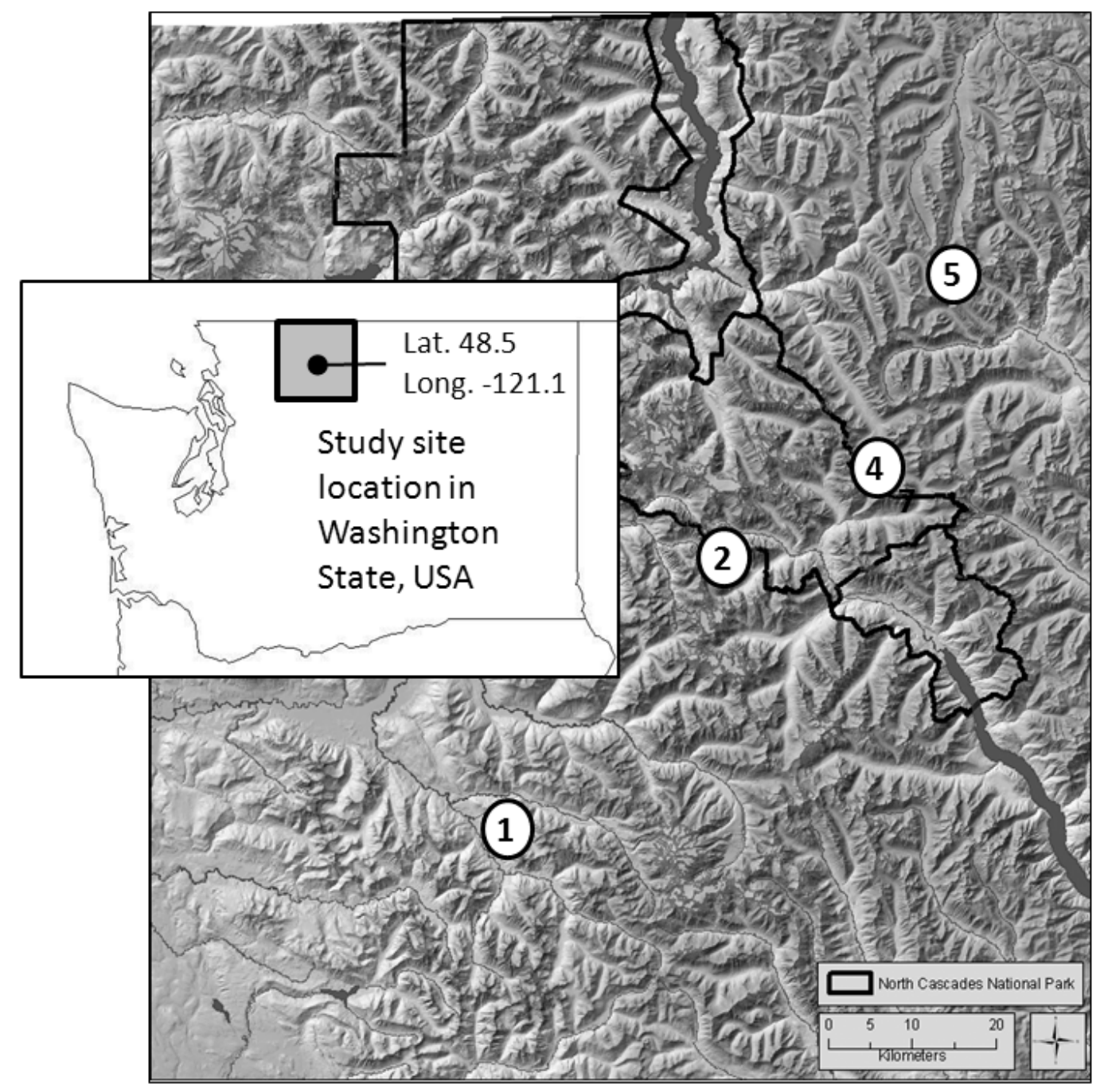

Figure 25. Location of the four study sites in Washington State, USA. 


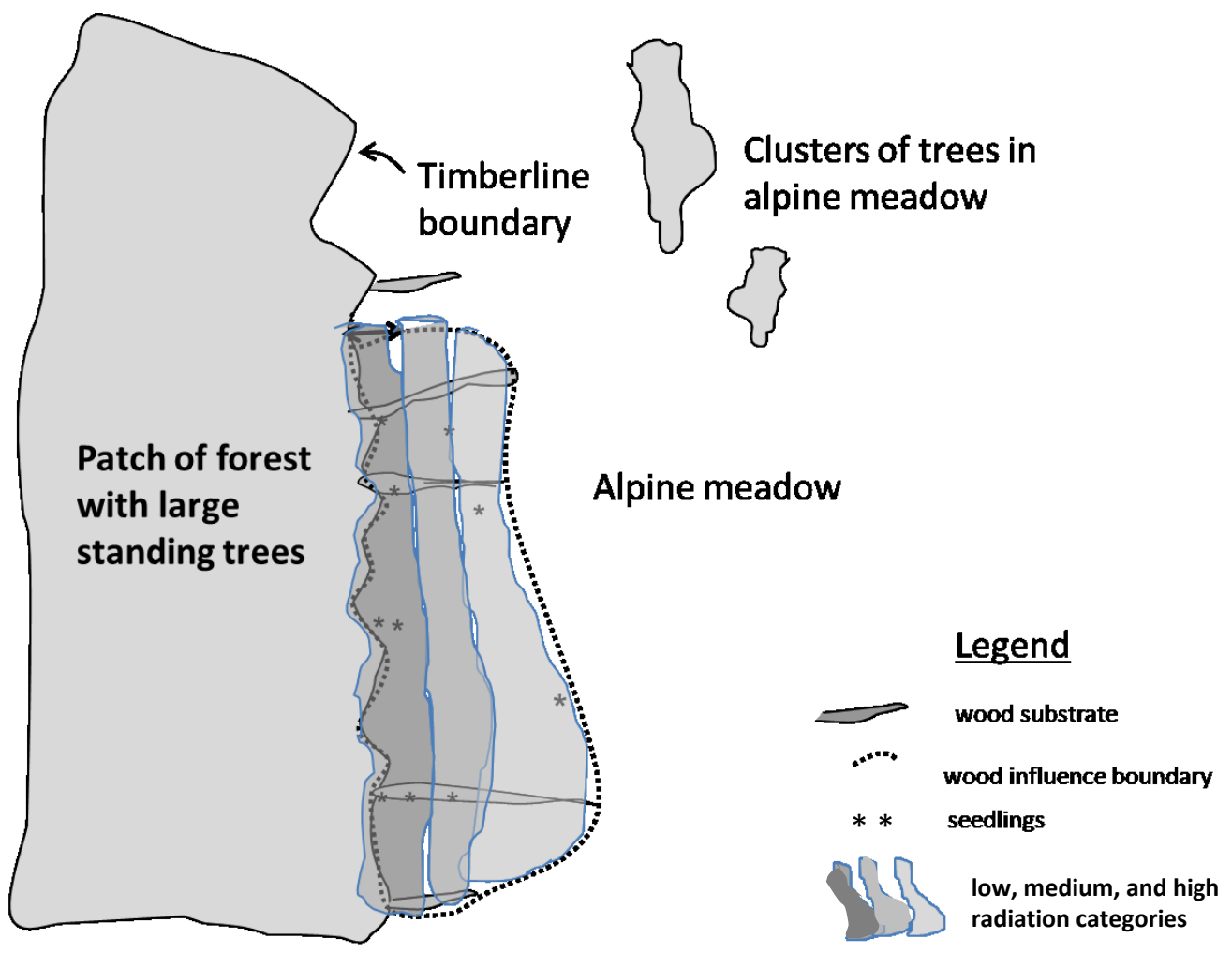

Figure 26. Patch of trees with canopy overstory categories from which measurements of radiation were calculated. 


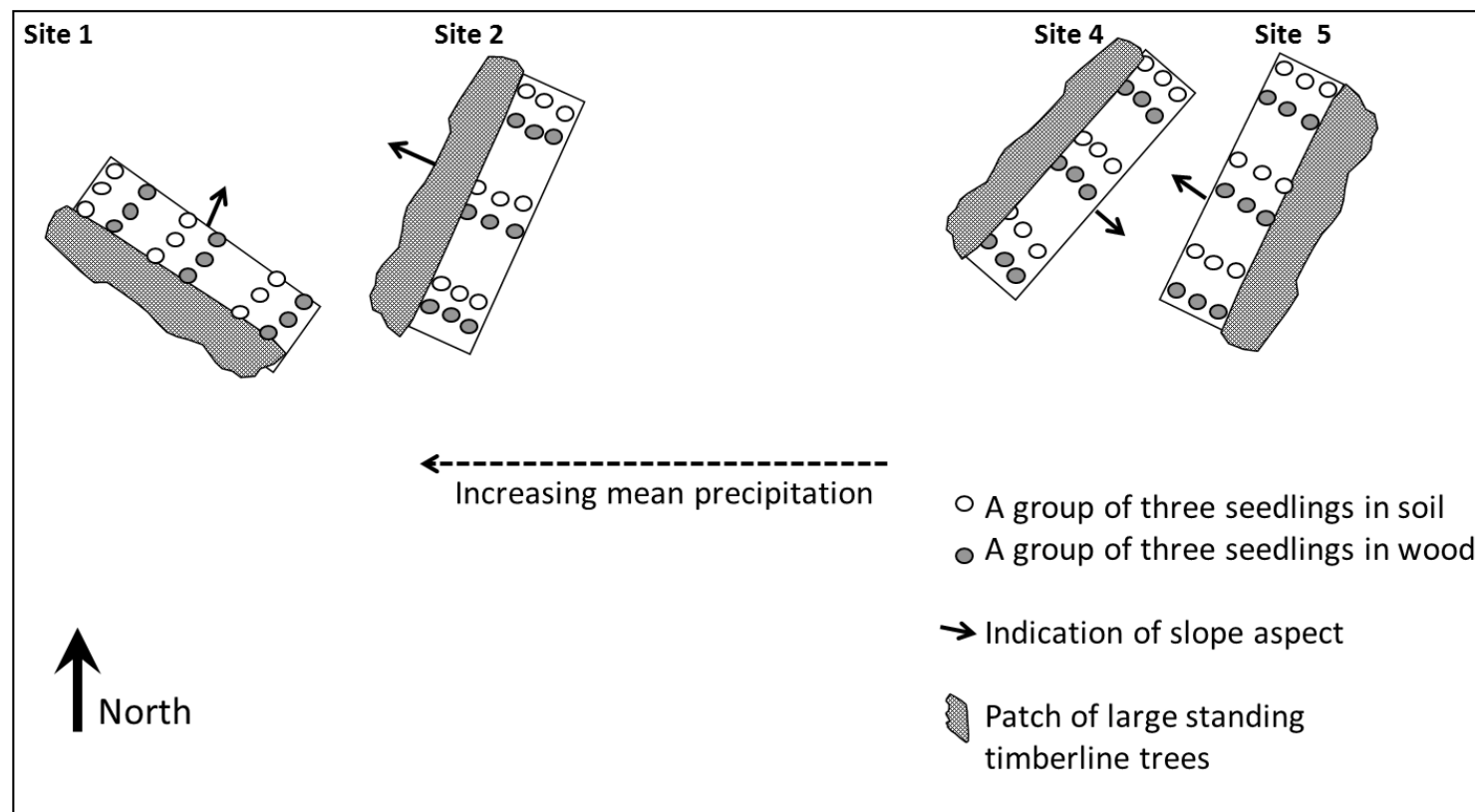

Figure 27. Site aspect and location of seedling clusters where measurements of stomatal conductance, water potential, and volumetric water content were made. 


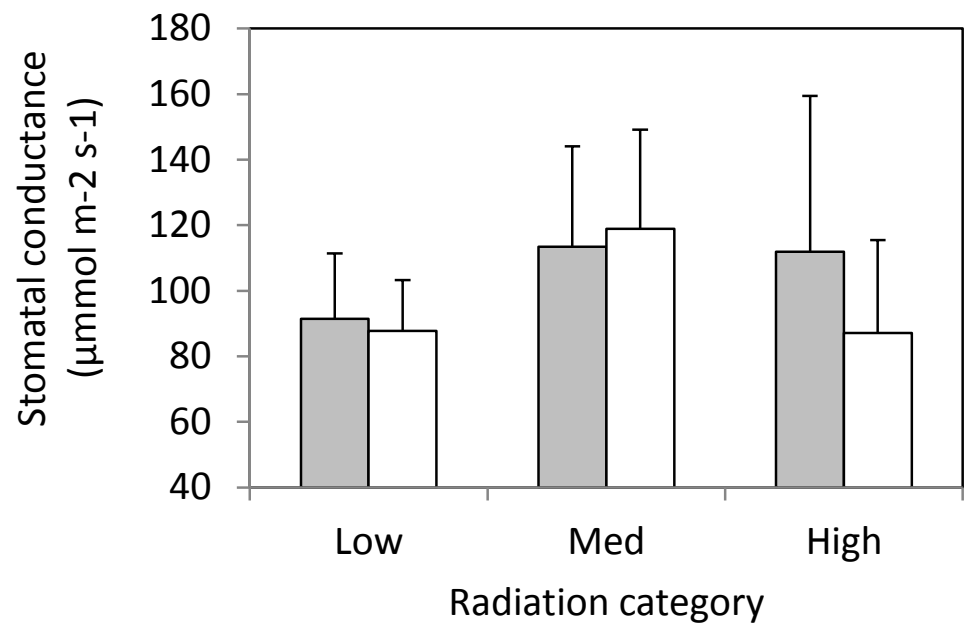

Figure 28. Barplots of stomatal conductant by radiation category. Means for four sites (each having three radiation categories) and $95 \%$ confidence intervals for stomatal conductance by radiation category for a) entire field season $(\mathrm{n}=$ ranges from 17 to 55 per bar, $p=0.31$ ) 


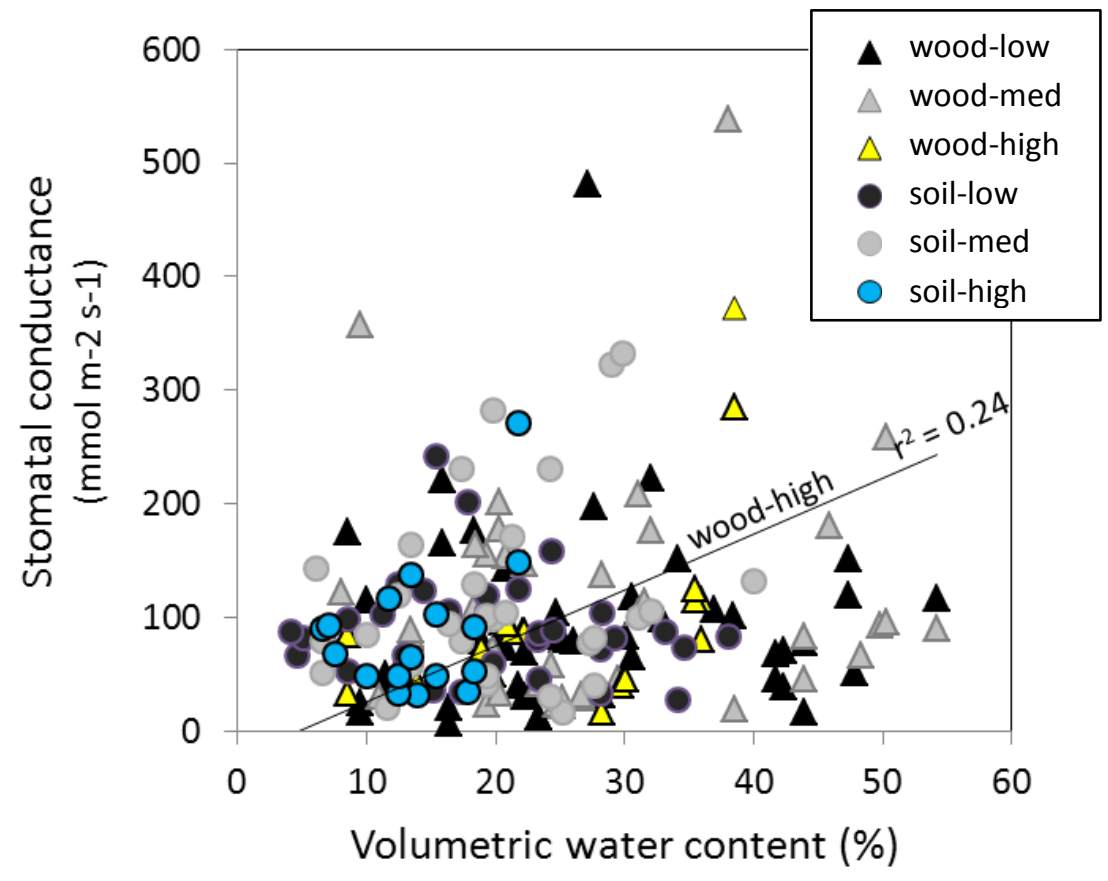

a)

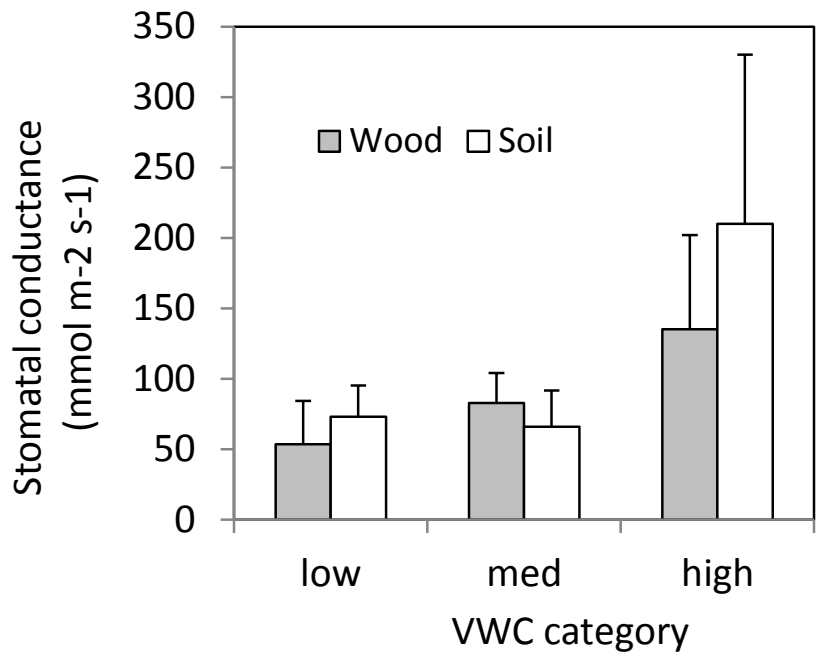

Figure 29. Stomatal conductance and site moisture. a) Stomatal conductance versus volumetric water content (VWC) for wood and soil with radiation category indicated. An increase in VWC for wood in the high radiation category (yellow triangles for wood) is associated with an increase in stomatal conductance $\left(p=0.03, \mathrm{r}^{2}=0.24\right)$, b) Barplots showing means and $95 \%$ confidence intervals for stomatal conductance by low $(<14 \%)$, medium (14 to $21 \%$ ), and high $(>21 \%$ ) categories of VWC. 


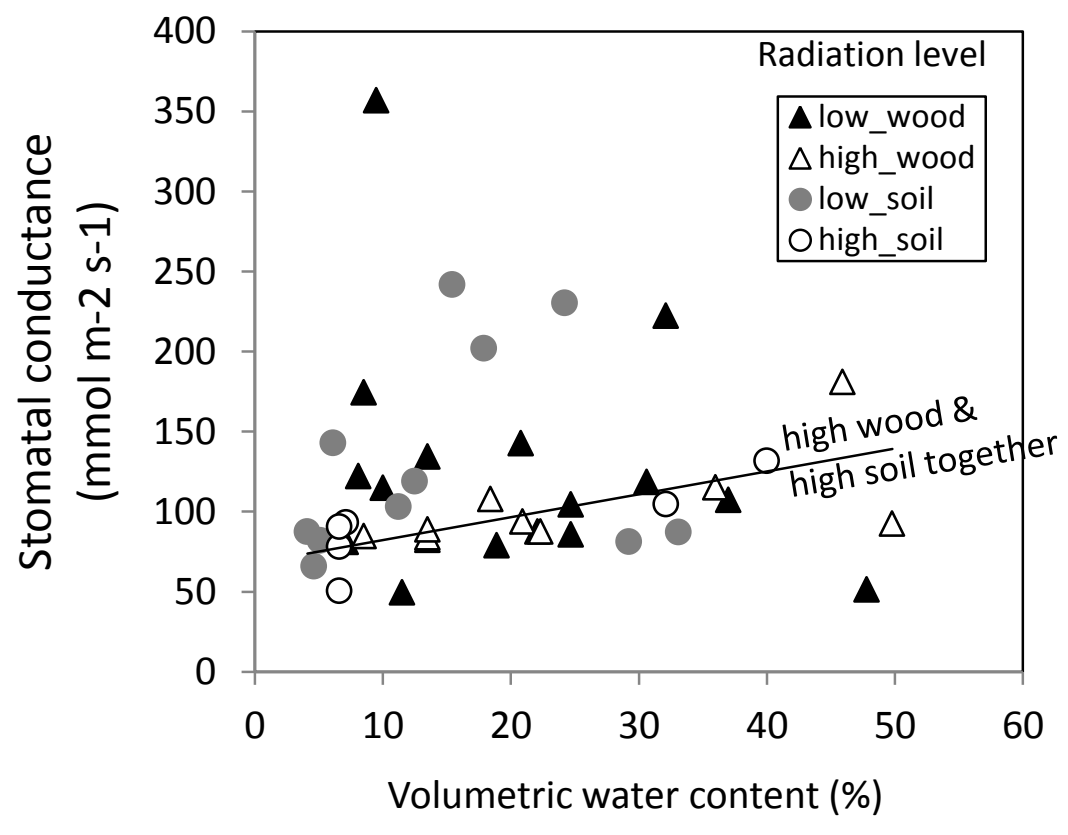

Figure 30. Stomatal conductance versus volumetric water content (VWC) for wood and soil in September when the VWC was lowest. Here, percent transmitted transmitted radiation considered high is $>25 \%$. For high radiation wood and soil sites combined, significant increases in stomatal conductance occured with increase in VWC $(p=0.004$, $\left.r^{2}=0.44\right)$. For substrates assessed by separately, no significant relationships exist ( $p>$ $0.1)$. 


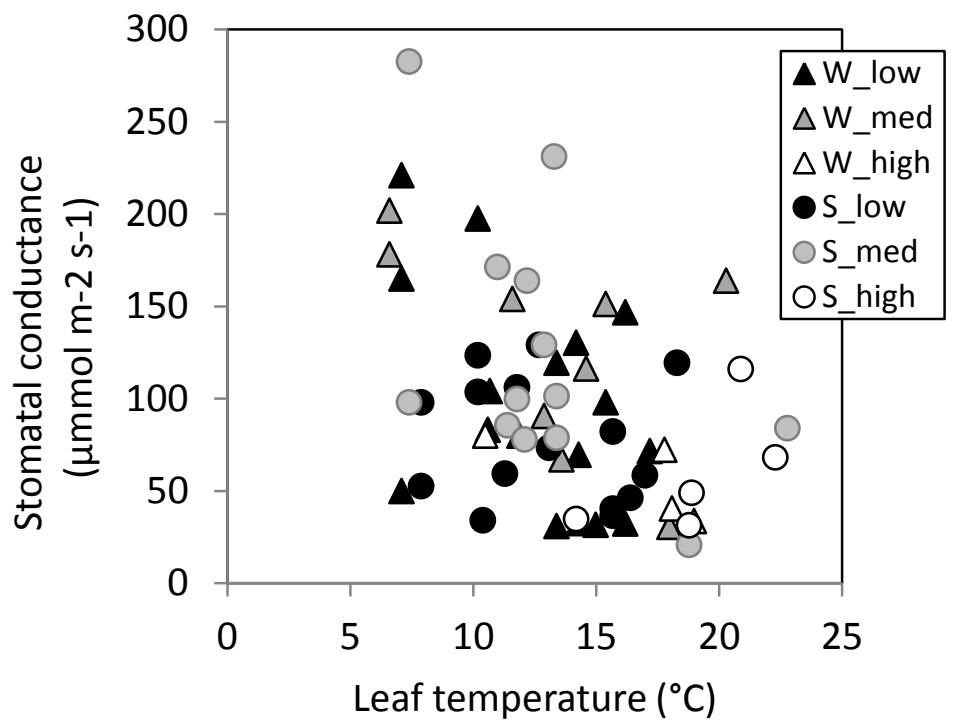

a)
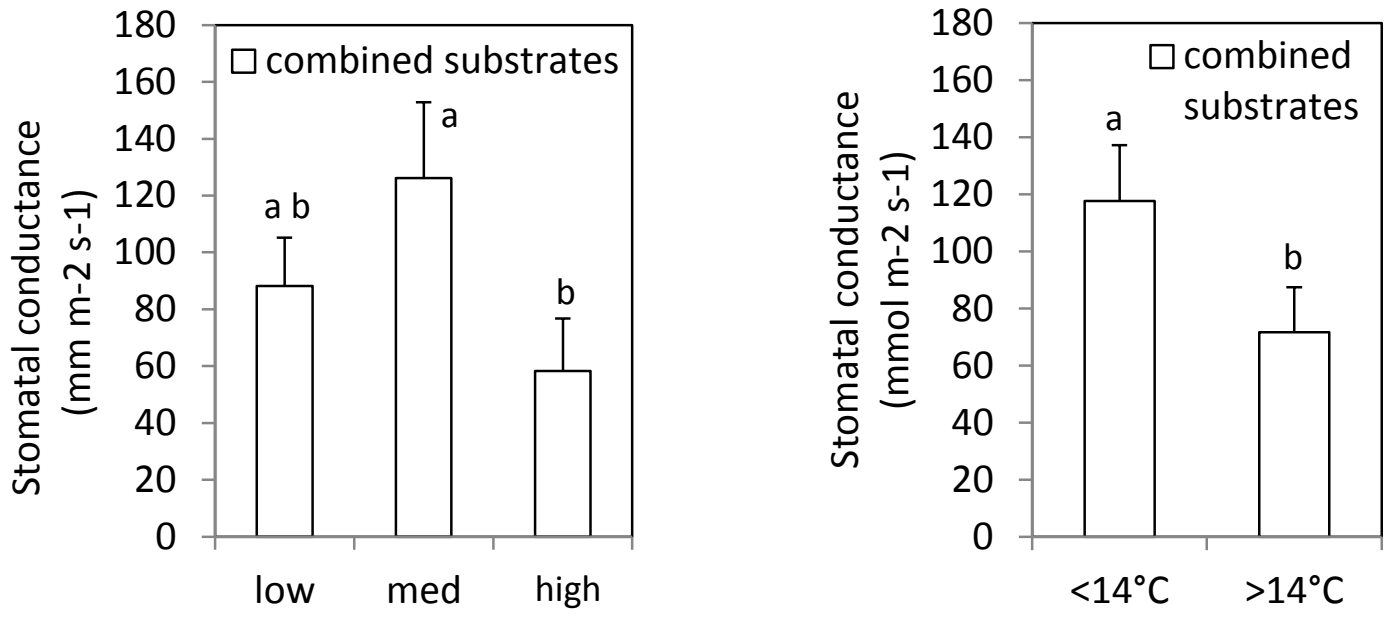

b)

Radiation category

c)

Leaf temperature category

Figure 31. Stomatal conductance and leaf temperature for seedlings on wood and soil substrates during the month of August. For four sites, each having three radiation categories stomatal conductance is presented: a) versus leaf temperature (for all sites combined, $p=0.0005, \mathrm{r}^{2}=0.17$ ); and by barplots showing means and $95 \%$ confidence intervals for $\mathrm{b}$ ) low, medium, and high levels of radiation for wood and soil substrates combined $(\mathrm{n}=32,22$, and 9 for low, medium, and high radiation categories, respectively; medium transmitted radiation had significantly higher stomatal conductance than sites with high transmitted radiation, $p=0.008)$, and by c) leaf temperature by $14^{\circ} \mathrm{C}$ threshold for seedlings on substrates combined $(\mathrm{n}=35$ and 28 for $<14^{\circ} \mathrm{C}$ and $>14^{\circ} \mathrm{C}$, respectively; $p<0.001$ ). Note: Significant differences are indicated by different letters. 


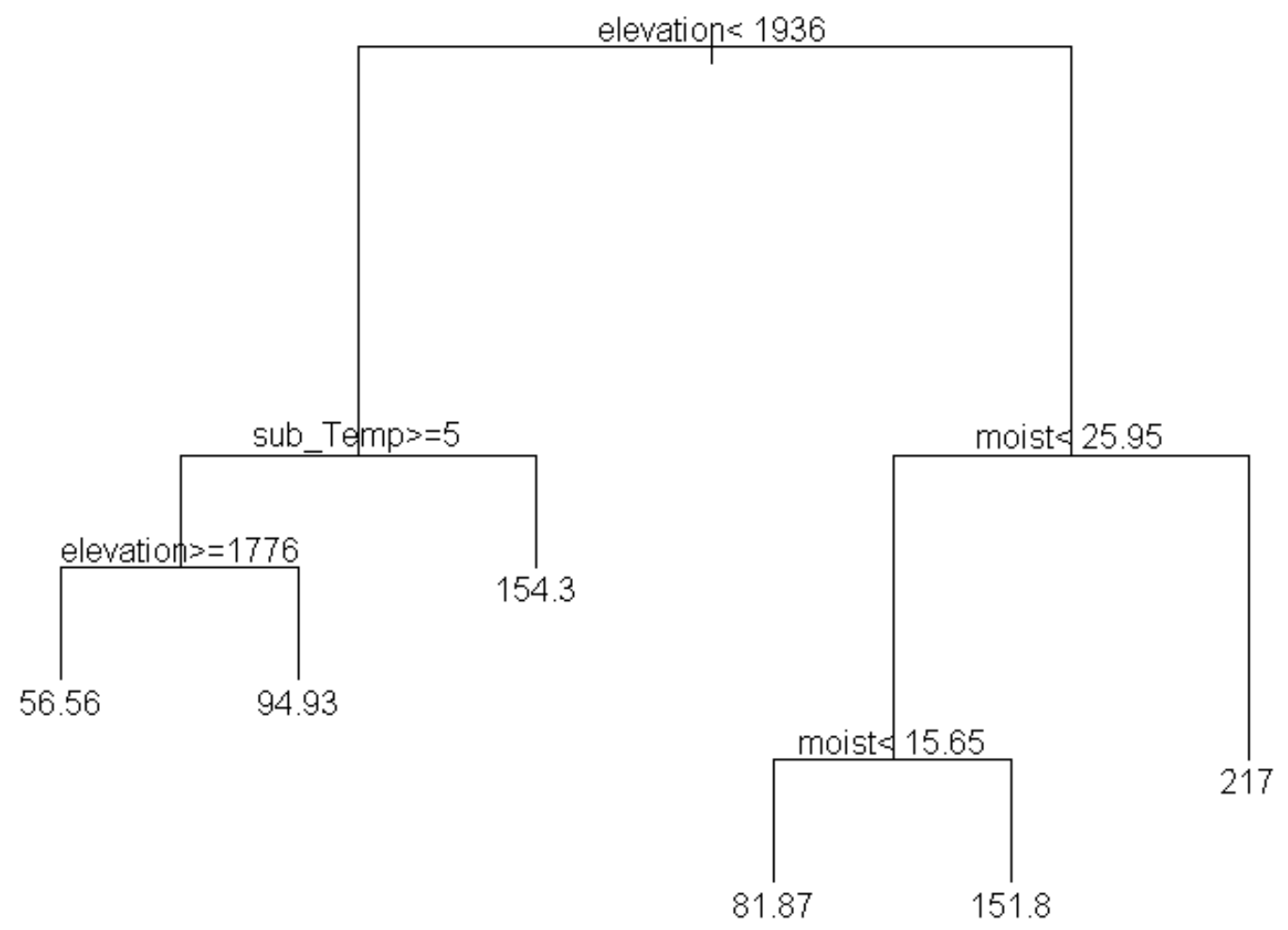

Figure 32. Classification and regression tree for prediction of stomatal conductance. Major splits (labels indicate split direction to the left) are elevation and moisture (volumetric water content). Elevation split at $1936 \mathrm{~m}$ represents a split between the most east site (5) in the Cascade Mts with the other sites $(1,2,4)$ having elevations below 1936 m. 


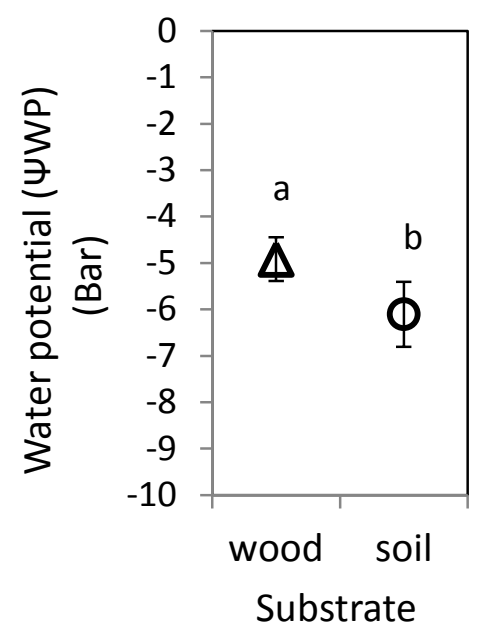

a)

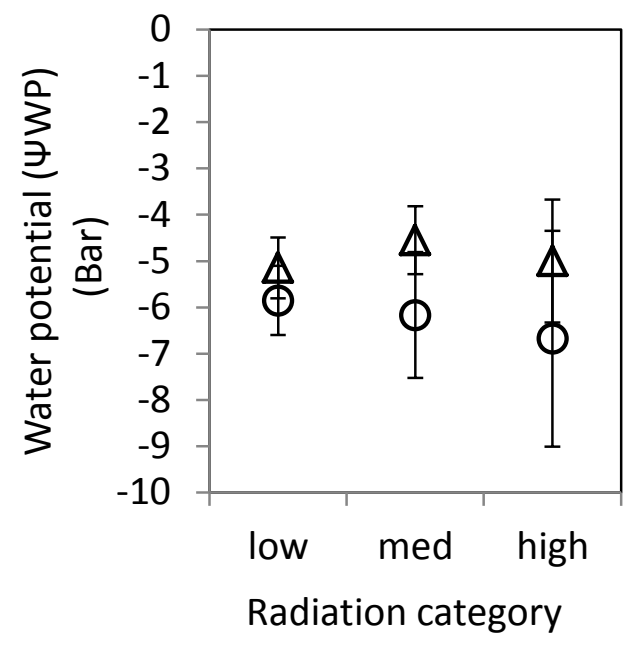

b)

Figure 33. Early morning water potential for seedlings growing on wood and soil substrates. Mean values and 95\% confidence intervals for: a) wood and soil substrates ( $\mathrm{n}=69$ and 54 per bar for wood and soil, respectively, $p=0.007$, wood is less negative), b) wood and soil substrates by radiation category ( $\mathrm{n}=$ ranges from 14 to 30 per bar, $p=0.89$ ). 


\title{
Chapter 5:
}

\section{Evaluation of Microsites Promoting Seedling Regeneration in the}

\author{
Alpine Treeline Ecotone: A Global Perspective
}

\begin{abstract}
Although alpine timberline forest advance and alpine meadow conifer invasion associated with climate warming is often associated with favorable microsites, there is no known global summary of microsite type along with regional climate and tree species association within alpine treeline ecotones (ATE). Such a summary accomplishes three goals: (1) to put wood microsites in the context of other microsites globally, (2) to relate regeneration on microsites with regional climate patterns, and (3) to create a means by which prediction of possible changes in regeneration patterns associated with climate warming could be better theorized. From 52 studies from 22 countries on five continents, five dominant microsite types were differentiated (terrain-related, elevations, depressions, wood, and shade/shelter-related) and relationships between microsites type and climate trends including annual precipitation and mean annual temperature were evaluated. Precipitation, ranging from 39 to over $300 \mathrm{~cm}$ per year, was different by both microsite type and by the most common tree genera in the ATE $(p=0.0033, p=0.027)$. Wetter timberlines, dominated by Abies sp., had more seedlings on topographic elevation microsites and wood microsites. I found that processes facilitating creation and use of wood microsites occurred in a wide range of high elevation forests having woody debris. It is suggested that the role of wood microsites at timberline-meadow and timberline-
\end{abstract}


grassland borders throughout the world is currently under-recognized as an important substrate facilitating conifer regeneration. This research suggests that global increase in temperature and associated increase in rainfall is likely to increase importance of wood microsites at locations with mean annual temperatures $<5^{\circ} \mathrm{C}$. With annual temperatures $>5^{\circ} \mathrm{C}$ it is possible that shade and terrain microsite types could dominate as seedling regeneration sites worldwide. Any changes in microsite importance will be dependent on precipitation pattern, frequency, timing, and magnitude.

Keywords: microsites, precipitation, timberline, regeneration, alpine treeline ecotone.

\section{Introduction}

Timberline locations, offering ideal sites for monitoring effects of global climate change, are conspicuous high-elevation forest edges located on all continents except Antarctica (Holtmeier 2009). Ecological response to climate change may vary because regional changes in temperature and precipitation are highly heterogeneous spatially and temporally (Walther et al. 2002). Possible upward advance of forests is dependent on a number of site-specific factors occurring within the broad alpine tree ecotone (ATE). Here, ATE is defined as the region extending from closed subalpine forest to treeline (Chapter 1, Fig. 1).

Factors influencing regeneration in the ATE include current forest age and structure, orographic influences such as snow avalanching and rock fall, viability of seed supply, limits on carbon sequestration and utilization, animal and insect herbivery, fire 
history, human impacts, and localized microsite availability (Malanson et al. 2007, Holtmeier 2009). Microsites may enhance survival and growth of seedlings at the ATE where growth is often limited due to stressful growing conditions including high wind speeds, high radiation, cold air and soil temperatures, soil pathogens, and short growing season due to snow cover (Baig and Tranquillini 1980; Wardle and Coleman 1992, Calloway 1995, Zhong and van der Kamp 1999, Bansal and Germino 2008). At the local scale, microsites may ameliorate temperature extremes, enhance moisture, and decrease solar radiation at sites where seedlings become established (Holtmeier 2009).

A summary of general microsite trends at a range of ATE locations would enhance understanding of site conditions promoting seedling growth in a variety of climatic settings. In general, microsites have been classified on the basis of broad topographic landforms such as slope and aspect; substrate microtopography including convexities, concavities, and flat surfaces; substrate type including various soils and wood; and by the shadow influence of trees and rocks that alters wind and radiation pattern (Hunziker and Brang 2005, Holtmeier 2009). Sites may be influenced by multiple microsites, but often, one microsite may appear to have the greatest effect on ameliorating one or more abiotic stressors.

Locally, associations have been made between microsite type, site location, and seedling species. In general, enhancement of local moisture, increased growing season, and protection of seedlings from frost stress and wind are emphasized as reasons for seedling survival on particular microsites. For example, in assessing growth of subalpine trees in the Front Range of Colorado, USA, slope aspect and steepness were found to be 
the most critical site factors influencing air temperature and soil moisture pattern thereby influence spatial pattern of Pinus engelmanni and Abies lasciocarpa (Villalba et al. 1994). In Ecuador, lower altitude tree lines on east-facing slopes have been related to radiation received by east-facing slopes in the clear mornings, resulting in photoinhibition of Polylepis seedlings (Cierjacks et al. 2007). In the U.S. Rocky Mountains, Abies lasciocarpa and Picea engelmannii have been linked to shadow effects of tree clumps (Butler et al. 2004, Hättenschwiler and Smith 1999, Maher et al. 2005, Daly and Shankman 1985). Shading the ground by the canopy reduces winter/spring sun radiation and night time radiation, reducing the risk of winter desiccation (Kullman 2007). Pinus albicaulis survival in the Beartooth Plateau, Montana, is linked to caches of the Clark's nutcracker on the leeward side of trees (Mellmann-Brown 2005). Survival of Pinus cembra seedlings is associated with south facing slopes of the Austrian Alps (Li and Yang 2004). In the Caucasus Mountains of Georgia, north Finland, Finnish Lapland, and the Swedish Scandes, Betula litwinowii, Betula pubescens, Picea abies and Pinus sylvestris seedlings, respectively, have been associated with small valleys and furrow microsites (Hughes et al. 2009, Kullman 1985, Autio and Colpaert 2005, Kullman and Öberg 2009; respectively). In the Pacific Northwest (PNW), Abies lasciocarpa and Tsuga meriensiana have been associated with ridges and convexities (Brink 1959, Lowery 1972, Rochefort and Peterson 1996) that can be as little as $50 \mathrm{~cm}$ above interridge depressions (Zald, University of Oregon, Forestry Department, personal communication). In the PNW, I found Abies lasciocarpa and Tsuga meriensiana seedlings on wood microsites extending into alpine meadows from timberline in the 
North Cascades of Washington, at Mt. Rainier, and in SE Alaska. Others have noted significant regeneration of Abies densa, Picea abies, and Rhododendron calophytum on wood microsites, in the subalpine forests of central Bhuton, European Alps, and mountainous southwest China (Gratzer 1999, Ziolonka and Niklossen 2004, Motta et al. 2006, Baier et al. 2007, Ran et al. 2010).

Although it has been emphasized that microsites may dictate locations for forest advance (Rochefort et al. 1994), studies describing the functional relationships between survival of seedlings and saplings and topographically-controlled site conditions in the alpine timberline ecotone are "still rare and are urgently needed" (Holtmeier and Broll 2007). Assessing these functional relationships in a broad variety of settings not only provides a basis for greater understanding of tree requirements given variation in regional climates, but also sets the stage for better prediction of how climate change will affect timberline locations given climate change.

Here, I assess microsites in a world-wide context in order to assess trends in successful regeneration in the ATE. The goal of this study was to assemble world-wide ATE microsite information, associate it with precipitation level, and make a first step in classifying site characteristics likely to shift with climate warming. The two specific hypotheses of the study include:

$\mathrm{Ho}_{1}$ : In comparing microsite preference for seedling regeneration globally, there is no difference in the mean annual precipitation or mean annual temperature for the five dominant microsites types. 
$\mathrm{Ho}_{2}$ : There is no relationship between microsite type and dominant tree species.

\section{Methods}

\section{Creation of the data set}

The initial data search included ten key search terms including: microsite, timberline, treeline, subalpine, alpine, mountain, seedlings, advance, precipitation, and regeneration. The key terms produced five microsite categories: (1) convex (also elevations and mounds), (2) concave (also including furrows, depressions, and mires), (3) shade (associated with vegetation, rock or wood), (4) topographic features (including aspect), and (5) wood substrates (including nurse logs). In this inventory, I included my on-going research on the role of nurse logs on seedling survival in the PNW. When compiling the dataset, duplicates of location/microsite/tree combinations were deleted. For example, if multiple studies in a specific area examined interactions of both a particular tree species on a similar microsite, only one reference was incorporated in the dataset. If precipitation was not indicated in the study used in the dataset, mean annual precipitation information was gathered from another source as close to the study area as possible. The resulting dataset consisted of 52 ATE locations, including 22 countries on five continents (Fig. 34). The data compiled included at least five examples of each microsite type (Tables 8, 9, and 10). Parameters compiled in the dataset included: microsite type, mean annual precipitation, mean annual temperature, dominant species, aspect (eight directions), slope (low $<10^{\circ}$, moderate $10-20^{\circ}$, and high $>20^{\circ}$ ), distance from ocean, and latitude. If a range of elevations were part of a study in the ATE, I averaged the elevation for the 
dataset. Slope and aspect was estimated from Google Earth imagery, if not included in the reference. If multiple aspects were included, I used the aspect associated with higher timberline or most successful regeneration. Creation of the dataset involved some subjective interpretation. For example, if it was stated that most seedlings grew on elevations (convexities or mounds) and regeneration appeared or was also implied to be influenced by overstory canopy, elevation microsites were used in the analysis because this reference was used because it was most dominant. If multiple variables were listed, it was assumed that the first one mentioned was dominant. It a range was listed, the end points were averaged.

\section{Statistical analysis}

One-way analysis of variance (ANOVA) tests assessed microsite type (five categories) with mean annual precipitation $(39-280 \mathrm{~cm})$, mean annual temperature $\left(-3.7^{\circ} \mathrm{C}-\right.$ $10.0^{\circ} \mathrm{C}$ ) and dominant species (Abies, Betula, Nothofagu, Picea, Pinus, Polylepis, and Tsuga). For data used, transformations were used to increase normality and decrease variance. Post-hoc multiple comparison tests (Tukey's) used when significant differences were detected. Statistical significance was assessed with $\alpha=0.05$ and all statistical analyses were conducted with the R statistics package (R Core Development Team 2005). 


\section{Results}

Mean annual precipitation was significantly different for microsites $(p=0.0033$; $\mathrm{n}=6,10,12,13$, and 11 for depression, elevation, shade, topographic, and wood microsites, respectively; Fig. 35). Wood microsites had greater precipitation levels than topographic microsites $(p=0.025)$. Elevated microsites had greater precipitation than broad topography and depression microsites $(p=0.045, \mathrm{p}=0.022$, respectively). Mean annual temperature was significantly different $(p=0.014)$ shade microsites having significantly greater temperatures than depression microsites ( $p=0.026$, Fig. 35).

Mean annual precipitation for species was significantly different $(p=0.027, \mathrm{n}=2$ to 14 per genus group, Fig. 36). Post-hoc Tukey analysis indicates that the Abies group had significantly greater annual precipitation than Picea and Pinus groups $(p=0.012 ; \mathrm{n}=$ 11, 14, and 9 for Abies, Picea, and Pinus, respectively; $p=0.040$, respectively). Mean temperature was not significantly different for any other species $(p>0.5)$.

Regression of all microsite types by annual temperature versus annual precipitation was not significant ( $p=0.62$, Fig. 37a). Regressions of annual temperature for wood, topographic-related, elevation, and depression microsites were not significantly related to annual precipitation $(p=0.57, p=0.30, p=0.98, p=0.39$; respectively, Fig. 37a). A significant positive relationship between annual temperature and annual precipitation was found for shade microsites $\left(p=0.045 r^{2}=0.34\right.$, Fig. 37a). 


\section{Discussion}

A better understanding of the range of tree species and climates associated with wood microsites was gained by summarizing global occurrence of wood microsites. As indicated by this summary of wood microsites globally, processes facilitating use of wood microsites occur in a wide range of high elevation forests having woody debris. These forests have mean annual precipitation ranging from $86 \mathrm{~cm}$ to $320 \mathrm{~cm}$ and annual temperatures ranging from 1.5 to 4.7 (Fig. 37b). The conceptual model of wood input, wood decay, and seedling use developed in Chapter 2 (Fig. 2) with applicability to all forested locations, was instructive for ascertaining the processes associated with wood microsite creation in other locations presented here. These forests, both tropical and temperate, had disturbances that introduced wood, promoted extensive wood decay, and facilitated seedling growth. Likely, the same processes that created microsites within these specific subalpine forests also created microsites at respective higher elevation timberline locations - providing that these timberlines were relatively pristine with no forest harvest or grazing. Given these observations, it is suggested that currently the role of wood microsites at timberline-meadow and timberline-grassland borders throughout the world is currently under-recognized and under-appreciated.

The role of wood microsites in a warming climate depends on multiple factors including timing, frequency, magnitude, and form of precipitation and snow melt pattern; wood decay rate; moisture holding capacity of wood substrates; and growing requirements of species growing on wood microsites. Global increases in temperature correspond with precipitation change estimates ranging from near zero (Smith et al. 
2006) to predicted increases in precipitation (Wentz et al. 2007), with precipitation changes expected to cause both shortage and excess precipitation in many regions (Zhou et al. 2011). Orography and latitude play a major role in effecting atmospheric circulation and climate with precipitation responses sensitive not only to the continental geometry, but also to the shape of nearby mountain ranges and wind flow direction (Beniston et al. 1997, Solomon 2007, Grunewald 2009). As indicated by our summary of microsites globally, dry and cool climates favoring regeneration on shade, elevation, and topographic microsites could shift to warmer and moister climates favoring seedling regeneration on wood microsites (see Fig. 37a). Gaps in summer rainfall may be associated with periods of drought, particularly in the Pacific Northwest and parts of the European Alps (Dirnböck 2003, Mote and Salanthé 2010, Casalegno et al. 2010). In the Alps, species shifts are expected to occur depending on changes in factors including site moisture, species competitive interactions, species adaption to change, and human influence (Theurillat and Guisan 2001). With moderate drought, the added moisture provided by wood microsites is speculated to enhance seedling regeneration, but with longer periods of drought, regeneration could be enhanced most by shade microsites. With climate warming, the role of downed wood structure and function could change. More moisture and greater temperature could enhance decay of downed wood in some locations. In other locations, wood microsite role could shift to downed wood serving as shade microsites. For example, in regions where seedlings are currently growing on top of highly decayed wood microsites, newly germinating seedlings might have a better advantage by growing in locations of shade provided by wood. In both 
cases, wood is likely to continue to be an important facilitator of seedling regeneration at the upper limit of continuous subalpine forests.

Summarization of microsite types by associated annual temperature and annual precipitation provided a first step in highlighting the importance of microsites globally. In the future, better quantification of the attributes associated with various microsites and better collection of climate data associated with these micriosites will enhance studies aimed at summarizing research findings across studies.

\section{Conclusion}

A summary of climate and tree species associated with microsites around the world in the alpine treeline ecotone (ATE) was created to accomplish two goals: (1) better understand the role of wood microsites globally and (2) relate regeneration on microsites with regional climate patterns. From 52 studies from 22 countries on five continents, five dominant microsite types were differentiated (terrain-related, elevations, depressions, wood, and shade/shelter-related) and relationship between microsites type and climate trends including annual precipitation and mean annual temperature were evaluated. Precipitation, ranging from 39 to over $300 \mathrm{~cm}$ per year, was different by microsite type. Also level of precipitation was significantly different for the most common tree genera in the ATE. A significant positive relationship between temperature versus precipitation existed for shade microsites.

This summary of typical microsites located in ATEs suggests that an increase in temperature and change in timing, frequency, and magnitude of precipitation, is likely to 
increase importance of wood microsites at timberline-alpine meadow borders. At timberlines having treefall as a dominant disturbance, wood substrates will promote regeneration on wood microsites in moister climates and shade microsites in drier climates. 
Table 8. Typical characteristics of alpine treeline ecotone (ATE) microsite types.

\begin{tabular}{lcl}
\hline Microsite & Symbol & Characteristic \\
\hline Wood microsites (nurse log) & W & Seedlings growing on decayed wood \\
Elevation & E & $\begin{array}{l}\text { Convexities on ground surface } \\
\text { Depression } \\
\text { Terrain related }\end{array}$ \\
Shade & $\mathrm{D}$ & $\begin{array}{l}\text { Concavities on the ground surface } \\
\text { Landscape features such as slope and } \\
\text { aspect } \\
\text { Association of seedlings with trees, plants, } \\
\text { or rocks }\end{array}$ \\
\hline
\end{tabular}


Table 9. Locations of wood microsites in alpine treeline ecotones of the world.

\begin{tabular}{lll}
\hline Study location & Dominant species & Source \\
\hline Paneveggio, Italian Alps & Picea abies & Motta et al. 2006 \\
Tatra Mts., Poland & Picea abies & Zielonka and Niklossen 2001 \\
Southeast AK, USA & Tsuga meriensiana & Johnson and Yeakley, unpublished \\
North Cascade Mts., USA & Abies lasiocarpa & Johnson and Yeakley, 2013 \\
Mt. Rainier, WA, USA & Abies lasiocarpa & Johnson and Yeakley, unpublished \\
Bavarian Alps, Germany & Picea abies & Baier et al. 2006, 2007 \\
Cental Bhutan & Abies densa & Gratzer, 1999 \\
Yatsugatake Mts. Japan & Tsuga diversifolia & Narukawa et al. 2003 \\
Mt. Ontake, Japan & Picea jezoensis & Mori et al. 2004 \\
S. Andes, Chile & Nothofagus dombeyi & Veblen, 1989 \\
Monteverde, Costa Rica & Didymopanax pittieri & Lawton and Putz 1988 \\
Dawodang Mtn, China & Rhododendron calophytum & Ran et al. 2010 \\
\hline
\end{tabular}


Table 10. Depression (D), elevation (E), shade (S), and topographic (T) microsites.

\begin{tabular}{|c|c|c|c|}
\hline $\begin{array}{l}\text { Micro- } \\
\text { site }\end{array}$ & Study location & Species & Source \\
\hline $\mathrm{D}$ & Piedmont, Italy & Pinus cembra & Motta and Nola 2001 \\
\hline $\mathrm{D}$ & Presidential Range, USA & Betula papyrifera & Kimball and Weihrauch 2000 \\
\hline $\mathrm{D}$ & N. Finland & Betula pubescens & Kullman 1985 \\
\hline $\mathrm{D}$ & Swedish Scandes & Pinus sylvestris & Kullman and Öberg 2009 \\
\hline $\mathrm{D}$ & Caucasus Mts., Georgia & Betula litwinowii & Hughes et al. 2009 \\
\hline $\mathrm{E}$ & Front Range, Colorado & Pinus flexalis & Holtmeier 1992 \\
\hline $\mathrm{E}$ & Mt. Lassen, California & Tsuga meriensiana & Taylor 1995 \\
\hline $\mathrm{E}$ & Mt. Jefferson, OR, USA & Tsuga meriensiana & Zald unpublished \\
\hline $\mathrm{E}$ & Mt. Rainier, WA, USA & Abies lasiocarpa & Rochefort and Peterson 1996 \\
\hline $\mathrm{E}$ & Mt. Baker, WA, USA & Abies lasiocarpa & Heikkinen 1984 \\
\hline $\mathrm{E}$ & N. Cascades, WA, USA & Abies lasiocarpa & Lowery 1972 \\
\hline $\mathrm{E}$ & Upper Engadine, Switzerland & Pinus cembra & Hiller and Müterthies 2005 \\
\hline $\mathrm{E}$ & N. Anatolia, Turkey & Pinus sylvestris & Çolak 2003 \\
\hline $\mathrm{E}$ & Central Honshu Island, Japan & Abies mariesii & Mori and Hasegawa 2007 \\
\hline $\mathrm{E}$ & S.Coastal, B.C., Canada & Chamaecyparis sp. & Brett and Klinka 1998 \\
\hline $\mathrm{S}$ & Glacier Park, Montana, USA & Abies lasiocarpa & Butler et al. 2004 \\
\hline $\mathrm{S}$ & Beartooth Mtns, MT, USA & Pinus albicaulis & Mellman-Brown 2005 \\
\hline $\mathrm{S}$ & Med. Bow Mtn, WY, USA & Picea engelmannii & Germino et al. 2002 \\
\hline $\mathrm{S}$ & Rocky Mts, USA & Abies lasiocarpa & Maher et al 2006 \\
\hline $\mathrm{S}$ & Niwot Ridge, CO, USA & Picea engelmannii & Daly and Shankman 1985 \\
\hline $\mathrm{S}$ & Snowy Range, WY, USA & Picea engelmannii & Moir et al. 1999 \\
\hline $\mathrm{S}$ & Tianshan Mts., NW China & Picea shrenkiana & Wang an Qiu 2006 \\
\hline $\mathrm{S}$ & Spanish Pyrnees & Pinus uncinata & Batllori et al. 2009 \\
\hline $\mathrm{S}$ & Mt. Hotham, Australia & Eucalyptus $s p$ & Wearne and Morgan 2001 \\
\hline $\mathrm{S}$ & Pa'ramo de Papallacta, Ecuador & Polylepis sp. & Cierjacks et al. 2007 \\
\hline $\mathrm{S}$ & Central Argentina & Polylepis australis & Enrico et al. 2004 \\
\hline $\mathrm{S}$ & Monteverde, Costa Rica & Quercus sp. & Oosterhoorn and Kappelle 2000 \\
\hline $\mathrm{T}$ & Rocky Mtn. Park, Colorado & Picea engelmannii & Hessl and Baker 1997 \\
\hline $\mathrm{T}$ & Front Range, Colorado & Picea engelmannii & Villalba et al. 1994 \\
\hline $\mathrm{T}$ & Central OR, USA & Tsuga meriensiana & Miller and Halpern 1998, \\
\hline $\mathrm{T}$ & Olympic Mts., WA, USA & Abies lasiocarpa & Woodward et al. 1995 \\
\hline $\mathrm{T}$ & Manang, Nepal & Betula utils & Shrestha et al. 2007 \\
\hline $\mathrm{T}$ & Davos and Sidrun, Swiss Alps & Picea abies & Cunningham et al. 2006 \\
\hline $\mathrm{T}$ & Davos, Switzerland & Pinus cembra & Holtmeier 2009 \\
\hline $\mathrm{T}$ & Finnish Lapland & Picea abies & Juntunen et al. 2002 \\
\hline $\mathrm{T}$ & Swedish Scandes & Betula pubescens & Kjallgren and Kullman 2002 \\
\hline $\mathrm{T}$ & Southern Swedish Scandes & Pinus sylvestris & Kullman 2007 \\
\hline $\mathrm{T}$ & Sangay National Park, Ecuador & Escallonia sp. & Bader and Ruijten 2008 \\
\hline $\mathrm{T}$ & Austrian Alps & Picea abies & Li and Yang 2004 \\
\hline $\mathrm{T}$ & Finnish Lapland & Picea abies & Autio \& Colpaert 2005 \\
\hline
\end{tabular}




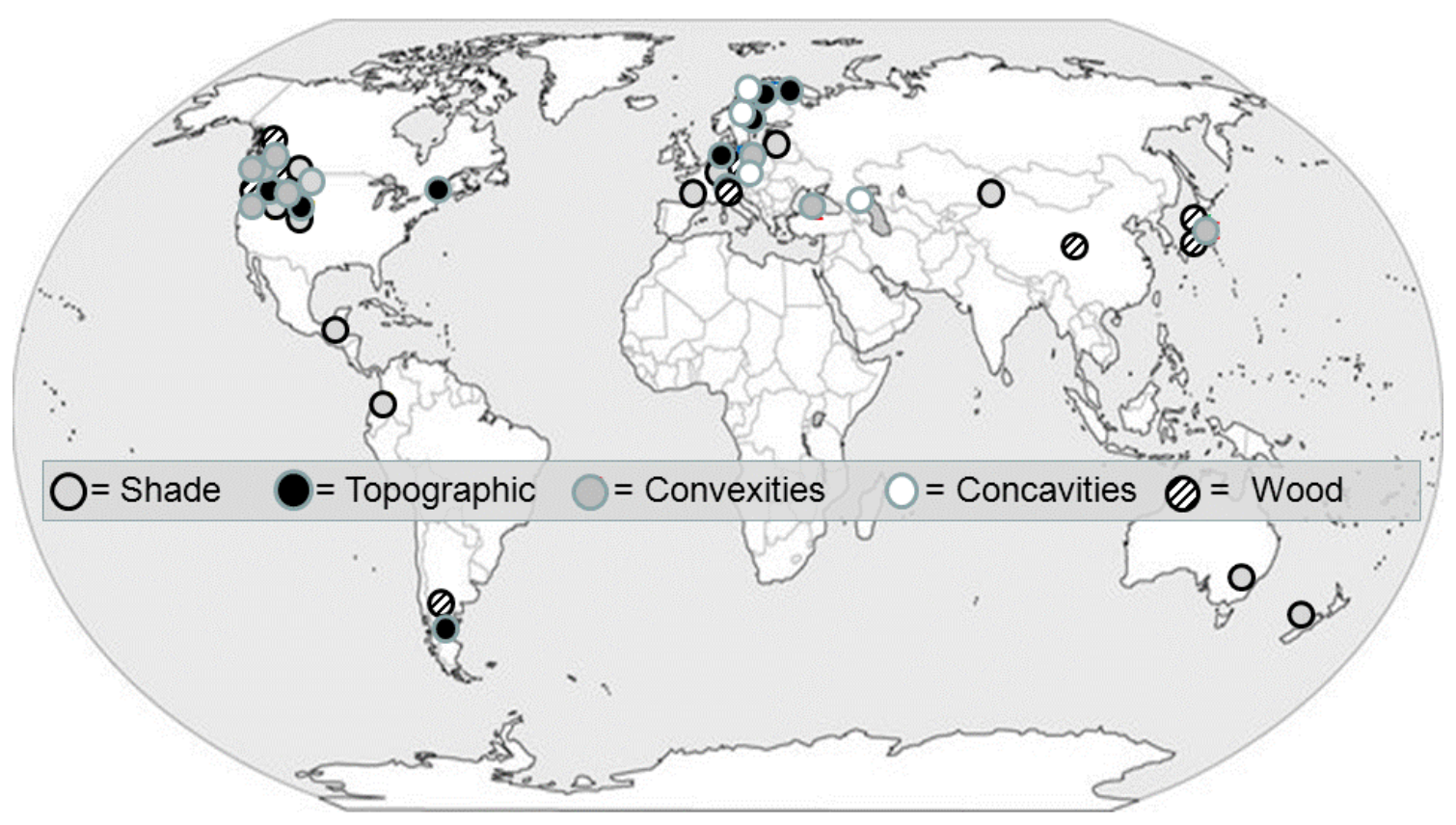

Figure 34. Dominant microsites for seedling regeneration in the alpine treeline ecotone around the world. 

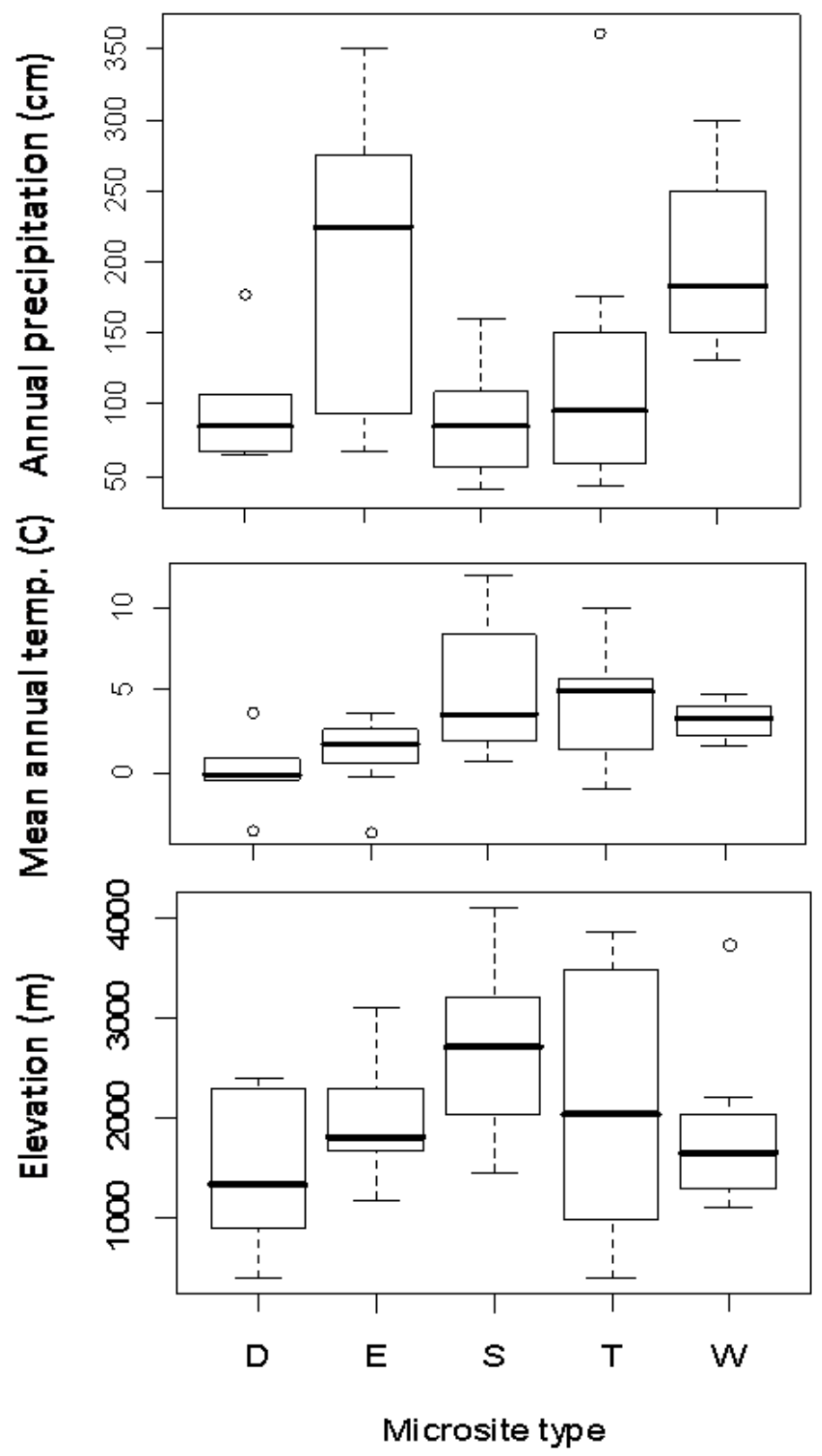

Figure 35. Boxplots of precipitation, mean annual temperature, and elevation per microsite. Microsite types are as follows: $\mathrm{D}=$ depressions, $\mathrm{n}=6 ; \mathrm{E}=$ elevations, $\mathrm{n}=10$; $\mathrm{S}=$ shade, $\mathrm{n}=12 ; \mathrm{T}=$ topographic, $\mathrm{n}=13$; and $\mathrm{W}=$ wood microsites, $\mathrm{n}=11$ (precipitation is significantly different for microsite types, $p=0.0033$ ). 

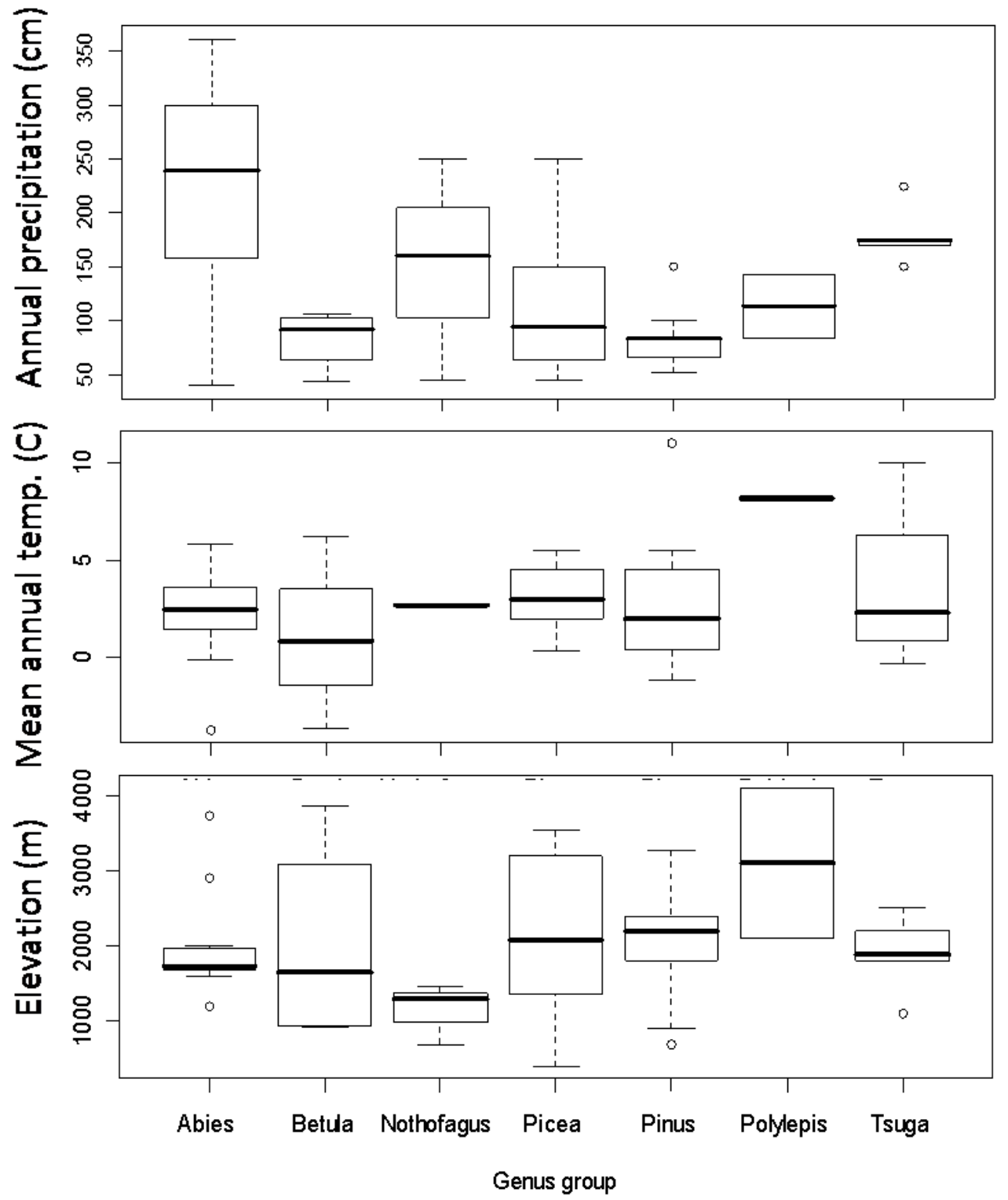

Figure 36. Boxplots of precipitation, mean annual temperature, and elevation per genus group (precipitation was significantly different for species, $p=0.027, \mathrm{n}=2$ to 14 per genus group). 


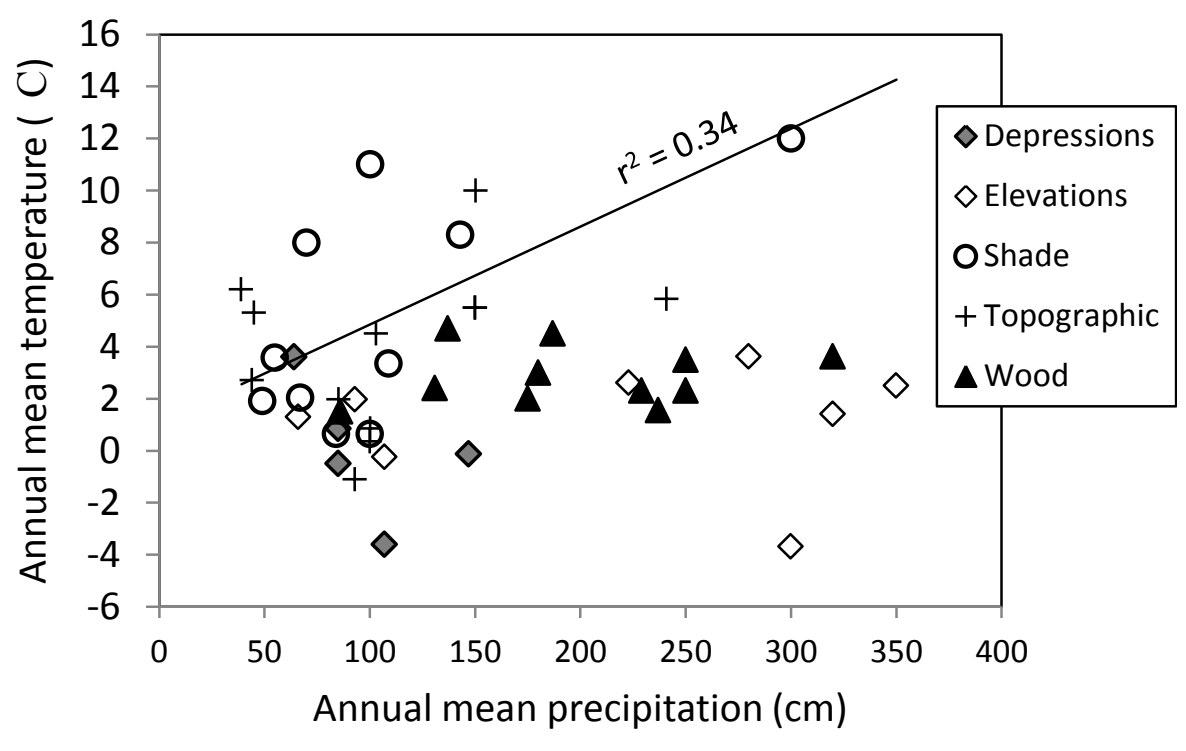

a)

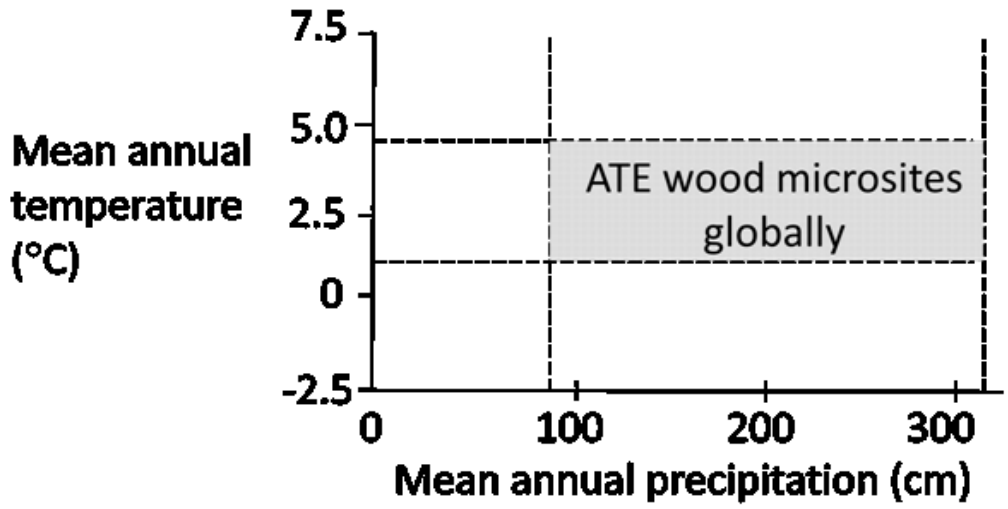

b)

Figure 37. Annual mean temperature versus annual mean precipitation for microsites in the alpine treeline ecotone globally. For : a) all five microsites, a significant positive relationship between temperature and precipitation existed for shade microsites only $\left(p=0.045, \mathrm{r}^{2}=0.34\right)$ and $\left.\mathrm{b}\right)$ wood microsite presence summarized by mean annual temperature and mean annual precipitation. 


\section{Chapter 6:}

\section{Summary}

The overarching aim of the four studies presented here was to describe wood microsite ecological context and determine possible advantages of wood microsites for conifer regeneration at timberline-alpine meadow borders. First, origin and characteristics of wood microsites supporting conifer seedlings was determined. Then, attributes of wood microsites and physiologic aspects of seedlings growing on wood microsites were compared to adjacent soil substrates, and finally, typical climatic features associated with regeneration on wood microsites were compared with other microsites in a global context. Combined results can be used explain current and future roles of wood microsites for conifer invasion at timberline-alpine meadow borders (Fig. 38).

Results from the first step of the research (Chapter 2) demonstrated that conifer seedling regeneration was facilitated more by wood microsites than by adjacent soil substrates at timberline-alpine meadow borders. Wood microsites had greater seedling density (3.6 versus $6.9, p=0.026)$, greater seedling survival, and provided warmer and moister substrates than adjacent soil substrates. Highly rotted wood, primarily originating from treefall, supported regeneration particularly for Abies sp. Comparable to lower elevation forests, wood was shown to be a superior site for germinating seedlings, particularly at sites having higher levels of shade. Potential conifer invasion into alpine meadows via wood substrates was found to be dependent on four steps: (1) disturbance processes introducing large wood from timberline to meadows, (2) a climate facilitating 
wood decay, (3) successful germination of seedlings, and (4) growth of seedlings to maturity. Given these requirements, conifer invasion was estimated to occur between 0.005 to $0.10 \mathrm{~m}^{*} \mathrm{y}^{-1}$. Seedling growth on wood microsites was judged most likely to occur in other regions typified by large trees at timberline-alpine meadows, high precipitation, mild summers, and lack of forest harvesting.

The second part of this research (Chapter 3) was aimed at gaining a better understanding the details of substrate temperature as influenced by percent transmited radiation for wood and adjacent soil substrates at timberline-alpine meadow borders. For wood and adjacent soil substrates having three levels of radiation, I found no significant differences in date of spring thaw and fall freeze. Although annual temperature was significantly lower for wood microsites, summer temperature and growing degree hours were significantly greater for wood than for soil microsites. Because lower VWC was associated with increased substrate temperature and decreased seedling density, it was suggested that timberline locations may be already close to optimum temperatures, given availability of water during the growing season - particularly at eastern Cascade Mt sites. This research proposes that wood microsites, by providing more moisture, will facilitate survival of seedlings up to threshold beyond which the added moisture provided by highly decayed wood will not compensate for young seedling moisture requirements.

The third part of the research foculsed on physiologic measures of active seedling growth on wood and adjacent soil substrates (Chapter 4). Measurements including stomatal conductance, water potential, and leaf chlorophyll a content were made to determine whether the positive abiotic attributes attributed to wood microsites facilitated 
greater measures of seedling growth activity on wood microsites. Although there were no differences in stomatal conductance overall, greater stomatal conductance was associated with increased volumetric water content at sites having higher percent transmitted radiation. Early morning water potential of seedlings growing on rotten wood at the timberline edge, found to be significantly less negative than water potential of seedlings growing on soil, did not demonstrably enhance stomatal conductance. Lack of difference in chlorophyll a and $\mathrm{N}$ content for seedlings growing at sites with varying levels of radiation suggests that photoinhibition, common at Rocky Mt sites, is not as important as a seedling stressor at PNW timberlines

By summarizing the typical microsites associated with seedling regeneration globally (Chapter 5), it was determined that wood microsites were found in a wide range of forests and therefore, it was suggested that the role of wood microsites globally may be underrepresented as a factor facilitating seedling regeneration at timberline-alpine meadows or timberline-grasslands. With climate warming, both increases in precipitation and increases in summer drought are likely to change wood microsite structure and function. Wood microsite current role could shift to the role of a shade microsite in some locations. For example, in regions where seedlings are currently growing on top of highly decayed wood microsites, newly germinating seedlings might move into locations of shade provided by wood. In both cases, wood is an important facilitator of seedling regeneration at the upper limit of continuous subalpine forests. The role of wood microsite in a warming climate will depend on changes in wood decay rates, precipitation frequency, magnitude, and timing; moisture holding capacity of wood substrates; and the 
growing requirements of species growing on wood microsites. In the future, better quantification of the attributes associated with various microsites and better collection of climate data associated with these microsites will enhance studies aimed at summarizing research findings across studies.

This research, assessing seedling regeneration on wood microsites, may provide some guidance for forest restoration efforts in North Cascades timberline-alpine meadow borders. Given periods of summer drought, the moisture provided by wood microsites may be instrumental in rehabilitation of disturbed high recreation locations and areas previously disturbed by fire. Highly decayed pieces of wood would likely facilitate seedling regeneration better than soil substrates due to less freeze-thaw damage and greater water content. 


\section{Alpine treeline ecotone (ATE) trends for wood microsites versus soil comparisons}

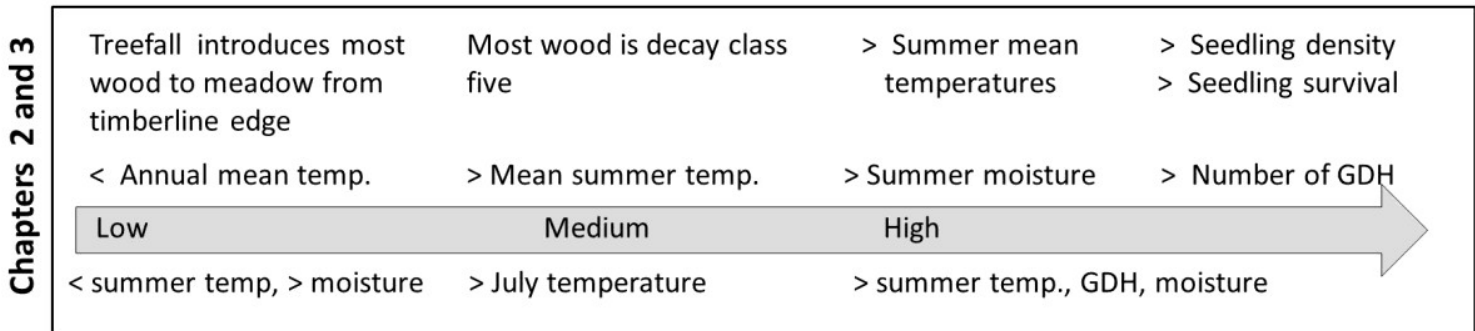

West side Cascade Mts.

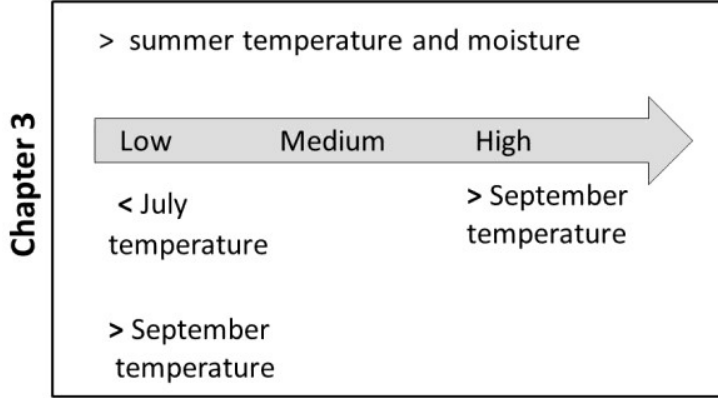

Seedlings on wood microsites had:

- > water potential and > stomatal conductance at medium radiation sites in August,

- $\quad>$ stomatal conductance at strong radiation sites in September,

- were mostly Abies sp. and Picea abies,

- wood microsite importance may increase in some locations with global warming by providing enhanced site moisture.
East side Cascade Mts.

$>$ Summer temperature, GDH, and moisture

$>$ survival of $<2 \mathrm{yr}$ old seedlings with increasing VWC

\begin{tabular}{|clc|}
\hline Low & Medium & High \\
\hline $\begin{array}{c}\text { July, August, } \\
\text { September } \\
\text { temperature }\end{array}$ & > July & $>$ August, \\
& temperature & $\begin{array}{c}\text { September } \\
\text { temperature }\end{array}$ \\
& $>$ mean & $>$ Summer \\
& summer GDH & moisture \\
\hline
\end{tabular}

Mean annual temperature

$\left({ }^{\circ} \mathrm{C}\right)$

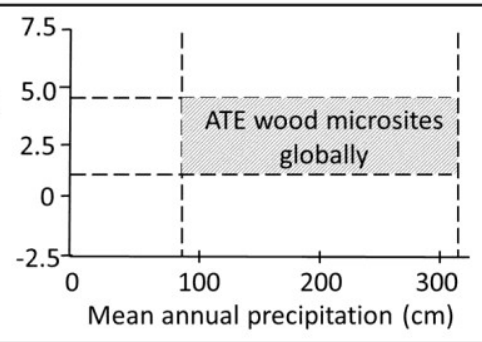

Figure 38. Summary of dissertation results by chapter. Results of tests, summarized by $>$ or $<$, indicate level for wood microsites as compared to soil substrates, respectively. Within each box, general information is located at the top and information associated with percent transmitted radiation (indicated within large shaded arrows) level is described directly under that level. 


\section{References}

Agee, J. K. 1993. Fire Ecology of Pacific Northwest Forests. Island Press, Washington, DC.

Agee, J. K., and C. N. Skinner. 2005. Basic principles of forest fuel reduction treatments. Forest Ecology and Management 211:83-96.

Alexander, R. R., R. C. Shearer, and W. D. Shepperd. 1984. Silvical characteristics of subalpine fir. Rocky Mountain Forest and Range Experiment Station General Technical Report RM-115. Fort Collins, CO.

Alvarez-Uria, P., and C. Körner. 2007. Low temperature limits of root growth in deciduous and evergreen temperate tree species. Functional Ecology 21(2):211218.

Amaranthus, M. P., D. Parrish, and D. A. Perry. 1989. Decaying logs as moisture reservoirs following drought and wildfire. In E. Alexander (editor), Proceedings Stewardship of Soil, Air and Water Resources, Watershed 89, USDA Forest Service General Technical Report R10-MB-77, Juneau, AK. Pp.191-194.

Anschlag, K., G. Broll, and F-K. Holtmeier. 2008. Mountain birch seedlings in the tundra ecotone, subarctic Finland: variation in above- and below-ground growth depending on microtopography. Arctic, Antarctic, and Alpine Research 40:609616.

Arno, S. F. 1984. Timberline. The Mountaineers, Seattle.

Autio, J., and A. Colpaert. 2005. The impact of elevation, topography and snow load damage of trees on the position of the actual timberline on the fells in central Finnish Lapland. Fennia 183(1):15-36.

Bader, M. Y., Rietkerk, M., and A. K. Bregt. 2008. A simple spatial model exploring positive feedbacks at tropical alpine treelines. Arctic, Antarctic, and Alpine Research 40(2):269-278.

Baier, R., R. Ettl, C. Hahn, and A. Göttlein. 2006. Early development and nutrition of Norway spruce (Picea abies [L.] Karst) seedlings on mineral soil, organic layer, and decayed woody debris origin from dolomite sites of the Bavarian Limestone Alps. Annual Forest Science 63:339-348.

Baier, R., J. Meyer, and A. Gottein. 2007. Regeneration niches of Norway spruce (Picea albies [L.] karst.) saplings in small canopy gaps in mixed mountain forest of the Bavarian Limestone Alps. European Journal of Forest Research 126:11-22. 
Baig, M. N. and W. Tranquillini. 1980. The effects of wind and temperature on cuticular transpiration of Picea abies and Pinus cembra and their significance in dessication damage at the alpine treeline, Oecologia 47:252-256.

Baker, W. L., P. H. Flaherty, J. D. Lindemann, T. T. Veblen, K. S. Eisenhart, and D. Kulakowski. 2002. Effect of vegetation on the impact of a severe blow down in the southern Rocky Mountains, USA. Forest Ecology and Management 168:6375 .

Balisky, A. C., and P. J. Burton. 1995. Root-zone soil temperature variation associated with microsite characteristics in high-elevation forest openings in the interior of British Columbia. Agricultural and forest meteorology 77(1):31-54.

Ball, M. C., V. S. Hodges, and G. P. Laughlin. 1991. Cold-induced photoinhibition limits regeneration of snow gum at tree-line. Functional Ecology 5:665-668.

Bansal, S., and M. J. Germino. 2008. Carbon balance of conifer seedlings at timberline: relative changes in uptake, storage, and utilization. Oecologia 158(2):217-227.

Barber, B. L., and D. H. Van Lear. 1984. Weight loss and nutrient dynamics in decomposing woody loblolly pine logging slash. Soil Science Society of America Journal 48:906-910.

Batllori, E., Blanco-Moreno, J. M., Ninot, J. M., Gutierrez, E., and E. Carrillo. 2009. Vegetation patterns at the alpine treeline ecotone: the influence of tree cover on abrupt change in species composition of alpine communities. Journal of vegetation science 20(5):814-825.

Battin, J., M. W. Wiley, M. H. Ruckelshaus, R. N. Palmer, E. Korb, K. K. Bartz, and H. Imaki. 2007. Projected impacts of climate change on salmon habitat restoration. Proceedings of the National Academy of Sciences of the United States of America 104:6720-6725.

Bauer, M. L. 2003. Walddynamik nach Borkenbefall in den Hochlagen des Bayerischen Waldes Ph.D. Dissertation, Lehrstuhlfür Waldbau und Forsteinrichtung, Germany, Munich.

Blanchette, R. A. 1991. Wood-decay fungi. Annual Review of Phytopathology 29:38198.

Bowden, W.B., Petersen, B.J., Finlay, J.C., and J. Tucker. 1992. Epilithic chlorophyll $a$, photosynthesis, and respiration in control and fertilized reaches of a tundra stream. Hydrobiologia 240:121.131. 
Brang, P., J. Moran, P. Puttonen, and A. Vyse. 2003. Regeneration of Picea Engelmannii and Abies lasiocarpa in high-elevation forests of south-central British Columbia depends on nurse logs. The Forestry Chronicle 79:273-279.

Brett, R. B., and K. Klinka. 1998. A transition from gap to tree-island regeneration patterns in the subalpine forest of south-coastal British Columbia. Canadian Journal of Forest Research 28(12):1825-1831.

Brink, V. C. 1959. A directional change in the subalpine forest-heath ecotone in Garibaldi Park, British Columbia. Ecology 40:10-16.

Butler, D. R., Malanson, G. P., and Resler, L. M. 2004. Turf-banked terrace treads and risers, turf exfoliation, and possible relationships with advancing treeline. Catena $58: 259-274$.

Callaway, R. M. 1995. Positive interactions among plants. Botanical Review 61:306349.

Casalegno, S., Amatulli, G., Camia, A., Nelson, A., and Pekkarinen, A. 2010. Vulnerability of Pinus cembra L. in the Alps and the Carpathian mountains under present and future climates. Forest Ecology and Management 259(4):750-761.

Castro, J., R. Zamora, J. A. Hódar, and J. M. Gómez. 2002. Use of shrubs as nurse plants: a new technique for reforestation in Mediterranean mountains. Restoration Ecology 10:297-305.

Caza, C.L. 1993. Woody debris in the forests of British Columbia: a review of the literature and current research. British Columbia Ministry of Forests Land Management Report (ISSN 0702-9861; 78), Victoria, B.C.

Chapin, F. S., III. 1980. The mineral nutrition of wild plants. Annual Review Ecological Systems 11:233-260.

Chapin, F. S., III, P. A. Matson, H. A. Mooney. 2002. Principals of Terrestrial Ecosystem Ecology. Springer-Verlag, New York.

Chen, H. 1999. Root decomposition in three coniferous forests: effects of substrate quality, temperature, and moisture. Ph.D. Dissertation, Oregon State University, Corvallis, OR.

Christy, E. J., and R. N. Mack. 1984. Variation in demography of juvenile Tsuga heterophylla across the substratum mosaic. Journal of Ecology 72:75-91.

Cierjacks, A., Iglesias, J. E., Wesche, K., and I. Hensen. 2007. Impact of sowing, canopy 
cover and litter on seedling dynamics of two Polylepis species at upper tree lines in central Ecuador. Journal of Tropical Ecology 23(3):309.

Çolak, A. H. and I. D. Rotherham. 2006. A review of the forest vegetation of Turkey: its status past and present and its future conservation. In Biology \& Environment: Proceedings of the Royal Irish Academy 106(3):343-354.

Collatz, G. J., Ball, J. T., Grivet, C., and J.A. Berry. 1991. Physiological and environmental regulation of stomatal conductance, photosynthesis and transpiration: a model that includes a laminar boundary layer. Agricultural and Forest Meteorology 54(2):107-136.

Cornett, M. W., P. B. Reich, K. J. Puettmann, and L. E. Frelich. 2000. Seedbed and moisture availability determine safe sites for early Thuja occidentalis (cupressaceae) regeneration. American Journal of Botany 87:1807-1814.

Cuevas, J. G. 2002. Episodic regeneration at the Nothofagus pumilio alpine timberline in Tierra del Fuego, Chile. Journal of Ecology 90:52-60.

Cui, M. and M. K. Smith. 1991. Photosynthesis, water relations and mortality in Abies lasciocarpa seedlings during natural establishment. Tree Physiology 8:37-46.

Cunningham, C., Zimmermann, N. E., Stoeckli, V., and H. Bugmann. 2006. Growth of Norway spruce (Picea abies) saplings in subalpine forests in Switzerland: Does spring climate matter? Forest ecology and management 228(1):19-32.

Dale, V. H., L. A. Joyce, S. McNulty, R. P. Neilson, M. P. Ayres, M. D. Flannigan, P. J. Hanson, L. C. Irland, A. E. Lugo, C. J. Peterson, D. Simberloff, F. J. Swanson, B. J. Stocks, and B. M. Wotton. 2001. Climate change and forest disturbances. BioScience 51:723-734.

Daly, C. and D. Shankman. 1985. Seedling establishment by conifers above tree limit on Niwot Ridge, Front Range, Colorado, USA. Arctic and Alpine Research 17:389400 .

Dirnböck, T., Dullinger, S., and G. Grabherr. 2003. A regional impact assessment of climate and land-use change on alpine vegetation. Journal of Biogeography 30(3):401-417.

Donovan, L. A., Richards, J. H. and M. J. Linton. 2003. Magnitude and mechanisms of disequilibrium between predawn plant and soil water potentials. Ecology 84(2):463-470. 
Edburg, S. L., J. A. Hicke, P. D. Brooks, E. G. Pendall, B. E. Ewers, U. Norton, D. Gochis, Gutmann, E. D., and A. J. H. Meddens. 2012. Frontiers in Ecology and the Environment 10:416-424.

Eichrodt, R. 1969. Über die Bedeutung von Moderholzfür die natürliche Verjüngungim subalpinen Fichtenwald. BeihSchweizZorstw 45:122.

Enrico, L., Funes, G., and M. Cabido. 2004. Regeneration of Polylepis australis Bitt. in the mountains of central Argentina. Forest Ecology and Management 190(2): 301309.

Erickson, H. E., Edmonds, R. L. and C. E. Peterson. 1985. Decomposition of logging residues in Douglas-fir, western hemlock, Pacific silver fir, and ponderosa pine ecosystems. Canadian Journal of Forest Research 15:914-921.

Eriksson, O. and J. Ehrlén. 1992. Seed and microsite limitation of recruitment in plant populations. Oecologia 91:360-364.

Everham, III E. M., and N. V. L. Brokaw. 1996. Forest damage and recovery from catastrophic wind. Botanical Review 62:113-85.

Fattorini, M. 2001. Establishment of transplants on machine-graded ski runs above timberline in the Swiss Alps. Restoration Ecology 9:119-126.

Franklin, J. F. and R. G. Mitchell. 1967. Successional status of subalpine fir in the Cascade Range (Vol. 46). Pacific Northwest Forest and Range Experiment Station, US Dept. of Agriculture.

Franklin, J. F., W. H. Moir, G. W. Douglas, and C. Wiberg. 1971. Invasion of subalpine meadows by trees in the cascade range of Washington and Oregon. Arctic and Alpine Research 3:215-224.

Franklin, J. F., and C. T. Dyrnes. 1979. Natural Vegetation of Oregon and Washington. USDA Forest Service General Technical Report PNW-8. Portland, OR.

Franklin, J. F., T. A. Spies, R. van Pelt, A. Carey, D. Thornburgh, D. R. Berg, D. B. Lindenmayer, M. Harmon, W. Keeton, and D. C. Shaw. 2002. Disturbances and the structural development of natural forest ecosystems with some implications for silviculture. Forest Ecology and Management 155:399-423.

Frazer, G. W., Canham, C. D., \& Lertzman, K. P. 1999. Gap Light Analyzer (GLA): Imaging software to extract canopy structure and gap light transmission indices from true-colour fisheye photographs, user's manual and program documentation. Simon Fraser University, Burnaby, BC.[doi: 10.1016/S0168-1923 (01) 00274-X]. 
Fukasawa, Y. 2012. Effects of wood decomposer fungi on tree seedling establishment on coarse woody debris. Forest Ecology and Management 266:232-238.

Gavin, D. G., D. J. Hallett, F. S. Hu, K. P. Lertzman, S. J. Prichard, K. K. Brown, J. A. Lynch, A. Bartlein, and D. L. Peterson. 2007. Forest fire and climate change in western North America: insights from sediment charcoal records. Frontiers in Ecology and the Environment 5:499-506.

Germino, M. J., and M. K. Smith. 1999. Sky exposure, crown architecture, and lowtemperature photoinhibition in conifer seedlings at alpine treeline. Plant, Cell, and Environment 22:407-415.

Germino, M. J., M. K. Smith, and C. A. Resor. 2002. Conifer seedling distribution and survival in an alpine-treeline ecotone. Plant Ecology 162:157-168.

Germino, M.J., W.K. Smith and A.C. Resor. 2003. Conifer seedling distribution and survival in an alpine-treeline ecotone. Plant Ecology 162:157-168.

Germino, M. J., N. J. Hasselquist, T. M. McGonigle, W. K. Smith, and P. P. Sheridan. 2006. Colonization of conifer seedling roots by fungal mycelium in an alpinetreeline ecotone. Canadian Journal of Forest Research 36:901-909.

Gesch, D. B. 2007. The National Elevation Dataset, In D. Maune (editor), Digital Elevation Model Technologies and Applications: The DEM User's Manual, 2nd Edition: Bethesda, Maryland, American Society for Photogrammetry and Remote Sensing.

Graae, B., R. Ejrnæs, S. Lang, E. Meineri, P. Ibarra, and H. Bruun. 2011. Strong microsite control of seedling recruitment in tundra. Oecologia 166:565-576.

Grabherr, G. 2003. Alpine vegetation dynamics and climate change-a synthesis of longterm studies and observations. In Alpine biodiversity in Europe (pp. 399-409). Springer Berlin Heidelberg.

Gratzer, G., P. B. Rai, and G. Glatzel. 1999. The influence of the bamboo Yushaniamicrophylla on regeneration of Abies densa in central Bhutan. Canadian Journal of Forest Research 29:1518-1527.

Grunewald, K., Scheithauer, J., Monget, J. M., and D. Brown. 2009. Characterisation of contemporary local climate change in the mountains of southwest Bulgaria. Climatic change 95(3-4):535-549. 
Gray, A. N., and T. A. Spies. 1997. Microsite controls on tree seedling establishment in conifer forest canopy gaps. Ecology 78:1458-2473.

Hallinger, M., Manthey, M., and M. Wilmking. 2010. Establishing a missing link: warm summers and winter snow cover promote shrub expansion into alpine tundra in Scandinavia. New Phytologist 186(4):890-899.

Harmon, M. E., D. F. Whigham, J. Sexton, and I. Olmsted. 1995. Decomposition and mass of woody detritus in the dry tropical forests of the northeastern Yucatan Peninsula, Mexico. Biotropica 27:305-316.

Harmon, M. E., J. F. Franklin, F. J. Swanson, P. Sollins, S. V. Gregory, J. D. Lattin, N. H. Anderson, S. P. Cline, N. G. Aumen, J. R. Sedell, G. W. Lienkaemper, K. Cromack, and K. W. Cummins. 1986. Ecology of coarse woody debris in temperate ecosystems. Advances in Ecological Research 15:133-302.

Harmon, M. E., and J. F. Franklin. 1989. Tree seedlings on logs in Picea-Tsuga forests of Oregon and Washington. Ecology 70:48-59.

Harper, J. L., J. N. Clatworthy, I. H. McNaughton, and G. R. Sagar. 1961. The evolution and ecology of closely related species living in the same area. Evolution 15:209227.

Hasselquist, N., M. J. Germino, T. McGonigle, and W. K. Smith. 2005. Variability of Cenococcum colonization and its ecophysiological significance for young conifers at alpine-treeline. New Phytologist 867-873.

Hättenschwiler, S., and C. Körner. 1995. Responses to recent climate warming of Pinus sylvestris and Pinus cembra within their montane transition zone in the Swiss Alps. Journal of Vegetation Science 6:357-368.

Havranek, W. 1972. Über die Bedeutung der Bodentemperatur für die Photosynthese und Transpirationjunger Forstpflanzen und für die Stoffproduktion an der Waldgrenze. Angew Bot 46:101-116.

He, J., Chee, C. W., and C. J. Goh. 2006. 'Photoinhibition'of Heliconia under natural tropical conditions: the importance of leaf orientation for light interception and leaf temperature. Plant, Cell \& Environment 19:1238-1248.

Heikkinen, O. 1984. Dendrochronological evidence of variation of Coleman Glacier, Mt. Baker, Washington, U.S.A. Arctic and Alpine Research 53-64. 
Hemstrom, M. A., and J. F. Franklin. 1982. Fire and other disturbances of the forests in Mount Rainier National Park. Quaternary Research 18:32-51.

Hennon, P.E. 1995. Are heart rot fungi major factors of disturbance in gap-dynamic forests. Northwest Science 69:284-293.

Hessl, A. E., and W. L. Baker. 1997. Spruce and fir regeneration and climate in the forest-tundra ecotone of Rocky Mountain National Park, Colorado, USA. Arctic and Alpine Research 173-183.

Hicks, W.I. 2000. Modeling nitrogen fixation in dead wood. Ph.D. Dissertation. Oregon State University, Corvallis.

Hiller, B. and A. Müterthies. 2005. Humus forms and reforestation of an abandoned pasture at the alpine timberline (Upper Engadine, Central Alps Switzerland). Mountain Ecosystems: Studies in Treeline Ecology 2:203-218.

Hofgaard, A. 1993. Structure and regeneration patterns in a virgin Picea abies forest in northern Sweden. Journal of Vegetation Science 4:601-60.

Holtmeier, F., and G. Broll. 1992. The influence of tree islands and microtopography on pedoecological conditions in the forest-alpine tundra ecotone on Niwot Ridge, Colorado Front Range, USA. Arctic and Alpine Research 24:216-228.

Holtmeier, F. K., and G. Broll. 2005. Sensitivity and response of northern hemisphere altitudinal and polar treelines to environmental change at landscape and local scales. Global Ecology and Biogeography 14:395-410.

Holtmeier, F. K., and G. Broll. 2007. Treeline advance-driving processes and adverse factors. Landscape Online 1:1-33.

Holtmeier, F. 2003. Mountain Timberlines. Kluwer Academic Publishers, Boston.

Holtmeier, F. 2009. Mountain timberlines: ecology, patchiness, dynamics. Advances in Global Change Research 36:5-10.

Homer, C. C., L.Huang, B. Yang, E. Wylie, and M. Coan. 2004. Development of a 2001 National Land Cover Database for the United States. Photogrammetric Engineering and Remote Sensing 70:829-840.

Hughes, N. M., Johnson, D. M., Akhalkatsi, M., and O. Abdaladze. 2009. Characterizing Betula litwinowii seedling microsites at the alpine-treeline ecotone, central Greater Caucasus Mountains, Georgia. Arctic, Antarctic, and Alpine Research 41(1):112-118. 
Hunziker, U. and P. Brang. 2005. Microsite patterns of conifer seedling establishment and growth in a mixed stand in the southern Alps. Forest Ecology and Management 210:67-79.

Johnson, A. C. and J. A. Yeakley. 2013. Wood Microsites at Timberline-Alpine Meadow Borders: Implications for Conifer Seedling Regeneration and Alpine Meadow Conifer Invasion, Northwest Science 82(2):140:160.

Johnson, D. M., Germino, M. J., and W. K. Smith. 2004. Abiotic factors limiting photosynthesis in Abies lasiocarpa and Picea engelmannii seedlings below and above the alpine timberline. Tree Physiology 24(4):377-386.

Johnson, E. A. 1987. The relative importance of snow avalanche disturbance and thinning on canopy plant populations. Ecology 68:43-53.

Juntunen, V., Neuvonen, S., Norokorpi, Y., and T. Tasanen. 2002. Potential for timberline advance in northern Finland, as revealed by monitoring during 198399. Arctic, 348-361.

Kearney, M. S. 1982. Recent seedling establishment at timberline in Jasper National Park, Alta. Canadian Journal of Botany 60(11):2283-2287.

Kimball, K. D., and D. M. Weihrauch. 2000. Alpine vegetation communities and the alpine-treeline ecotone boundary in New England as biomonitors for climate change. In USDA Forest Service Proceedings 15(3):93-101.

Kirdyanov, A. V., F. Hagedorn, A. A. Knorre, E. V. Fedotova, E. A. Vaganov, M. M. Naurzbaev, P. A. Moiseev, and A. Rigling. 2012. 20th century tree-line advance and vegetation changes along an altitudinal transect in the Putorana Mountains, northern Siberia. Boreas 41:56-67.

Kjallgren, L. and L. Kullman. 2002. Geographical patterns of tree-limits of Norway spruce and Scots pine in the southern Swedish Scandes. Norwegian Journal of Geography 56:237-245.

Kluber, M. R., Olson, D. H. and K. J. Puettman. 2009. Northwest Science 83(1):25-34.

Knapp. A. K. and W. K. Smith. 1982. Factors influencing understory seedling establishment of Engelmann spruce (Picea Engelmannii) and subalpine fir (Abies lasiocarpa). Canadian Journal of Botany 60: 2753-2761.

Körner, C.1989. The nutritional status of plants from high altitudes. Oecologia 81:379391. 
Körner, C. 1998. A re-assessment of high elevation treeline positions and their explanation. Oecologia 115:445-459.

Körner, C., 2003. Alpine Plant Life: Functional Plant Ecology of High Mountain Ecosystems. Springer Berlin, Heidelberg, Germany.

Körner, C., and J. Paulsen. 2004. A world-wide study of high altitude treeline temperatures. Journal of Biogeography 31:713-732.

Kramer, P. J., and J. S. Boyer. 1995. Water relations of plants and soils. Academic Press, Inc.

Kramer, M. G., P. Sollins, and R. S. Sletten. 2004. Soil carbon dynamics across a windthrow disturbance sequence in southeast Alaska. Ecology 85:2230-2244.

Kulakowski, D., and T. T. Veblen. 2002. Influences of fire history and topography on the pattern of a severe wind blowdown in a Colorado subalpine forest. Journal of Ecology 90:806-819.

Kullman, L. 1985. Demography of Betula pubescens ssp. Tortuosa sown in contrasting habitats close to the birch tree-limit in Central Sweden, Vegetatio 65:13-20.

Kullman, L. 2006. Botanical signs of a new and warmer alpine world. Fauna and Flora 104:10-21.

Kullman, L. 2007. Tree line population monitoring of Pinus sylvestris in the Swedish Scandes, 1973-2005: implications for tree line theory and climate change ecology. Journal of Ecology 95(1):1-52.

Kullman, L. and L. Öberg. 2009. Post-Little Ice Age tree line rise and climate warming in the Swedish Scandes: a landscape ecological perspective. Journal of Ecology, 97(3):415-429.

Laiho, R., and C. E. Prescott. 1999. The contribution of coarse woody debris to carbon, nitrogen, and phosphorus cycles in three Rocky Mountain coniferous forests. Canadian Journal of Forest Research 29(10):1592-1603.

Lawton, R. O. and F. E. 1988. Natural disturbance and gap-phase regeneration in a wind-exposed tropical cloud forest. Ecology 69(3):764-777.

Leung, L. R., and M. S. Wigmosta. 1999. Potential climate change impacts on mountain watersheds in the Pacific Northwest. Journal of American Water Resources Association 35:1463-1471. 
Lewis, K. J., and S. B. Lindgren. 1999. Influence of decay fungi on species composition and size class structure in mature Picea glauca, Engelmannii and Abies lasiocarpain sub-borealforests of central British Columbia. Forest Ecology and Management 123:135-143.

Li, M. H. and J. Yang. 2004. Effects of microsite on growth of Pinus cembra in the subalpine zone of the Austrian Alps. Annals of Forest Science, 61(4):319-325.

Li, M. H., M. F. Xiao, P. Shi, S. G. Wang, Y. D. Zhong, X. L. Liu, X. D. Wang, X. H. Cai, and Z. M. Shi. 2008. Nitrogen and carbon source-sink relationships in trees at the Himalayan treelines compared with lower elevations. Plant, Cell and Environment 31:1377-1387.

Lindemann, J. D., and W. L. Baker. 2001. Attributes of blowdown patches from a severe wind event in the southern Rocky Mountains, USA. Landscape Ecology 16:313325.

Long, S. P., Humphries, S., and P. G. Falkowski. 1994. Photoinhibition of photosynthesis in nature. Annual review of plant biology 45(1):633-662.

Lowery, R. F. 1972. Ecology of subalpine zone tree clumps in the north Cascade Mountains of Washington. Ph.D. Dissertation. University of Washington, Seattle.

Lusk, C. H. 1995. Seed size, establishment sites and species coexistence in a Chilean rain forest. Journal of Vegetation Science 6(2):249-256.

Lusk, C. H., and C. K. Kelly. 2003. Interspecific variation in seed size and safe sites in a temperate rain forest. New Phytologist 158(3):535-541.

Magee T. K., and J. A. Antos. 1992. Tree invasion into a mountain-top meadow in the Oregon Coast Range, USA. Journal of Vegetation Science 3:485-494.

Maher, E. L., M. J. Germino, and N. J. Hasselquist. 2005. Interactive effects of tree and herb cover on survivorship, physiology, and microclimate of conifer seedlings at the alpine tree-line ecotone. Canadian Journal of Forest Research 35:567-574.

Malanson, G.P., D. R. Butler, D. B. Fagre, S. J. Walsh, D. F. Tomback, L. D. Daniels, L. M. Rester, W. K. Smith, D. J. Weiss, D. L. Peterson, A. G. Bunn, C. A. Hiemstra, D. Liptzin, P. S. Bourgeron, Z. Shen, and C. I. Millar. 2007. Alpine treeline of western North America and global climate change: linking organism-to-landscape dynamics. Physical Geography 28:378-396. 
Marchand, P. J., 1996. The changing snowpack. Life in the Cold. 3rd ed. Hanover: University Press of New England, 11-39.

Markoff, M. F. and A. F. Cullen. 2008. Impact of climate change on Pacific Northwest hydropower. Climatic Change 87:451-469.

Marra, J. L., and R. L. Edmonds. 1996. Coarse woody debris and soil respiration in a clearcut on the Olympic Peninsula, Washington, USA. Canadian Journal of Forest Research 26:1337-1345.

Maser, C., R. G. Anderson, K, Cromack., Jr., J. T. Williams, and R. E. Martin. 1979. Dead and down woody material. In J. W. Thomas (editor), Wildlife habitats in Managed Forests, The Blue Mountains of Oregon and Washington. USDA Forest Service Agricultural Handbook 553, Portland, OR Pp. 78-95.

Mayer, H., and E. Ott. 1991.Gebirgswaldbau. Schutzwaldpflege. Gustav Fisher, Stuttgart, Germany.

McCarthy, J. 2001. Gap dynamics of forest trees: a review with particular attention to boreal forests. Environmental Reviews 9:1-59.

McNab, W. H., D. T. Cleland, J. A. Freeouf, J. E. Keys, Jr., G. J. Nowacki, C. Carpenter, and C. A. Comps. 2005. Description of ecological subregions: sections of the conterminous United States. [CD-ROM] Washington, DC: U.S. Department of Agriculture, Forest Service.

Mellmann-Brown, S. 2005. Regeneration of whitebark pine in the timberline ecotone of the Beartooth Plateau, USA: spatial distribution and responsible agents. In G. Broll and B. Keplin (editors), Mountain Ecosystems: Studies in Treeline Ecology. Springer, New York, N.Y.

Mitchell, S. J. 2012. Wind as a natural disturbance agent in forests: a synthesis. Forestry (early access). DOI: 10.1093.forestry/cps058.

Moir, W. H., Rochelle, S. G., and A. W. Schoettle. 1999. Microscale patterns of tree establishment near upper treeline, Snowy Range, Wyoming, USA. Arctic, Antarctic, and Alpine Research 379-388.

Mori A., E. Mizumachi, T. Osono, and Y. Doi. 2004. Substrate-associated seedling recruitment and establishment of major conifer species in an old-growth subalpine forest in central Japan. Forest Ecology and Management 196:287-297.

Mori, A., and S. F. Hasegawa. 2007. Structural characteristics of Abies mariesii saplings in a snowy subalpine parkland in central Japan. Tree physiology 27(1):141-148. 
Mote, P. W. 2003a. Twentieth-century fluctuations and trends in temperatures, precipitation, and mountain snowpack in the Georgia Basin-Puget Sound region. Canadian Water Resources Journal 28:567-585.

Mote, P. W. 2003b. Trends in snow water equivalent in the Pacific Northwest and their climatic causes. Geophysical Research Letters 30:1601.

Mote, P. W. 2003c Trends in temperature and precipitation in the Pacific Northwest during the twentieth century. Northwest Science 77:271-282.

Mote, P. W., A. F. Hamlet, M. P. Clark, and D. P. Lettenmaier. 2005. Declining mountain snowpack in western North America. Bulletin of the American Meteorological Society 86:39-49.

Mote, P. W. and E. P. Salanthé, Jr. 2010. Future climate in the Pacific Northwest. Climate Change 102:29-50.

Motta, R. and P. Nola. 2001. Growth trends and dynamics in sub-alpine forest stands in the Varaita Valley (Piedmont, Italy) and their relationships with human activities and global change. Journal of Vegetation Science 12:219-230.

Motta, R., R. Berretti, E. Lingua, and P. Piussi. 2006. Coarse woody debris, forest structure and regeneration in the Valbona Forest Reserve, Paneveggio, Italian Alps. Forest Ecology and Management 235:155-163.

Nakashizuka, T. 1989. Role of uprooting in composition and dynamics of an oldgrowth forest in Japan. Ecology 1273-1278.

Narukawa, Y., S. Iida, H. Tanouchi, S. Abe, and S. Yamamoto. 2003. State of fallen logs and the occurrence of conifer seedlings and saplings in boreal and subalpine oldgrowth forests in Japan. Ecological Research 18:267-277.

Noble, I. R. 1993. A model of the responses of ecotones to climate change. Ecological Applications 3:396-403.

Oberhuber, W. 2004. Influence of climate on radial growth of Pinus cembra within the alpine timberline ecotone. Tree Physiology 24:291-301.

O’Hanlon-Manners, D. L., and P. M. Kotanen. 2004. Evidence that fungal pathogens inhibit recruitment of a shade-intolerant tree, white birch (Betula papyrifera), in understory habitats. Oecologia 140(4):650-653.

Oosterhoorn, M., and M. Kappelle. 2000. Vegetation structure and composition along an 
interior-edge-exterior gradient in a Costa Rican montane cloud forest. Forest Ecology and Management 126(3):291-307.

Peltola, H., S. Kellomäki, and H. Väisänen. 1999. Model computations of the impact of climatic change on the wind throw risk of trees.Climate Change 41:17-36.

Perry, D. A., J. G. Borchers, S. L. Borchers, and M. P. Amaranthus. 1990. Species migrations and ecosystem stability during climate change: the below ground connection. Conservation Biology 4:266-274.

Peterson, D. L. 1998. Climate, limiting factors and environmental change in high-altitude forests of western North America. In M. Beniston and J. L. Innes (editors), The Impacts of Climate Variability on Forests, Lecture Notes in Earth Sciences. Springer, Berlin, Germany. Pp. 191-208.

Peterson, D. W., D. L. Peterson, and G. J. Ettl. 2002. Growth responses of subalpine fir to climatic variability in the Pacific Northwest. Canadian Journal of Forest Research. 32:1503-1517.

Prentice, I. C., Cramer, W., Harrison, S. P., Leemans, R., Monserud, R. A., \& Solomon, A. M. 1992. Special paper: a global biome model based on plant physiology and dominance, soil properties and climate. Journal of Biogeography 117-134.

Pyle, C., and M. M. Brown. 1998. A rapid system of decay classification for hardwood logs of the eastern deciduous forest floor. Journal of the Torrey Botanical Society 125:237-245.

R Core Development Team, 2005. R: a language and environment for statistical computing. R Foundation for Statistical Computing, Vienna, Austria. Available online at http://www.R-project.org.

Ran, F., Wu, C., Peng, G., Korpelainen, H., and C. Li. 2010. Physiological differences in Rhododendron calophytum seedlings regenerated in mineral soil or on fallen dead wood of different decaying stages. Plant and soil 337(1):205-215.

Rochefort, R. M., R. T. Little, A. Woodward, and D. L. Peterson. 1994. Changes in subalpine tree distribution in western North America: a review of climatic and other causal factors. The Holocene 4:89-100.

Rochefort, R. M., and D. L. Peterson. 1996. Temporal and spatial distribution of trees in subalpine meadows of Mount Rainier National Park, Washington, USA. Arctic and Alpine Research 28: 52-59.

Saxe, H., Cannell, G. R., Johnsen, Ø. Ryan, M. G., and Vourlitus, G., 2001, New 
Phytologist 149: 369-400

Shaw III, C. G., Sidle, R. C., and A. S. Harris. 1987. Evaluation of planting sites common to a southeast Alaska clear-cut. III. Effects of microsite type and ectomycorrhizal inoculation on growth and survival of Sitka spruce seedlings. Canadian Journal of Forest Research 17(4):334-339.

Shrestha, B. B., Ghimire, B., Lekhak, H. D., and P. K. Jha. 2007. Regeneration of treeline birch (Betula utilis D. Don) forest in a trans-Himalayan dry valley in central Nepal. Mountain Research and Development 27(3):259-267.

Simard, M.J., Y. Bergeron, and L. Sirois. 1998. Conifer, seedling recruitment in a southeastern Canadian boreal forest: the importance of substrate. Journal of Vegetation Science 9:575-582.

Smit, C., D. Béguin, A. Buttler, and H. Mueller-Schaerer. 2005. Safe sites for tree regeneration in wooded pastures: a case of associational resistance? Journal of Vegetation Science 16:209-214.

Smith, T. M., X. Yin, and A. Gruber, 2006: Variations in annual global precipitation (1979-2004), based on the Global Precipitation Climatology Project $2.5^{\circ}$ analysis. Geophysical Research Letters. Res.Lett., 33, L06705, doi:10.1029/2005GL025393.

Smith, W. K., M. J. Germino, T. E. Hancock, and D. M. Johnson. 2003. Another perspective on Altitudinal limits of alpine timberlines. Tree Physiololgy 23:11011112.

Smith, W. K., and D. M. Johnson. 2007. Limitations to photosynthetic carbon gain in timberline Abies lasiocarpa seedlings during prolonged drought. Canadian Journal of Forest Resources 37:568-579.

Smith, W. K., Germino, M. J., Johnson, D. M., and K. Reinhardt. 2009. The altitude of alpine treeline: a bellwether of climate change effects. The Botanical Review 75(2):163-190.

Sollins, P. 1982. Input and decay of woody debris in coniferous stands in western Oregon and Washington. Canadian Journal of Forest Resources 12:18-28.

Sollins, P., S. P. Cline, T. Verhoeven, D. Sachs, and G. Spycher. 1987. Patterns of log decay in old-growth Douglas-fir forests. Canadian Journal of Forest Resources $17: 1585-1595$.

Solomon, S. (editor). 2007. Climate change 2007-the physical science basis: Working 
group I contribution to the fourth assessment report of the IPCC, Vol. 4. Cambridge University Press.

Stöckli, B. 1995. Moderholzfür die NaturverjüngungimBergwald, Anleitungzum Moderanbau. Wald Holz 76:16:8-14.

Storaunet, K. O., and J. Rolstad. 2002. Time since death and fall of Norway spruce logs in old-growth and selectively cut boreal forest. Canadian Journal of Forest Resources 32:180-1812.

Taiz L, Zeiger E. 2006. Plant Physiology. $4^{\text {th }}$ ed. Sinauer Associates, Inc. Publishers, Massachusetts.

Taylor, A. H. 1995. Forest expansion and climate change in the mountain hemlock (Tsuga metensiana) zone. Lassen Volcanic National Park. California, U.S.A. Arctic and Alpine Research 27:207-216.

Tett, P., Kelly, M.G., and Hornberger, G.M., 1975. A method for the spectrophometric measurement of river periphyton chlorophyll $a$ and phenophytin $a$ using several extractions with methanol. Limnology and Oceanography 20: 887-896.

Theurillat, J. P., and A. Guisan. 2001. Potential impact of climate change on vegetation in the European Alps: a review. Climatic change 50(1-2):77-109.

Thornton, P. E., M. M. Thornton, B. W. Mayer, N. Wilhelmi, Y. Wei, R. B. Cook. 2012. Daymet: Daily surface weather on a $1 \mathrm{~km}$ grid for North America, 1980 - 2011. Data acquired online (http://daymet.gov/) on 10 November 2010, Oak Ridge National Laboratory Distributed Active Archive Center, Oak Ridge, Tennessee, U.S.A. doi:10.3334/ORNLDAAC/Daymet_V2.

Tranquillini, W. 1979. Physiological Ecology of the Alpine Timberline, Springer-Verlag, New York.

USDA Natural Resources Conservation Service.2008. Soil Survey, Okanogan National Forest Area, Washington. Available online at: http://soils.usda.gov/survey/printed_surveys/(accessed online 2 February 2012).

USDA National Resource Conservation Service, National Water and Climate Center. Natural Resources Conservation Service Snowpack Telemetry(SNOTEL) site, Hart's Pass. Available online at: http://www.wcc.nrcs.usda.gov/nwcc/site?sitenum $=515 \&$ state=wa/ $($ accessed online 20 January 2012). 
Vanha-Majamaa, I., S. Lilja, R. Ryöma, J. S. Kotiaho,and S. Laaka-Lindberg. 2007. Rehabilitating boreal forest structure and species composition in Finland through logging, dead wood creation and fire: the EVO experiment. Forest Ecology and Management 250:77-88.

van Mantgem, P. J., N. L. Stephenson, J. C. Byrne, L. D. Daniels, J. F. Franklin, P. Z. Fule, M. E. Harmon, A. J. Johnson, J. M. Smith, A. H. Taylor, and T. T. Veblen. 2009. Widespread increase of tree mortality rates in the western United States. Science 323:521-524.

Veblen, T. T. 1989. Tree regeneration responses to gaps along a transandean gradient. Ecology 70:541-543.

Veblen, T. T., K. S. Hadley, and M. S. Reid. 1991. Disturbance and stand development of a Colorado subalpine forest. Journal of Biogeography 18:707-716.

Villalba, R., Veblen, T. T., and J. Ogden. 1994. Climatic influences on the growth of subalpine trees in the Colorado Front Range. Ecology 1450-1462.

Walther, G. R., Post, E., Convey, P., Menzel, A., Parmesan, C., Beebee, T. J., Jean-Marc Fromentin, Ove Hoegh-Guldberg, and F. Bairlein. 2002. Ecological responses to recent climate change. Nature 416(6879):389-395.

Wang, B., and Y. L. Qiu. 2006. Phylogenetic distribution and evolution of mycorrhizas in land plants. Mycorrhiza 16(5):299-363.

Wardle, P. 1973. New Zealand timberlines. Arctic and Alpine Research 5:127-136.

Wardle, P. 1981. Winter desiccation of conifer needles simulated by artificial freezing. Arctic and Alpine Research 13:419-423.

Wardle, P., and M. C. Coleman. 1992. Evidence for rising upper limits of four native New Zealand forest trees. New Zealand Journal of Botany 30:303-314.

Wearne, L. J., and J. W. Morgan. 2001. Recent forest encroachment into subalpine grasslands near Mount Hotham, Victoria, Australia. Arctic, Antarctic, and Alpine Research 33:369-377.

Wentz, F. J., Ricciardulli, L., Hilburn, K., and C. Mears. 2007. How much more rain will global warming bring? Science 317(5835):233-235.

Westerling, A. L., H. G. Hidalgo, D. R. Cayan, and T. W. Swetnam. 2006. Warming and earlier spring increase western U. S. forest wildfire activity. Science 313:940-943. 
Wieser, G., and M. Bahn. 2004. Seasonal and spatial variation of woody tissue respiration in a Pinus cembra tree at the alpine timberline in the central Austrian Alps. Trees 18:575-580.

Wieser, G., and M. Tausz. 2007. Trees at their upper limit: treelife limitation at the alpine timberline (Vol. 5). Springer.

Wilmking M. J. Harden, and K. Tape. 2006. Effect of tree line advanceon carbon storage in northwest Alaska. Journal of Geophysical Research 111:1-10.

Wilmking, M., T. Sanders, Y. Zhang, S. Kenter, S. Holzkämper, and P. Crittenden. 2012. Effects of climate, site conditions and seed quality on recent treeline dynamics in northwest Russia: permafrost and lack of reproductive success hamper treeline advance? Ecosystems 15:1053-1064.

Woodward, A., E. G. Schreiner, and D. G. Silsbee. 1995. Geography, and tree establishment in subalpine meadows of the Olympic Mountains, Washington, USA. Arctic and Alpine Research 27:217-225.

Wullschleger, S. D., Meinzer, F. C., and R. A. Vertessy. 1998. A review of whole-plant water use studies in tree. Tree physiology 18(8-9):499-512.

Yatshov, M., M. E. Harmon, and O. N. Krankina. 2003. A chronosequence of wood decomposition in the boreal forests of Russia. Canadian Journal of Forest Research 33:1211-1226.

Zens, M. S., and D. R. Peart. 2003. Dealing with death data: individual hazards, mortality and bias. Trends in Ecology and Evolution 18:366-373.

Zhong, J. and B. J. van der Kamp. 1999. Pathology of conifer seed and timing of germination in high-elevation subalpine fir and Engelmann spruce forests of the southern interior of British Columbia. Canadian Journal of Forest Research 29(2):187-193.

Zhou, Y. P., Xu, K. M., Sud, Y. C., and A. K. Betts. 2011. Recent trends of the tropical hydrological cycle inferred from Global Precipitation Climatology Project and International Satellite Cloud Climatology Project data. Journal of Geophysical Research: Atmospheres (1984-2012):116(D9).

Zielonka T., and M. Niklossen. 2001. Dynamics of dead wood and regeneration pattern in natural spruce forest in the Tatra Mountains, Poland. Ecological Bulletins 49:159163. 


\section{Appendix}

\section{Chapter 3:}

Additional Figures

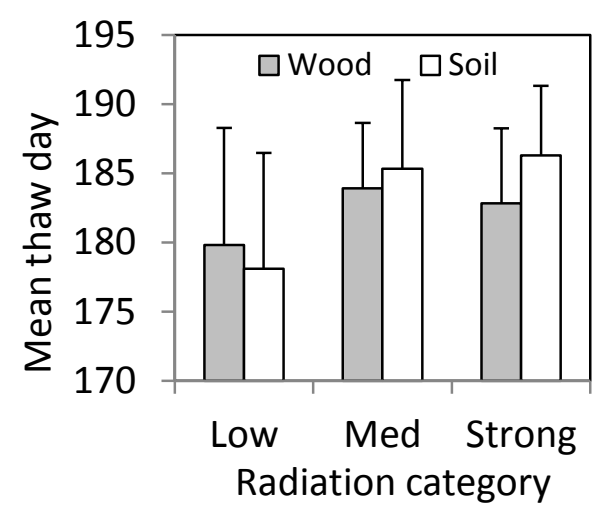

b)

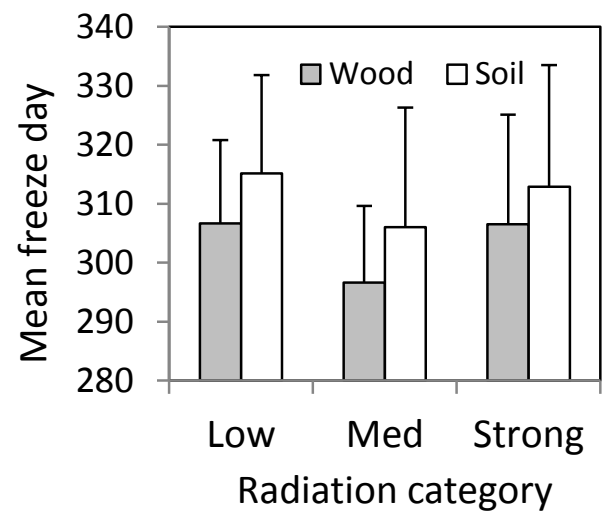

Figure I. Barplots of spring thaw and fall freeze date for wood and soil substrates. Means and $95 \%$ confidence intervals indicated for: a) spring thaw by substrate and radiation $(\mathrm{n}=$ 12 per bar) and $b)$ freeze date by substrate and radiation $(n=12$ per bar). Unless noted otherwise, wood microsites are indicated by shaded bars and soil substrates are indicated by open bars. 


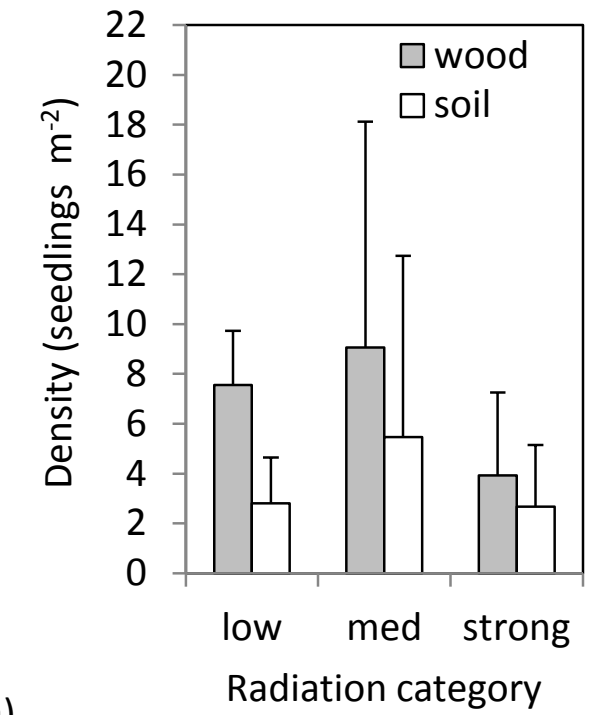

a)

Radiation category

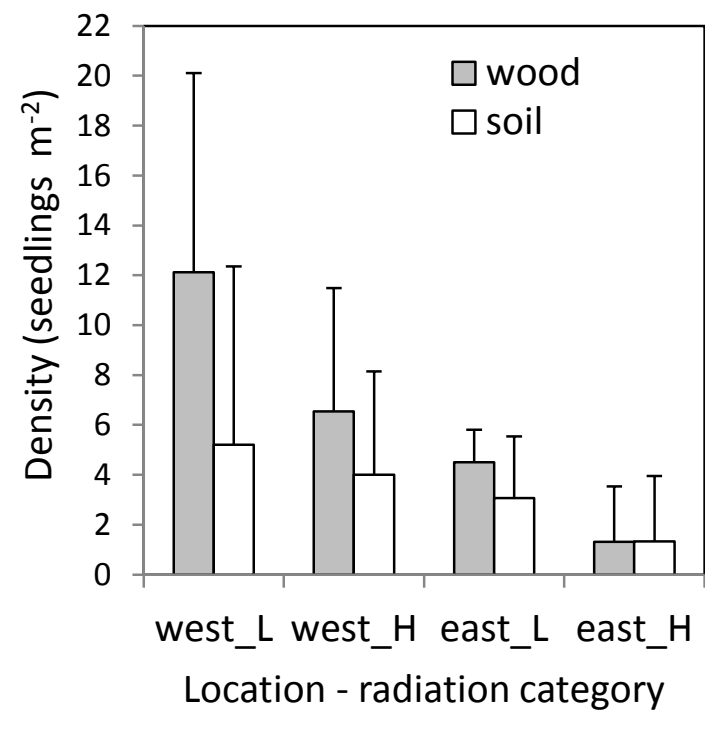

b)

Figure II. Density of $<3$ yr old seedlings indicated with barplots. Density indicated by a) barplots showing means and $95 \%$ confidence intervals of substrate type by radiation category and b) substrate type by location 


\section{Chapter 4:}

\section{Additional Figures}

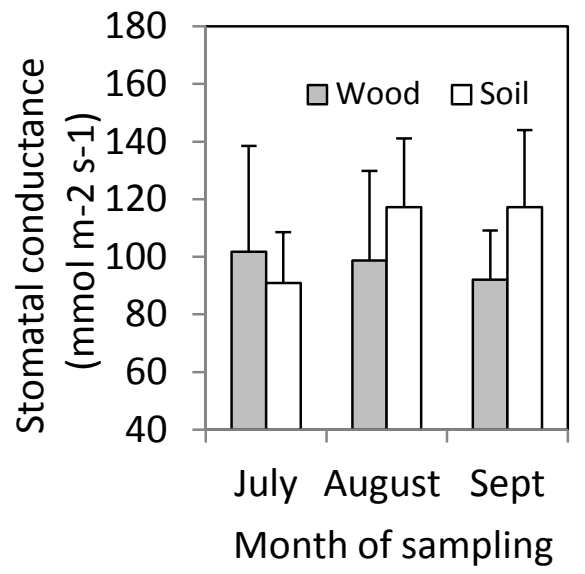

Figure III. Barplots of stomatal conductant by radiation category. Means and $95 \%$ confidence intervals for stomatal conductance by radiation category for entire field season ( $\mathrm{n}=$ ranges from 17 to 55 per bar, $p=0.4$ ). 

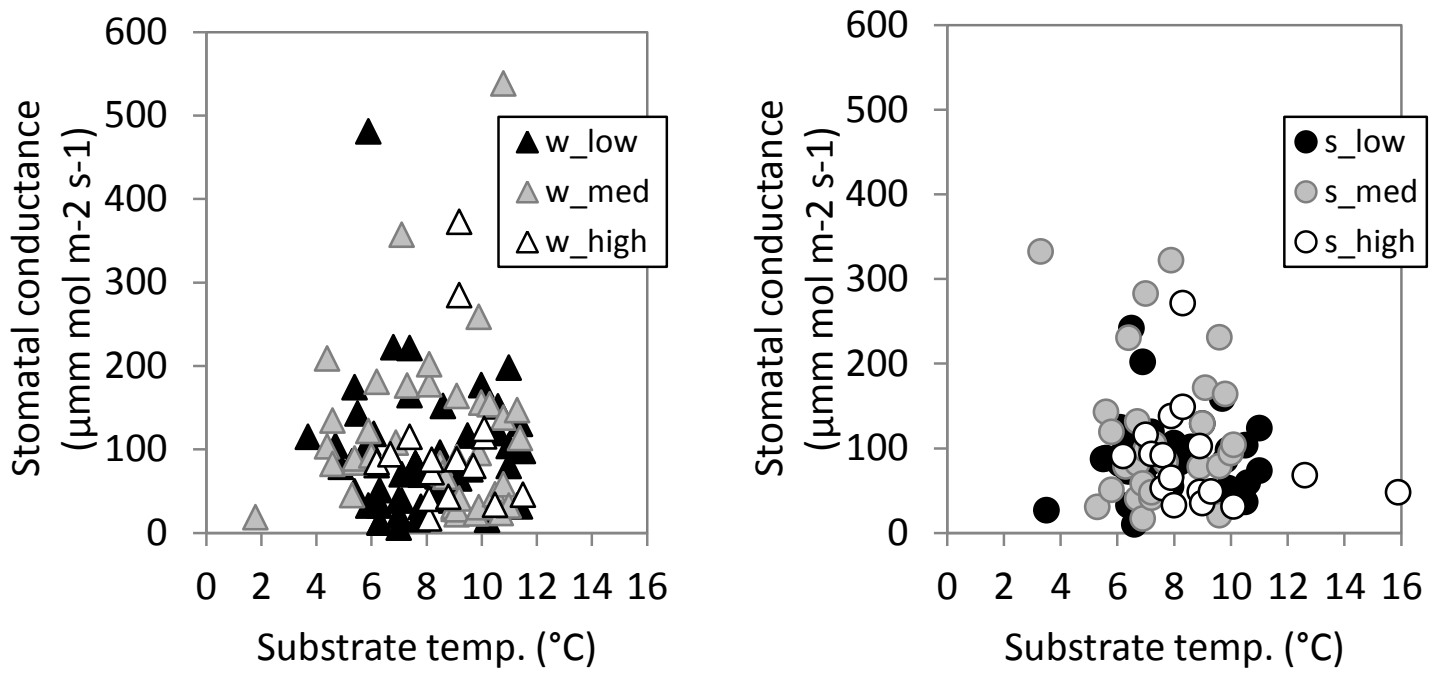

a)

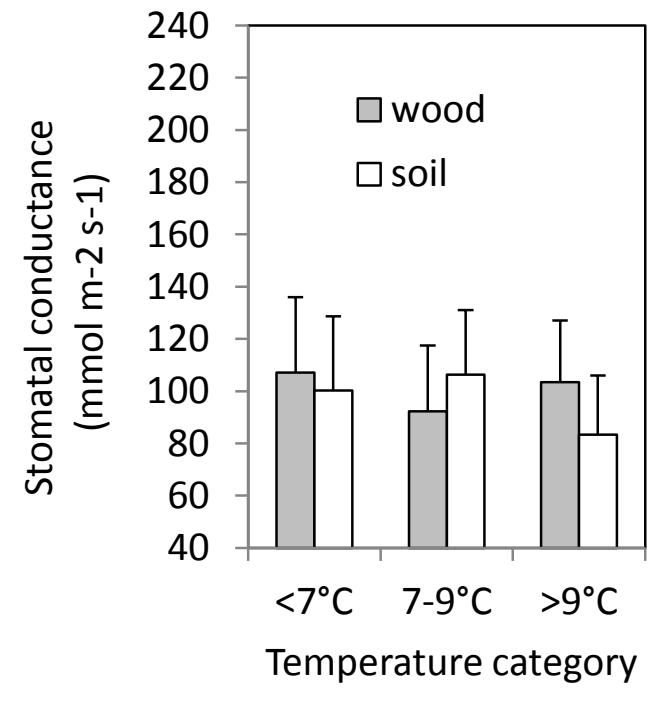

b)

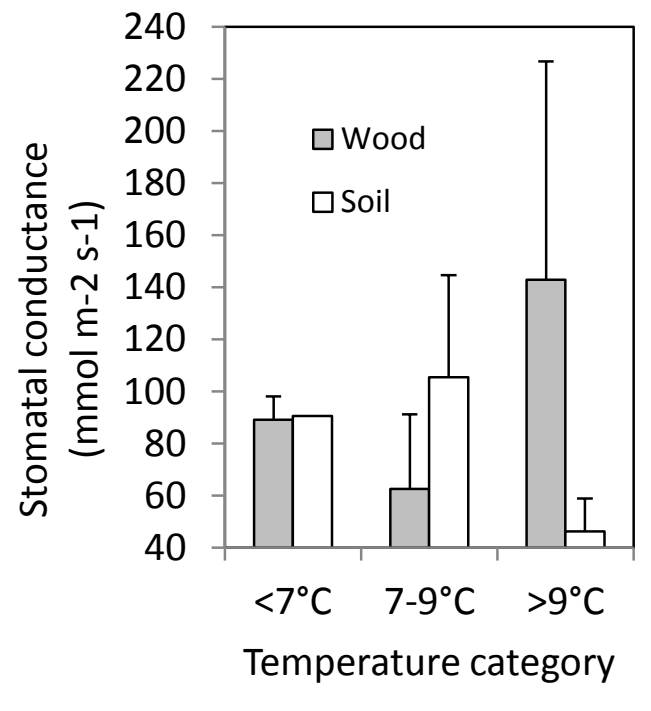

Figure IV. Stomatal conductance and substrate temperature. Stomatal conductance versus substrate temperature with incoming percent radiation indicated for a) wood substrates (all $p>0.05$ ) and b) soil substrates (all $p>0.05$ ), c) barplots showing means and 95\% confidence intervals for stomatal conductance versus three levels of temperature ( $p=$ 0.7 ), and d) barplots showing means and $95 \%$ confidence intervals for substrate temperature for the high incoming radiation category only $(p=0.2)$. 

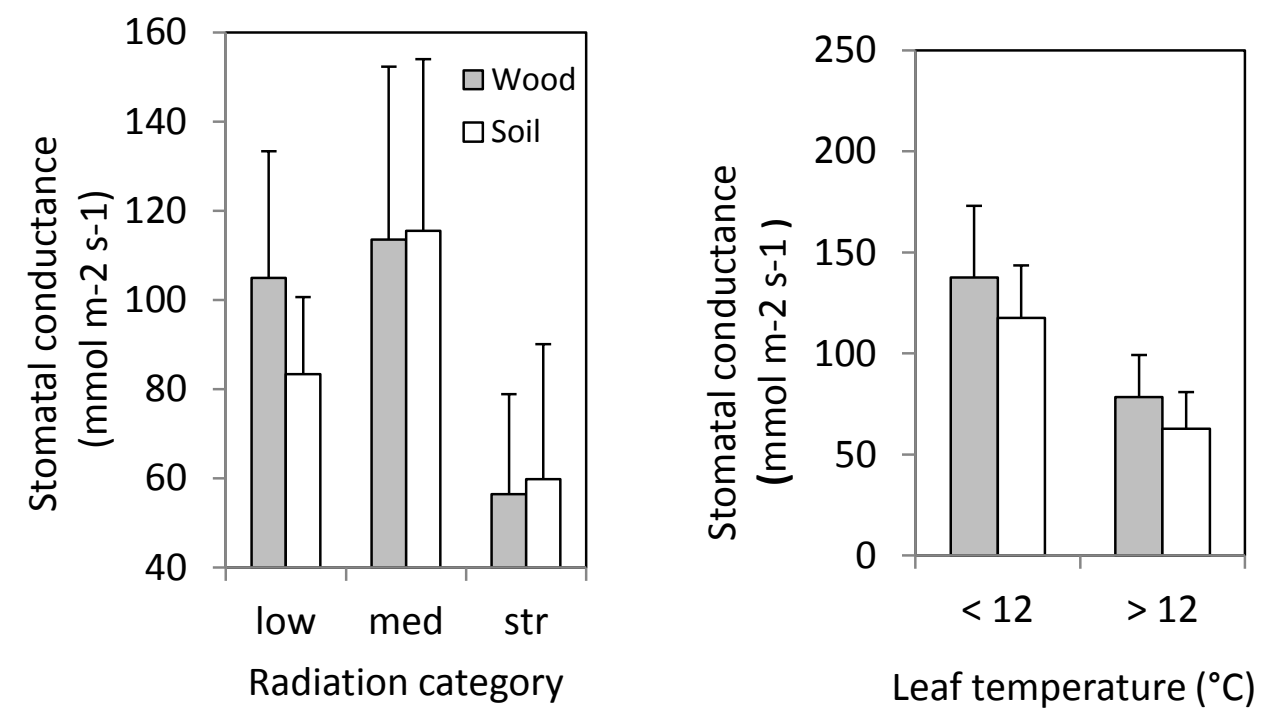

a)

b)

Figure V. Stomatal conductance and leaf temperature for seedlings on wood and soil substrates during the month of August. Barplots showing means and 95\% confidence intervals for stomatal conductance for a) low, medium, and high levels of radiation for wood and soil assessed separately and b) leaf temperature by $12^{\circ} \mathrm{C}$ threshold. 

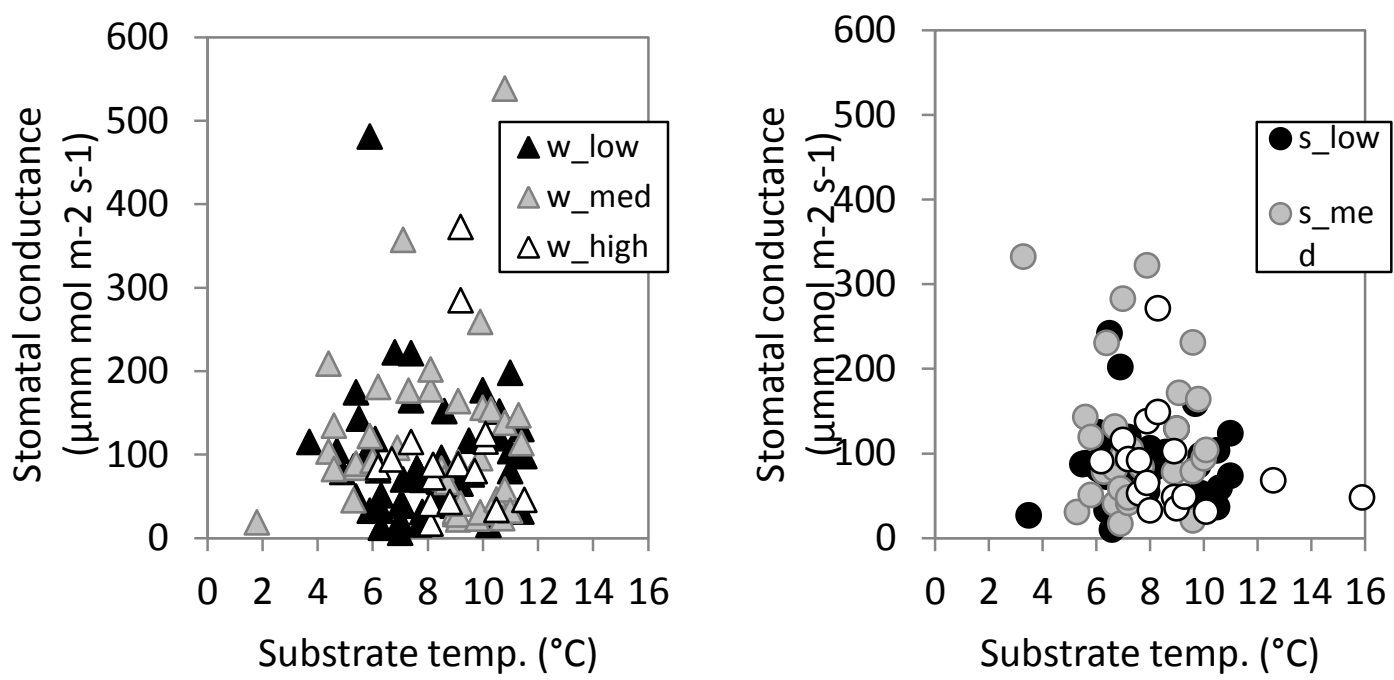

a)

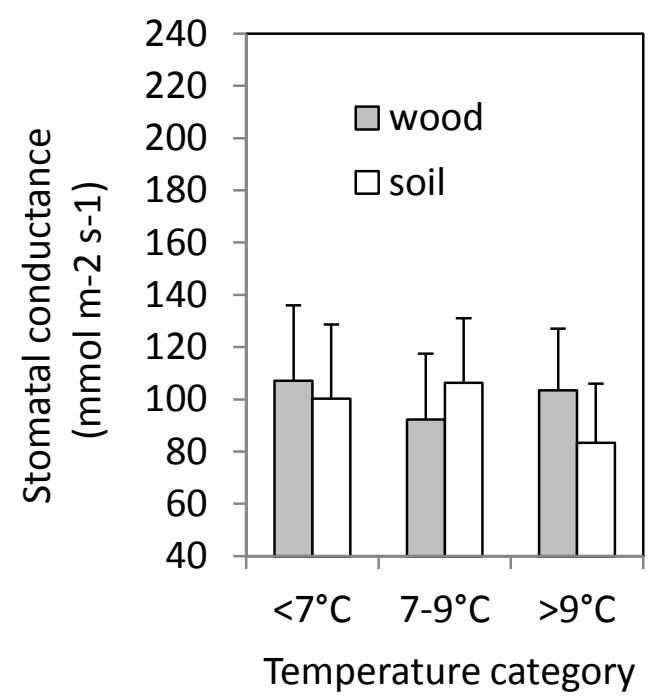

c) Temperature category b)

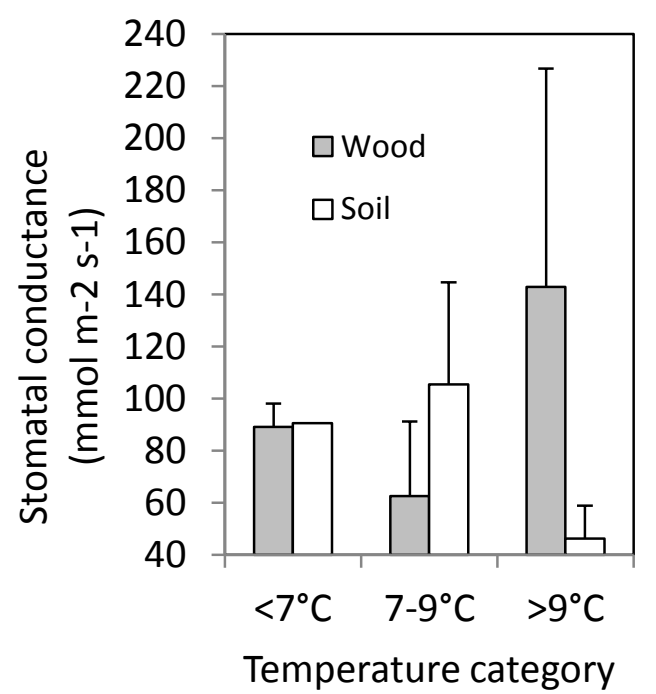

Figure VI. Stomatal conductance and substrate temperature. Stomatal conductance versus substrate temperature with incoming percent radiation indicated for a) wood substrates (all $p>0.05$ ) and b) soil substrates (all $p>0.05$ ), c) barplots showing means and 95\% confidence intervals for stomatal conductance versus temperature $(p=0.7)$, and $\mathrm{d})$ barplots showing means and $95 \%$ confidence intervals for substrate temperature for the high incoming radiation category only $(p=0.2)$. 


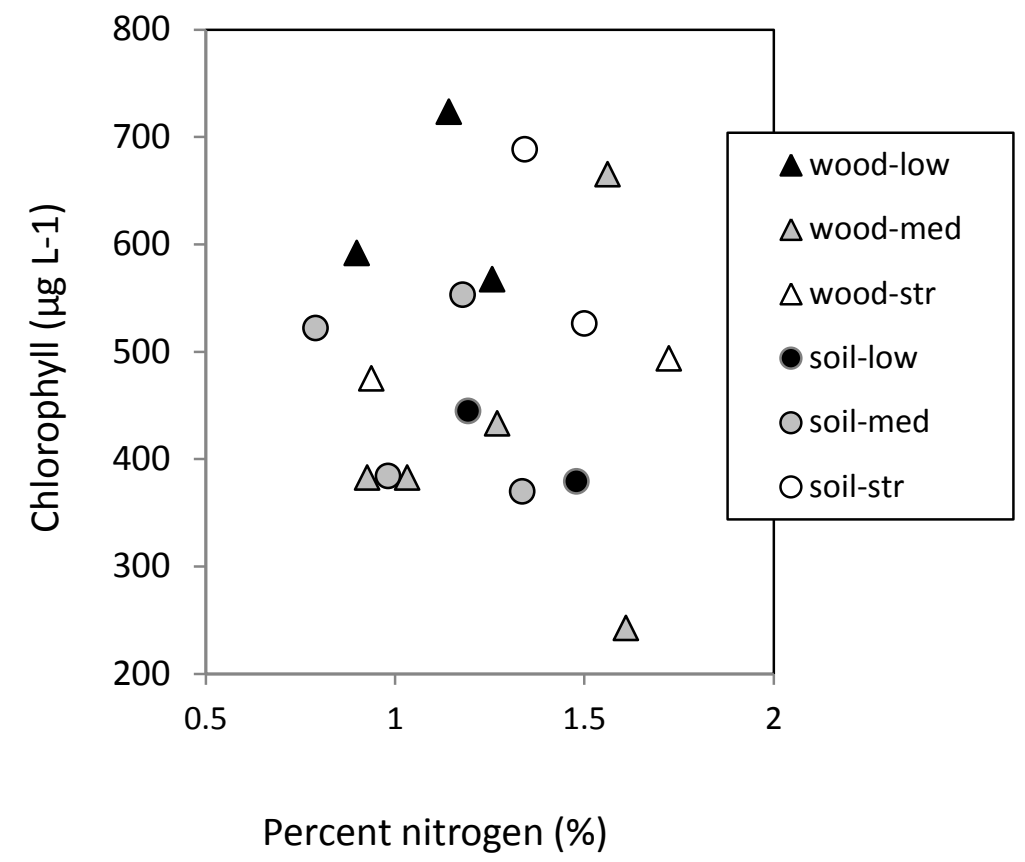

Figure VII. Chlorophyll a versus nitrogen content of seedlings growing on wood and soil substrates. There are no significant relationships $(p>0.05)$. 